\title{
Twelve thousand years of dust: the Holocene global dust cycle constrained by natural archives
}

\author{
S. Albani ${ }^{1,2}$, N. M. Mahowald ${ }^{1}$, G. Winckler ${ }^{3,4}$, R. F. Anderson ${ }^{3,4}$, L. I. Bradtmiller ${ }^{5}$, B. Delmonte ${ }^{2}$, R. François ${ }^{6}$, \\ M. Goman ${ }^{7}$, N. G. Heavens ${ }^{8}$, P. P. Hesse ${ }^{9}$, S. A. Hovan ${ }^{10}$, S. G. Kang ${ }^{11}$, K. E. Kohfeld ${ }^{12}$, H. Lu ${ }^{13}$, V. Maggi ${ }^{2}$, \\ J. A. Mason ${ }^{14}$, P. A. Mayewski ${ }^{15}$, D. McGee ${ }^{16}$, X. Miao ${ }^{17}$, B. L. Otto-Bliesner ${ }^{18}$, A. T. Perry ${ }^{1}$, A. Pourmand ${ }^{19}$, \\ H. M. Roberts ${ }^{20}$, N. Rosenbloom ${ }^{18}$, T. Stevens ${ }^{21}$, and J. Sun ${ }^{22}$ \\ ${ }^{1}$ Department of Earth and Atmospheric Sciences, Cornell University, Ithaca, NY, USA \\ ${ }^{2}$ Department of Environmental Sciences, University of Milano-Bicocca, Milano, Italy \\ ${ }^{3}$ Lamont-Doherty Earth Observatory, Columbia University, Palisades, NY, USA \\ ${ }^{4}$ Department of Earth and Environmental Sciences, Columbia University, New York, NY, USA \\ ${ }^{5}$ Department of Environmental Studies, Macalester College, Saint Paul, MN, USA \\ ${ }^{6}$ Department of Earth and Ocean Sciences, University of British Columbia, Vancouver, BC, Canada \\ ${ }^{7}$ Department of Geography and Global Studies, Sonoma State University, Rohnert Park, CA, USA \\ ${ }^{8}$ Department of Atmospheric and Planetary Sciences, Hampton University, Hampton, VA, USA \\ ${ }^{9}$ Department of Environmental Sciences, Macquarie University, Sydney, Australia \\ ${ }^{10}$ Department of Geoscience, Indiana University of Pennsylvania, Indiana, PA, USA \\ ${ }^{11}$ State Key Laboratory of Loess and Quaternary Geology, Institute of Earth Environment, Chinese Academy of Sciences, \\ Xi' an, China \\ ${ }^{12}$ School of Resource and Environmental Management, Simon Fraser University, Burnaby, BC, Canada \\ ${ }^{13}$ School of Geographic and Oceanographic Sciences, Nanjing University, Nanjing, China \\ ${ }^{14}$ Department of Geography, University of Wisconsin, Madison, WI, USA \\ ${ }^{15}$ Climate Change Institute, University of Maine, Orono, ME, USA \\ ${ }^{16}$ Department of Earth, Atmospheric and Planetary Sciences, Massachusetts Institute of Technology, Cambridge, MA, USA \\ ${ }^{17}$ Illinois State Geological Survey, Prairie Research Institute, University of Illinois, Champaign, IL, USA \\ ${ }^{18}$ National Center for Atmospheric Research, Boulder, CO, USA \\ ${ }^{19}$ Department of Marine Geosciences, Rosenstiel School of Marine and Atmospheric Science, \\ University of Miami, Miami, FL, USA \\ ${ }^{20}$ Department of Geography and Earth Sciences, Aberystwyth University, Aberystwyth, Wales, UK \\ ${ }^{21}$ Department of Earth Sciences, Uppsala University, Uppsala, Sweden \\ ${ }^{22}$ Key laboratory of Cenozoic Geology and Environment, Institute of Geology and Geophysics, \\ Chinese Academy of Science, Beijing, China
}

Correspondence to: S. Albani (s.albani@cornell.edu)

Received: 30 September 2014 - Published in Clim. Past Discuss.: 13 November 2014 Revised: 16 March 2015 - Accepted: 6 May 2015 - Published: 11 June 2015 
Abstract. Mineral dust plays an important role in the climate system by interacting with radiation, clouds, and biogeochemical cycles. In addition, natural archives show that the dust cycle experienced variability in the past in response to global and local climate change. The compilation of the DIRTMAP (Dust Indicators and Records from Terrestrial and MArine Palaeoenvironments) paleodust data sets in the last 2 decades provided a benchmark for paleoclimate models that include the dust cycle, following a time slice approach. We propose an innovative framework to organize a paleodust data set that builds on the positive experience of DIRTMAP and takes into account new scientific challenges by providing a concise and accessible data set of temporally resolved records of dust mass accumulation rates and particle grain size distributions. We consider data from ice cores, marine sediments, loess-paleosol sequences, lake sediments, and peat bogs for this compilation, with a temporal focus on the Holocene period. This global compilation allows the investigation of the potential, uncertainties, and confidence level of dust mass accumulation rate reconstructions and highlights the importance of dust particle size information for accurate and quantitative reconstructions of the dust cycle. After applying criteria that help to establish that the data considered represent changes in dust deposition, 45 paleodust records have been identified, with the highest density of dust deposition data occurring in the North Atlantic region. Although the temporal evolution of dust in the North Atlantic appears consistent across several cores and suggests that minimum dust fluxes are likely observed during the early to mid-Holocene period (6000-8000 years ago), the magnitude of dust fluxes in these observations is not fully consistent, suggesting that more work needs to be done to synthesize data sets for the Holocene. Based on the data compilation, we used the Community Earth System Model to estimate the mass balance of and variability in the global dust cycle during the Holocene, with dust loads ranging from 17.2 to $20.8 \mathrm{Tg}$ between 2000 and 10000 years ago and with a minimum in the early to mid-Holocene (6000-8000 years ago).

\section{Introduction}

Paleoclimate records from natural archives have laid foundations for understanding the variability in the Earth's climate system over different timescales. Paleoclimate proxies shed light on past environmental conditions, such as the composition of the atmosphere, global ice volume, sea level, and surface temperatures (Bradley, 1999). Paleodust reconstructions paired with other proxies showed the response of the climate system to orbitally induced forcing, including feedback mechanisms. Dust feedbacks on the climate system include scattering and absorption of solar radiation and indirect effects on clouds and the global carbon cycle (e.g., Boucher et al., 2013; Martin, 1990).
The story told by paleodust archives suggests that increased aridity (An et al., 1991; Liu, 1985; Liu and Ding, 1998) and wind gustiness (McGee et al., 2010; Muhs et al., 2013a) enhanced the dust cycle during cold periods over glacial-interglacial timescales, with additional mechanisms introducing characteristic geographic patterns and/or imprinting the archives with characteristic signals in different geographical settings. These mechanisms include increased sediment availability by glacial erosion (Delmonte et al., 2010a; Petit et al., 1999), reorganization of the atmospheric circulation between mid- and high latitudes (Fuhrer et al., 1999; Lambert et al., 2008; Mayewski et al., 1997, 2014), shifts in the intertropical convergence zone (ITCZ) (McGee et al., 2007; Rea, 1994), changes in the monsoonal variability (Clemens and Prell, 1990; Hovan et al., 1991; Tiedemann et al., 1994), and regional drying (Lu et al. 2010).

The growing number of paleodust archives and the inclusion of the dust cycle in climate models has promoted synthesis efforts in the compilation of global dust data sets (Mahowald et al., 1999). The Dust Indicators and Records from Terrestrial and MArine Palaeoenvironments (DIRTMAP) project (Kohfeld and Harrison, 2001) formalized the compilation of dust mass accumulation rates (dust MARs, or DMARs) from marine and ice cores, later complemented by terrestrial sedimentary records (Derbyshire, 2003). This project followed a time slice approach, providing reference values of DMARs for the Last Glacial Maximum (LGM) and late Holocene and for modern data, including from sediment traps. DMAR is the fundamental measurement necessary to cross-correlate variability among dust archives and sites. Without it, only the relative timing and amplitude of individual records can be studied. In combination with global climate models, DMAR data sets enable quantitative reconstructions of the global dust cycle. The DIRTMAP compilation showed a globally averaged glacial / interglacial ratio of $\sim 2.5$ in dust deposition. Subsequent work expanded upon the initial compilation (DIRTMAP2: Tegen et al., 2002), and the most recent version of the database (DIRTMAP3: Maher et al., 2010) also contains an extensive repository of additional metadata from the original publications. The DIRTMAP data sets have proven to represent an invaluable tool for paleoclimate research and model-data intercomparison.

The full definition of the global dust cycle in terms of DMAR is unavoidably linked to the dust grain size distributions that characterize the mass balance and its spatial evolution. The more advanced dust models define a model particle size range and distribution, which would require (although this has been often neglected) explicitly considering the size range of dust found in the dust deposition data in model-observation intercomparisons. This aspect was initially taken into account for terrestrial sediments in Mahowald et al. (2006) to match the specific model size range $(0.1-10 \mu \mathrm{m})$ and was recently extended by Albani et al. (2014). Nevertheless, the necessity of more extensive 
grain size information from dust data has been emphasized by Maher et al. (2010), as well as by other review papers on dust (e.g., Formenti et al., 2011; Mahowald et al., 2014). Coherent information on grain size is missing in DIRTMAP3 (Maher et al., 2010) because of the difficulty of making a synthesis from measurements produced by a variety of particle size measurement techniques often yielding quite different results (Mahowald et al., 2014; Reid, 2003).

A time slice approach is often used by the paleoclimate modeling community to target key periods in climate history, such as the Last Glacial Maximum $\sim 21000$ years Before Present (LGM: $21 \mathrm{kaBP}$ ), or the mid-Holocene (MH: $6 \mathrm{kaBP})$, in the framework of the Paleoclimate Modelling Inter-comparison Project (PMIP: Joussaume and Taylor, 2000). Continuing improvement in the performance of largescale supercomputers is opening up doors to performing transient simulations on paleoclimate timescales, both with intermediate complexity (Bauer and Ganopolski, 2014) and more complex Earth system models (ESMs) (Liu et al., 2009). PMIP3 called for additional key transient experiments to study abrupt climate change, with the implication that, at the same time, target observational data sets with the necessary temporal continuity and resolution are needed (Otto-Bliesner et al., 2009).

We propose an innovative framework to organize a paleodust data set that builds on the positive experience of DIRTMAP and takes into account the new scientific challenges outlined above by providing a synthesized and accessible data set of temporally resolved records of dust MARs and size distributions. We aim to provide a database that is a concise and accessible compilation of time series, including age (with uncertainty), dust MAR (with uncertainty), and dust particle size distribution (where available), standardized by the use of a common binning scheme and complemented by a categorical attribution of confidence based on general consensus. Besides the basic information mentioned above, we also report the ancillary information necessary to re-derive the dust MARs time series, i.e., the detailed depths and the relevant dust variables. Inspired by DIRTMAP, our new compilation considers DMARs as the key variable for a coherent study of paleodust archives. The elements of innovation that we introduce here (size distributions, temporal resolution, and attribution of confidence level), however, constitute a leap forward to a new-generation dust database.

We focus on dust variability during the Holocene, with an emphasis on the MH as a key PMIP scenario and also in relation to the large variability that affected the, at present, largest dust source in the world, northern Africa, with the termination of the African Humid Period (AHP) (deMenocal et al., 2000; McGee et al., 2013). For this reason we only selected paleodust records encompassing the $\mathrm{MH}$ with some degree of temporal resolution (see Sect. 3), although we show the time series from the LGM in the paper to provide reference to other key climate conditions and to placeour work in a fuller context with respect to the DIRTMAP compilation.
The developed framework is suitable for a more extensive compilation.

We acknowledge that there is a richness of information intrinsic to each sedimentary record (i.e., as in the original studies) that is not necessarily fully captured by the synthesized information we report, despite our efforts to be as complete as possible: simplification is inherent in a synthesis. For the sake of accessibility, we refrain from reporting extensive information that cannot be coherently organized. We therefore provide a brief summary and refer to the relevant literature for detailed descriptions of specific records (Supplement). In addition, because our purpose is to provide a quantitative constraint on the dust cycle, we only considered sedimentary records that allow the derivation of meaningful dust MARs with the information we could access. Many more studies have focused on dust and provided important, goodquality information, but they did not allow a time-resolved estimate of dust MAR. We refer to these studies when appropriate, as they provide further context to ensure our interpretations.

Finally, we use the Community Earth System Model (CESM) in combination with the DMAR and size data (Albani et al., 2014; Mahowald et al., 2006) from the compilation to estimate the mass balance of the global dust cycle and its variability during the Holocene.

Section 2 gives an overview of the kind of natural archives initially considered for this compilation, while in Sect. 3 we explain our methodological approach to selecting and organizing the records. In Sect. 4 we present the database and model-based reconstructions and discuss the emerging properties in relation to the climate features in different spatial domains. We summarize our work in Sect. 5.

\section{Paleodust archives}

Natural archives that preserve dust sediments have different characteristics in terms of geographical settings and spatial distributions around the globe, the accuracy of the age models and temporal resolution, and the ability to isolate eolian dust from other depositional contributions. Each type of paleodust archive has its own strengths and limitations, and it is only by considering high-quality records of all types (from land, ice, and ocean archives) that we can hope to build a consistent reconstruction of the global dust cycle. We only include paleodust records that allow the estimation of dust MARs with relevance for medium- or large-scale dust export.

Natural archives preserve eolian dust within a sedimentary matrix. The essential elements for a paleodust record are the possibility of establishing a reliable chronology, the estimation of the sedimentation rates, and the isolation of the eolian component (Fig. 1). Throughout the paper we use the term "sediment" in a broad sense that encompasses ice as well as other sediments in a strict sense. 


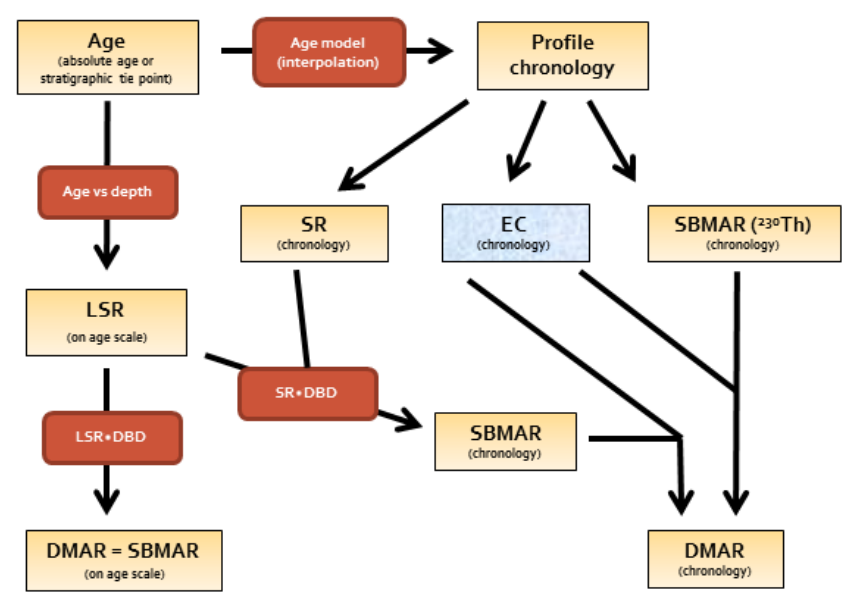

Figure 1. Schematic representation of the process of calculation of eolian DMAR (dust mass accumulation rate), and its relation to the SR (sedimentation rate), DBD (dry bulk density), SBMAR (sediment bulk MAR), and EC (eolian content). DMAR (on age scale) is the typical path for loess-paleosol records, whereas DMAR (chronology) indicates the final step of the workflow when EC is also measured.

One of the key elements in the production of a paleodust record is the possibility of establishing a depth-age relation. Typically the starting point for this procedure is the attribution of age to a series of specific depth layers along the profile, based on numerical dating or stratigraphic correlations. Numerical dating can be based on the counting of annual layers, radionuclide decays (e.g., $\left.{ }^{14} \mathrm{C}\right)$, or exposure to radiation (e.g., thermoluminescence (TL) or optically stimulated luminescence (OSL)) (Brauer et al., 2014). Stratigraphic correlations either exploit stratigraphic markers, such as known volcanic eruptions and spikes in tracers of the atmospheric thermonuclear test explosions, or are attributed by wiggle matching an age-carrier profile from the study site (e.g., $\delta^{18} \mathrm{O}$ of foraminifera in marine sediment cores or methane concentration in ice cores) with a reference record of global signatures, such as global ice volume (e.g., Martinson et al., 1987) or the variations in atmospheric methane concentrations (e.g., Loulergue et al., 2008).

Sediment chronologies can be established based on the initial age-depth relations identified along a profile. With "chronology" we mean a continuous function that provides a unique attribution of the depth-age relation along the entire profile, based on some kind of age model. Age models can vary from simple linear sedimentation models to complex Bayesian models (Brauer et al., 2014).

A general expression for dust (or eolian - the two terms will be used equivalently throughout the text) MARs is the following: DMAR $=$ SBMAR $\cdot E C$, where SBMAR is the sediment bulk mass accumulation rate and EC is eolian contribution.
The estimation of SBMAR relies on a couple of main approaches. The first one is based on estimating SBMARs between dated horizons as the product of sedimentation rates $(\mathrm{SRs})$ and dry bulk densities (DBDs): $\mathrm{SBMAR}=\mathrm{SR} \cdot \mathrm{DBD}$. Either a linear sedimentation rate (LSR) is derived between dated layers or more complex age models are applied, resulting in diverse SR profiles. The other approach is specific to the marine sediments realm, and it is largely (other than for decay correction) independent of the underlying age model: it is based on the assumption that the rapid scavenging of ${ }^{230} \mathrm{Th}$ produced in the water column by decay of dissolved uranium results in its flux to the seafloor being equal or close to its known rate of production. Measurements of ${ }^{230} \mathrm{Th}$ in marine sediments therefore allow us to estimate instantaneous SBMARs that are independent of LSRs (François et al., 2004).

Because eolian DMAR is the product of at least two factors (SBMAR and EC), the sampling (depth) resolution at which the two of them are available will determine the DMAR resolution, and in some cores the resolutions may coincide. Sometimes a constant LSR is assumed between dated depth layers, whereas stratigraphic samples are analyzed at a higher resolution and an estimated age is assigned based on the age model (Fig. 2). On the timescale of interest, it should be noted that deviations from the ideal pairing of EC and SBMAR measurements along a profile might be considered acceptable if the resolutions are not too different. On the other hand, if one variable (typically EC) has a much higher resolution than the other, then its high resolution is not informative with respect to their product (DMAR), and misinterpretations could arise. In those cases the lower-resolution variable should be used to provide the pace of the record's resolution. We did not make any adjustments to the data in this respect; note that we only have records where either the resolutions match or they are very similar (see Supplement).

An additional aspect to consider when dealing with dust MARs is the relationship between the dust deposition flux (DF) and the dust MAR, i.e., to what extent the measured DMAR is representative (in a quantitative way) of the dust deposition, which is of primary interest: ideally $\mathrm{DMAR}=\mathrm{DF}$. Deviations from this ideal relation occur, for instance, when sediment redistribution disturbs the ocean sediments (François et al., 2004) or when erosion leaves hiatuses in loess-paleosol sequences (Stevens et al., 2007). When there is an indication of such occurrences, we took focussing-corrected data in the former case or considered only the undisturbed sections of the records in the latter case.

The other fundamental piece of information is the size distribution of dust, which is tightly coupled to the DMAR in determining the magnitude (or mass balance) of the dust cycle (Albani et al., 2014; Mahowald et al., 2014; Schulz et al., 1998; Lu et al., 1999). In addition, size data is a necessary piece of information to determine the provenance of dust. At accumulation sites far from the major dust sources, size distribution allows (together with geochemical and mineralogi- 


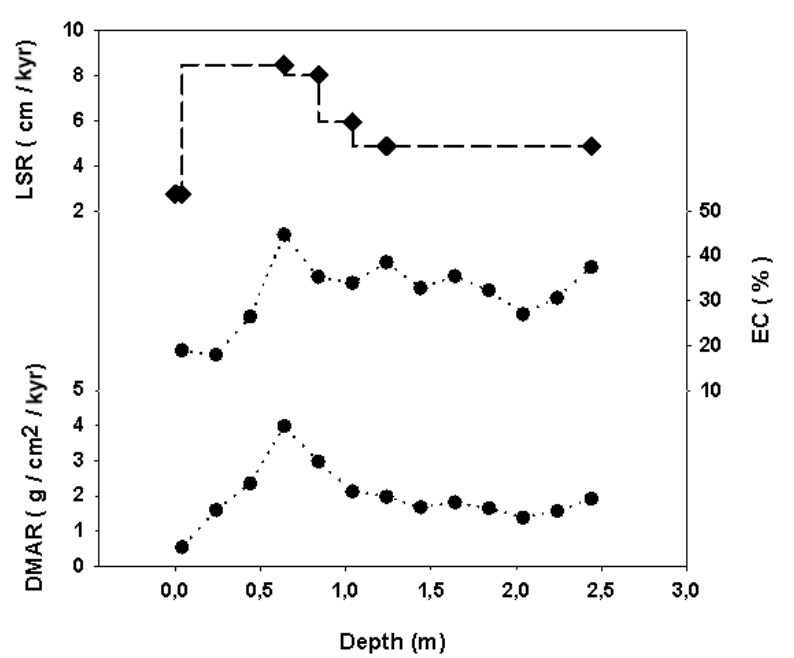

Figure 2. Example of different resolution of SBMAR and EC (Clemens and Prell, 1990).

cal data) the identification of local versus remote inputs (Albani et al., 2012a; Delmonte et al., 2010b). At terrestrial sites proximal to the source areas, it is necessary to evaluate the amount of dust actually available for long-range transport (Mahowald et al., 2006; Muhs et al., 2013a; Roberts et al., 2003).

We next analyze the main characteristics of the different kinds of paleodust records considered for this compilation: ice cores, marine sediments, loess-paleosol sequences, lake sediments and peat bogs.

\subsection{Ice cores}

Ice cores constitute a natural sampler of past atmospheric composition, including greenhouse gases and aerosols. The isolation of the eolian component from the ice matrix is rather straightforward - it is usually obtained by melting the ice at room temperature (Delmonte et al., 2004), although sublimation of the ice is another option (Iizuka et al., 2013), so that the ice allows the most pristine preservation of the locally deposited atmospheric aerosol.

The presence of perennial ice limits the geographical coverage of ice core records worldwide, and the recovery of long dust stratigraphies is limited to the high latitudes and a few alpine glaciers in the mid- and low latitudes. Often the EC is a direct measure of the insoluble dust concentration and size distribution in the ice samples, using either a Coulter counter (Delmonte et al., 2004) or a laser diffraction particle counter (Lambert et al., 2008). Alternatively a geochemical dust proxy can be used (e.g., McConnell et al., 2007), and the most common approach considers non-sea-salt calcium (Röthlisberger et al., 2002; Fischer et al., 2007). Despite the fact that the dust-calcium relation should be treated with caution under certain circumstances (Ruth et al., 2002, 2008), this approach has successfully been used to produce dust records in Greenland (e.g., Fuhrer et al., 1999; Mayewski et al., 1997) and Antarctica (Lambert et al., 2012; Schüpbach et al., 2013).

Since in most cases both dust (insoluble) and calcium records were produced at the same location, we focus on insoluble particle records, which also include dust size distributions. Possible non-dust contributions include volcanic tephra, which is usually identifiable and excluded from the records (e.g., Narcisi et al., 2010). For Greenland there is only one record spanning the Holocene, GISP2, for which we consider calcium as a proxy for dust (Mayewski et al., 1997).

For the estimation of SBMAR, postdepositional changes may potentially affect snow and ice accumulation rates through surface redistribution or sublimation. In the polar ice sheets plateaus these effects are probably negligible on domes, where ice cores are usually drilled (Frezzotti et al., 2007), so that dust DMAR $=\mathrm{DF}$.

Polar ice core age models are in continuous evolution, and they benefit from the growing number of deep ice cores. A striking feature is the absolute counting of annual layers in Greenland ice cores (Vinther et al., 2006), which in combination with several ice and stratigraphic markers (e.g., methane spikes, volcanic signals) allows establishing consistent chronologies for both Greenland and Antarctic ice cores. In this work we use the most recent Antarctic Ice Core Chronology 2012 (AICC2012) chronology for Antarctic ice cores (Veres et al., 2013). Because of the high sediment matrix accumulation rates compared to other natural archives, polar ice cores usually provide the highest-resolution dust records. Dust concentration records are also available from alpine glaciers (e.g., Thompson et al., 1995, 1997). While it is possible to derive estimates of dust MARs on the glacialinterglacial timescale (Kohfeld and Harrison, 2001), it is problematic to calculate DMAR time series. This is because there are no reliable age models due to the difficulty in establishing adequate accumulation stratigraphies in such environments.

With a few exceptions from sites on the edges of the ice sheets both in Greenland (Renland: Hansson, 1994) and Antarctica (e.g., TALDICE - TALos Dome Ice CorE: Albani et al., 2012a; Delmonte et al., 2013), polar ice cores are thought to archive almost exclusively dust from remote source areas (Bory et al., 2003; Delmonte et al., 2010b) and to be representative of the magnitude and variability in the dust cycle at least over the high latitudes in both hemispheres (Mahowald et al., 2011).

\subsection{Marine sediments}

With the oceans covering two thirds of the Earth's surface marine sediment cores represent key paleoclimate archives, recording among other things global land ice volumes, ocean productivity, and the main characteristics of the ocean deep circulation (e.g., Bradley, 1999). Dust particles deposited 
to the ocean's surface attach to other suspended particles and get scavenged throughout the water column, determining the accumulation of eolian material in pelagic sediments (Bory and Newton, 2000). Despite the complexity of and uncertainties in the dynamics of particle sedimentation throughout the water column (e.g., Bory and Newton, 2000; De La Rocha et al., 2008), as well as their potential advection downstream (Siegel and Deuser, 1997; Han et al., 2008), we can reasonably make the approximation that dust $\mathrm{DF}($ surface $)=\mathrm{DF}$ (benthic). This is valid in most regions (Siegel and Armstrong, 2002; Kohfeld and Tegen, 2007), with the notable exception of the Southern Ocean (Kohfeld and Harrison, 2001).

The pelagic environment is characterized by low deposition rates, so that most marine records naturally have a lower temporal resolution than ice cores. Chronologies for marine sediment cores are often derived by stratigraphic correlation of $\delta^{18} \mathrm{O}$ records of benthic or pelagic foraminifera (representative of a combination of global ice volume and temperature) with reference stacks such as Mapping Spectral Variability in Global Climate (SPECMAP) (Imbrie et al., 1984; Martinson et al., 1987) or LR04 (Lisiecki and Raymo, 2005).

In many studies, additional constraints for the age models are given by radiocarbon dating foraminifera (e.g., Anderson et al., 2006; McGee et al., 2013) or tephras (Nagashima et al., 2007), which is especially relevant for the Holocene. The age-depth relation is usually assigned by linear interpolation between dated layers. Chronologies only based on stratigraphic correlation of $\delta^{18} \mathrm{O}$ records are inherently affected by a significant degree of uncertainty for the Holocene because the youngest tie points in $\delta^{18} \mathrm{O}$ stacks can be considered the Last Glacial Maximum (18 ka BP) and the Marine Isotopic Stage (MIS) boundary MIS1-2 (14 ka BP) (Lisiecki and Raymo, 2005). Often, in the absence of absolute ages, the assumption is made that the surface sediment age is $0 \mathrm{kaBP}$, although the surface sediments may be disturbed or partially lost during the core recovery.

Two main strategies are used to derive dust records from marine cores. In the first, more traditional "operational" approach, SBMAR = LSR $\cdot$ DBD, with LSR calculated from the age model and DBD measured or estimated. EC is determined by isolating the lithogenic fraction from the sediment matrix by the subsequent removal of the organic component, carbonates, and biogenic opal by thermal or chemical treatments (Rea and Janecek, 1981). In this approach the basic assumption is that the entire lithogenic fraction is eolian in origin. Corrections for volcanic contributions were attempted by visual inspection (Hovan et al., 1991) or by the use of geochemical tracers (Olivarez et al., 1991), which could also help to distinguish fluvial from eolian inputs (Box et al., 2011). Other spurious lithogenic inputs may include material from turbidite currents, hemipelagic sediments, or ice-rafted debris (e.g., Rea and Hovan, 1995). Additionally, sediment redistribution may alter the depositional stratigraphy, biasing the true sedimentation rates (François et al., 2004); this is usually not accounted for in studies following this kind of approach. Here, we exclude sites known (or very likely) to be significantly affected by sediment redistribution (e.g., nepheloid layers: Kohfeld and Harrison, 2001) and ice-rafted debris (Kohfeld and Harrison, 2001) and those close to the continental margins (e.g., Serno et al., 2014).

The other strategy consists of deriving SBMAR from ${ }^{230} \mathrm{Th}$ profiling (François et al., 2004). Briefly, ${ }^{230} \mathrm{Th}$ (halflife: 75690 years) is produced uniformly throughout the ocean by radioactive decay of dissolved ${ }^{234} \mathrm{U}$. Due to its high particle reactivity, ${ }^{230} \mathrm{Th}$ is efficiently scavenged by particulate matter and has a short residence time in the ocean (<30 years) (Bacon and Anderson, 1982). The rain rate of scavenged ${ }^{230} \mathrm{Th}$ to the sediments is therefore equal to its known rate of production in the overlying water column (Henderson et al., 1999). SBMARs are calculated by dividing the production rate of ${ }^{230} \mathrm{Th}$ in the water column by concentrations of scavenged ${ }^{230} \mathrm{Th}$ in the sediment (Bacon, 1984; François et al., 2004).

At sites potentially influenced by sediment redistribution, the ${ }^{230} \mathrm{Th}$ profiling method is probably the more reliable approach for the determination of SBMAR, as it accounts for sediment focusing (Anderson et al., 2008; François et al., 2004). If it can be assumed that the lithogenic fraction is of eolian origin, EC can be derived from the ${ }^{232} \mathrm{Th}$ concentration in the sediment of a dust proxy $\left({ }^{232} \mathrm{Th}\right)$. As ${ }^{232} \mathrm{Th}$ concentrations in dust are generally more than 1 order of magnitude higher than in most volcanic materials, ${ }^{232} \mathrm{Th}$ levels closely track continental inputs and are insensitive to volcanic inputs. In addition, ${ }^{232} \mathrm{Th}$ offers the advantage, compared to other dust proxies, that its concentration in global dust sources is relatively invariable and close to the upper continental crust concentration (McGee et al., 2007). If non-eolian contributions (such as volcanic contributions) are present, multi-proxy approaches (using REE, ${ }^{4} \mathrm{He}$ ) can provide a means to isolate the eolian fraction (Serno et al., 2014). On continental margin settings, high sedimentation rates are related to the presence of fluvial inputs, which can be isolated from the eolian component by the use of grain size endmember modeling (McGee et al., 2013; Weltje, 1997).

Bioturbation, i.e., surface sediment mixing by benthic fauna, is a common unconstrained feature of marine sediments that acts as a smoothing filter on the sedimentary stratigraphy, including ages and other profiles of interest, with a typical vertical smoothing scale of $8-10 \mathrm{~cm}$. A few studies have evaluated the potential effects of the bioturbation of their records, although they do not correct their profiles (François et al., 1990; McGee et al., 2013), based on a simple deconvolution linear model (Bard et al., 1987).

\subsection{Loess-paleosol sequences}

The possibility of reconstructing the global dust cycle requires observations that are distributed geographically to constrain different regions, and that also encompass the evo- 
lution of dust spread from the source areas to the areas downwind and to remote regions. Terrestrial sediment records are therefore necessary to constrain the location and magnitude of past sources of dust. Loess can be defined as terrestrial eolian sediments, composed predominantly of silt-size particles, formed by the accumulation of wind-blown dust (Pye, 1995; Liu, 1985), and covering vast regions $(\sim 10 \%)$ of the land masses (e.g., Derbyshire et al., 1995; Rousseau et al., 2011). The formation of loess deposits is often associated with the proximity of major dust sources, the availability of fine-grained erodible sediments and adequate winds, and a suitable accumulation site (Pye, 1995; Liu, 1985). This requires that a complex deposition-erosion balance determines the actual rate of accumulation at a site and the alternation of accumulation and weathering phases depending on the dominant environmental conditions (Kemp, 2001; Muhs et al., 2003a). Loess-paleosol records (or soil profiles) spanning the late Quaternary have shown to be important proxies and dust archives, both on glacial-interglacial (e.g., Kohfeld and Harrison, 2003; Muhs et al., 2008; Lu and Sun, 2000; Lu et al., 1999) and millennial timescales (e.g., Mason et al., 2003).

Because of their nature, loess records are more challenging to interpret than marine or ice dust stratigraphies in quantitative terms, but they hold great potential under favorable circumstances. In the case of loess-paleosol sequences, the assumption is often made that $\mathrm{EC}=1$ because the other soil component, i.e., the organic matter content is usually very low, i.e., < $1 \%$ (e.g., Miao et al., 2007). Nonetheless, in carbon-rich soils, where organic matter can be $\sim 10 \%$, this contribution should be taken into account (Muhs et al., 2013b). Therefore, the implication is that the dust MAR is entirely determined by SBMAR $=\mathrm{LSR} \cdot \mathrm{DBD}$. Depending on the study, DBD is either measured or assumed based on literature surveys, which adds significant uncertainty to calculations. The LSR is determined based on the age-depth relation. For this compilation, focused on the Holocene, we only consider profiles for which absolute ages (or more correctly, numerical ages) have been measured rather than relying on stratigraphic correlations.

Depending on the availability of suitable material at loess sites, radiocarbon dating is carried out on different organic components such as plant material (e.g., charcoal, plant, and wood fragments) or Succineidae (land snails). Humic acid is also utilized; however, this medium provides less reliable dates. Scarcity of organic samples could be a limitation for chronologies relying on radiocarbon dating. An alternative category of methods for numerical dating of loess deposits is the luminescence-dating group of techniques (Roberts, 2008). In particular OSL dating of quartz grains with the single aliquot regenerative (SAR) dose protocol (Wintle and Murray, 2006) is considered to be quite robust (Roberts, 2008).

Bioturbation by faunal burrowing is an active process complicating the interpretations of soil profiles, as indicated
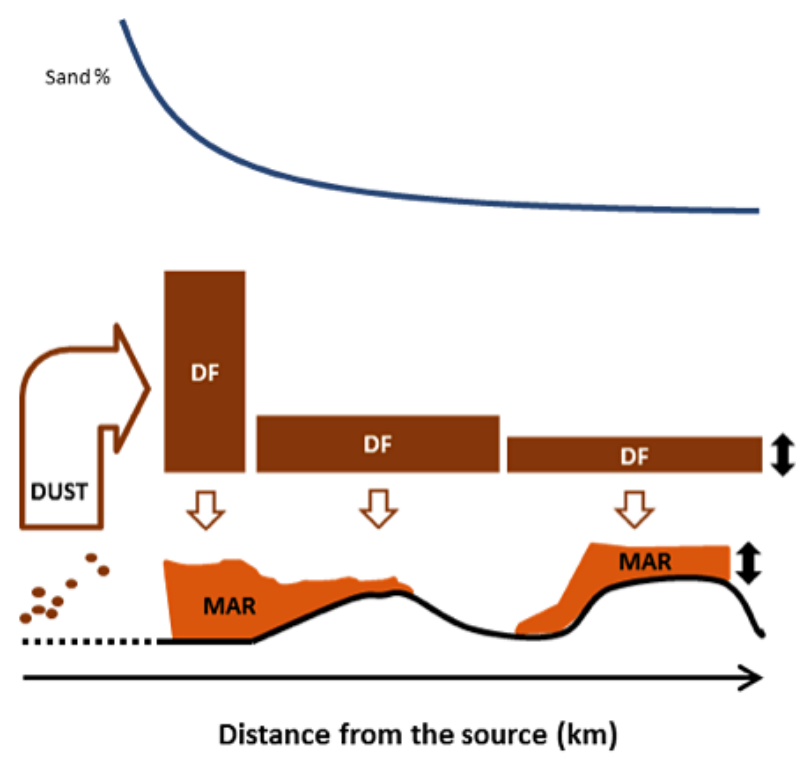

Figure 3. Conceptual plot of the evolution of dust deposition flux (DF) and size distribution (\% sand) as a function of distance from the source.

by stratigraphic age inversions. In addition human activities such as agriculture may cause significant perturbations to the upper sections of soil profiles (Roberts et al., 2001). Additional problems in the interpretation of soil profiles may arise in cases where the origin of the loess is not primarily eolian but rather the product or reworking of local deposits (Kemp, 2001). We therefore did not consider sections from areas where such occurrence was identified.

Even when a reworked origin can be excluded, it should not be taken for granted that the DMAR $=$ DF relation necessarily holds in the case of loess deposits. Conceptually, we can imagine the process of dust emission and deposition in a regional setting as follows: dust emanates from a source and starts to be deposited downwind at rates decreasing with distance from the source (Fig. 3). A clear example of this is evident in the maps showing the spatial variability in the thickness of last glacial Peoria loess deposits in North America (Bettis III et al., 2003) or the loess deposition in the Chinese Loess Plateau (CLP) (Liu, 1985; Lu and Sun, 2000). Understanding the spatial scale of this process is essential.

Grain size data from sampling transects at various locations suggest that a sharp decrease in DMAR immediately downwind of source areas is associated with a decrease in the size distribution within 20-50 km Chewings et al., 2014; Mason et al., 2003; Muhs et al., 2004; Winton et al., 2014), before a slower decline in DMAR and size keeps on the same trajectory on broader spatial scales (Ding et al., 2005; Lawrence and Neff, 2009; Porter, 2001; Prins et al., 2007; Sun et al., 2003). It is evident, then, that bulk DMARs (i.e., DMARs over the entire size range) from profiles located within a very short distance (i.e., $20-50 \mathrm{~km}$ ) from the sources 
are not suited for providing a representative estimate of DF over a broad spatial domain unless the spatial scale of interest is very fine (Cook et al., 2013). This has substantial implications for climate models and reconstructions of the mass balance of the global dust cycle in general because a misinterpretation of the significance of bulk DMARs can drive large overestimation of DF (Albani et al., 2014).

On the other hand, it happens that sites located in close proximity to the sources have the highest accumulation rates, allowing for better chances of obtaining high-resolution profiles that are of great utility in paleoclimate reconstructions. Thus, often some of the better-resolved sites, especially those having an adequate time resolution to show variability during the Holocene, tend to be close to the sources.

After the steep decline in bulk DMAR close to the source areas, we can imagine the DF blanketing the surface of the Earth, slowly decreasing as the distance from the source increases but approximately homogeneous over a broad area at a coarse enough spatial resolution (Fig. 3). In reality the DMAR is highly dependent on the local landforms, both for accumulation and preservation of the deposited dust (Stevens and $\mathrm{Lu}, 2009$ ). Thus loess deposited on escarpments facing the wind direction may be favorable for an enhanced dust deposition (Bowen and Lindley, 1977; Mason et al., 2003). More often erosion is a major player, so that DMAR $<\mathrm{DF}$. Upland sites are generally considered more suitable geomorphological settings to recover well-preserved profiles of DF (Derbyshire, 2003; Kohfeld and Harrison, 2003; Mason et al., 2003; Muhs et al., 2003a). Field examination of the broad area where a profile was studied may provide evidence of erosion ( $\mathrm{Lu}$ et al., 2006), i.e., if the horizon's stratigraphy is not widely reproduced regionally, but in some cases evidence for erosion is only available via detailed independent age models (Buylaert et al., 2008; Stevens et al., 2008). In addition, supporting data from other proxies in the profile, i.e., bio- or chemostratigraphy, can provide grounds for establishing the degree of coherence of specific sections (Marković et al., 2011).

\subsection{Other paleodust archives: lake sediments and peat bogs}

Beside loess-paleosol sequences other land archives carry the potential to preserve dust stratigraphies: lakes and ombrotrophic peat bogs. Both can be located at an opportune medium-range distance between the source areas and the more remote oceanic and polar sites. In addition, the preservation of large amounts of organic matter involves the possibility of high-resolution radiocarbon dating, which is of great value especially for a period such as the Holocene (Muhs et al., 2003b; Marx et al., 2009; Le Roux et al., 2012).

While diverse in nature, lakes and peat bogs also share some common issues that generally need to be addressed in order to provide reliable paleodust profiles: the possibility of quantitatively isolating remote from local dust deposi- tion and the basin-scale representativeness of eolian DMARs compared to DF.

In some circumstances (when fluvial inputs and rain outwash can be excluded), lake deposits can preserve reliable dust stratigraphies, with little or no unconformities and relatively abundant organic matter for radiocarbon dating (e.g., Muhs et al., 2003b). Maar lakes, developed in craters formed by explosive excavations associated with phreatomagmatic eruptions, are often an ideal setting when the mafic composition of the basin is substantially different than the mineralogical and geochemical characteristics of the remotely originated dust. However, a major problem with lakes is the possibility of sediment focusing in the deeper parts of the basin, which may substantially affect SBMAR. With one exception, we were not able to retrieve adequate DMARs from lakes for this compilation, mostly because of problems with either the age model, or a reliable estimation of EC (Supplement).

In recent years substantial progress has been made in recovering dust profiles from ombrotrophic peats. The estimation of SBMAR depends on the radiocarbon dating of the organic matter. The EC is determined by the elemental composition of the residual ash after the combustion of the organic matter. The identification of an adequate proxy for dust can be challenging (Kylander et al., 2013), so that several approaches, including multi-proxy-based approaches, have been suggested (Marx et al., 2009). Even more challenging is a quantitative isolation of the local versus remote dust input; this is also because of the lack of size distribution data in most cases, although a few studies have provided good approaches (Marx et al., 2009; Le Roux et al., 2012). At this stage, substantial uncertainties still exist in general in peat bog dust records for one or more of the variables necessary to determine a reliable quantitative estimate of dust MARs relevant for medium- or long-range transport. Nonetheless, we expect that in the near future this goal will be achieved because of the fast progress of research in this field (e.g., Ferrat et al., 2011; Kylander et al., 2013; Marx et al., 2009; McGowan et al., 2010; Le Roux et al., 2012; Sapkota et al., 2007; De Vleeschouwer et al., 2012).

\section{Methodology}

The goal of this compilation is to provide a quality-controlled data set with a specific reference to the possibility of deriving reliable quantitative time series of eolian DMAR relevant to broad spatial scales. According to this principle and considering the specific characteristics of the different paleodust archives, we performed an extensive literature review to identify records suitable for the study of dust variability within the Holocene, encompassing the MH period $\sim 6 \mathrm{kaBP}$.

There is a spectrum of possible approaches for the compilation of this kind of database, lying between two extremes: a minimal collection of DMARs (e.g., similar to DIRTMAP; Kohfeld and Harrison, 2001) and an extensive compilation 
including a wide variety of metadata (e.g., DIRTMAP3; Maher et al., 2010). For this work, we lean towards the first approach, although we include uncertainties and some additional information, but stick to the age models from the original studies (Appendix A).

The concise operational product of the database is a set of dust MAR time series, with quantitative estimates of the uncertainties associated with both the age and DMAR. Dust MAR uncertainty quantified here is only associated with the calculations; hence, it includes the analytical errors and the uncertainty associated with assumptions or approximations in the magnitude of specific variables. We express all quantitative uncertainties as $1 \sigma$ deviation, assuming a Gaussian distribution of the error. It will be expressed either in absolute terms or as a relative error, as specified in each case.

This approach does not convey the overall uncertainty related, for instance, to a specific technique or to a specific physical setting, which is difficult to express quantitatively. For this reason we complement the data set with a categorical attribution of the overall confidence on the reliability of the records for the purposes of this work.

Note that a large part of the actual uncertainties associated with each record are related to what we include in the attribution of the confidence level and that the estimates provided for the quantifiable uncertainty constitute a first-order approximation.

In the following paragraphs we report the criteria followed for site selection and attribution of a confidence level (Sect. 3.1), and we provide a general description of the approach used to report or calculate the age profiles of eolian DMAR, with relative uncertainties (Sects. 3.2 and 3.3), and the information on the size distributions where available (Sect. 3.4). More specific information for each record is reported in the Supplement. In Sect. 3.5 we describe the approach to estimating the mass balance of the global dust cycle throughout the Holocene with the CESM.

\subsection{Site selection and attribution of confidence level}

In an initial phase of scrutinizing the existing literature, we identified paleodust records of interest to our project, based on the requirements that they

(a) have potential for calculating DMAR (i.e., the dust fraction must be identified and quantified in some way; no records with only size information).

(b) have sufficient material within the Holocene to quantify DMAR (i.e., at least three data points occur between 0 and $11.7 \mathrm{kaBP}$, with at least one data point between 4.5 and $7.5 \mathrm{ka} \mathrm{BP}$; three data points means three ages for loess-paleosol sequences where $\mathrm{EC}=1$ and three values of dust MAR for all other cases).

(c) have absolute (i.e., numerical) ages (only for terrestrial sediments). (d) include size information (only for the loess-paleosol records).

We identified 124 sites meeting these criteria. We then labeled each of those sites with a categorical attribution of the overall confidence we have that each record provides a quantitative profile of eolian DMAR with respect to the age and that it is relevant to broad spatial scales, based on general consensus.

The attribution of the confidence level is based on whether or not there are substantial or critical uncertainties with respect to three aspects: (1) SBMAR (and confidence that DMAR = DF); (2) EC; (3) quantitative distinction between remote and local EC (see Supplement Table 1).

The first criterion is related to the chronology itself and/or to linking the chronology to SBMAR. We consider some types of dates more reliable than others in this context, depending on the kind of natural archive. Among the less reliable, some we consider acceptable per se ("substantial uncertainty"), while others we associate with a "critical uncertainty".

For marine sediments, we consider both absolute ages and stratigraphic correlation with oxygen stacks, bearing in mind that they are both acceptable in the case of records based on thorium profiling, but only absolute ages are acceptable when the isolation of the terrigenous fraction is the method of determining EC.

For ice cores, we regard age models based on a combination of absolute counting, stratigraphic correlations, and ice thinning modeling (e.g., Veres et al., 2013) with high confidence. These models apply to most of the polar ice cores. On the other hand, records from smaller ice caps and glaciers suffer from the lack of reliable age models, i.e., ice accumulation profiles, which cannot be resolved on Holocene timescales at present (L. Thompson, P. Gabrielli, C. Zdanowicz, personal communication, 2014).

For terrestrial sediments, we only considered numerical ages $\left(\mathrm{OSL},{ }^{14} \mathrm{C}\right)$, in the initial scrutiny phase. This is important as, in the case of loess-paleosol sequences, disturbances such as erosion and reworking (and agricultural practices, when they are not limited to depths attributed to the last $\sim 2.5 \mathrm{kyr}$ ) can disrupt the ideal correspondence between dust MAR and DF (Sect. 2.3). We consider evidence of such an occurrence as a critical uncertainty. In addition, we have attempted to identify sites whose stratigraphies are consistent regionally and therefore demonstrate that they are more likely to represent large-scale patterns. Sites with stratigraphies that diverge substantially from standard regional profiles suggest that these records are not likely to represent large-scale patterns in dust deposition, and this represents a critical uncertainty. When no critical uncertainties are identified, we still consider that SBMAR estimates from loesspaleosol sequences contain substantial uncertainty, according to this criterion (1). 


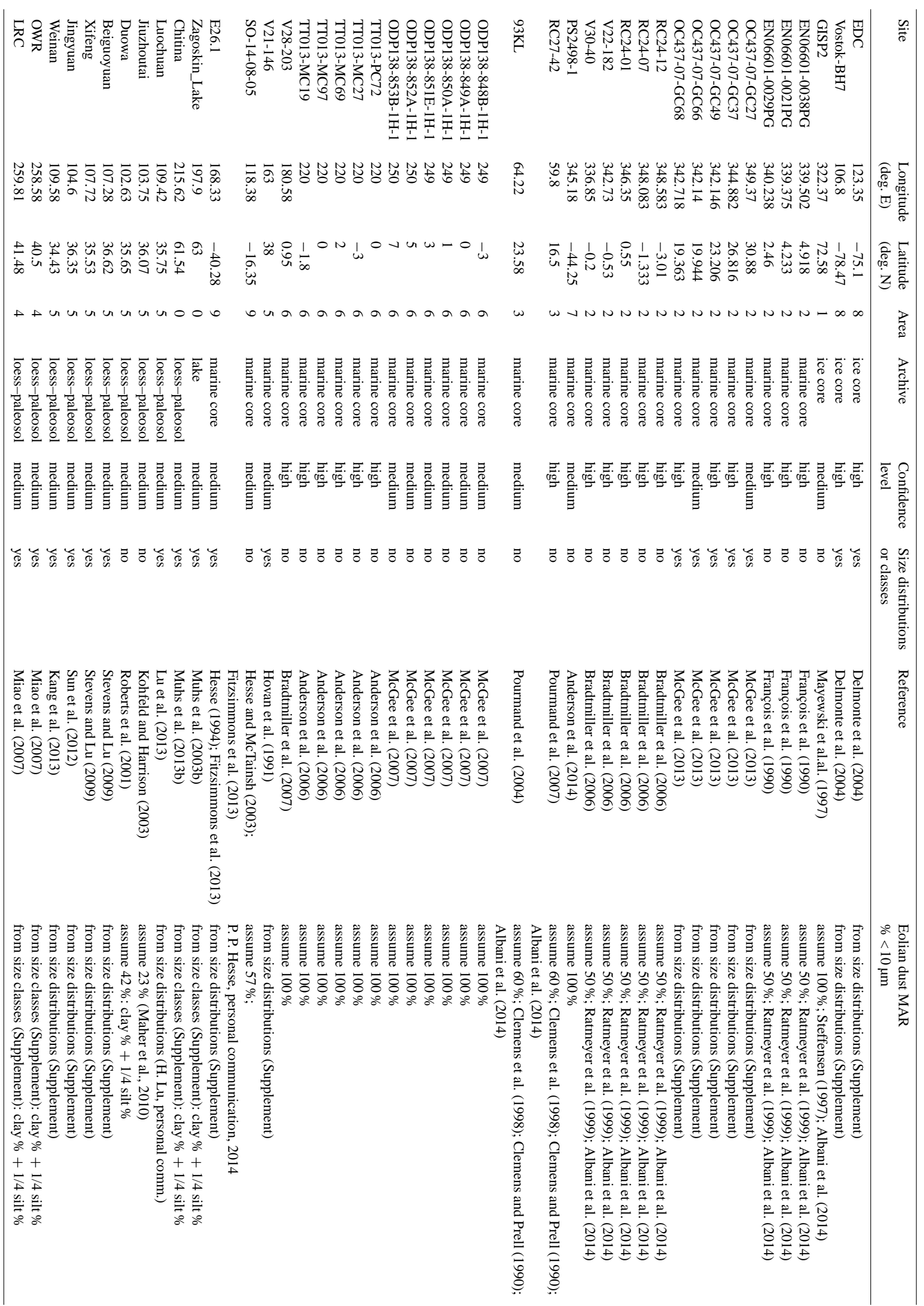

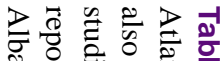

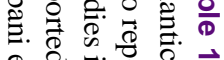
을

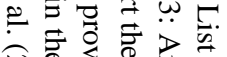

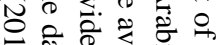

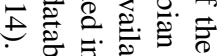

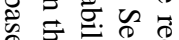

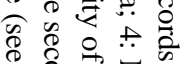

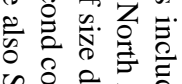
유을

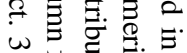
방 항. 要 要

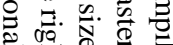

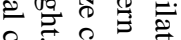

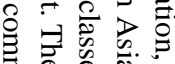

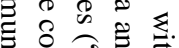
․ㅜ을 番.

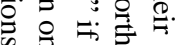
항 률 훙

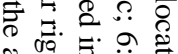

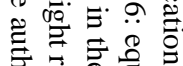
言 $\vec{\nabla}$ के : $\vec{E}=$ के है च

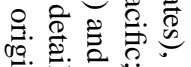

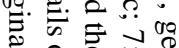
过它造

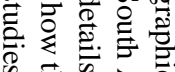

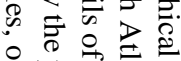

: $\overrightarrow{0}$ 它

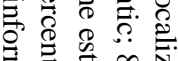
욜

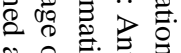
$\approx$ 율

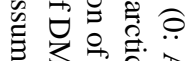
票变蛋

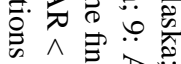
कि $\hat{\sigma} \vec{\partial} \overrightarrow{0}$

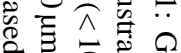
\& 율

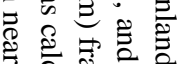

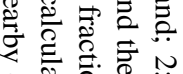

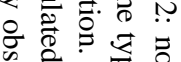

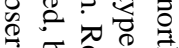

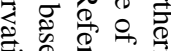
音.

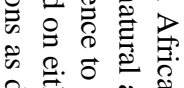

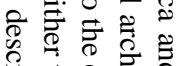

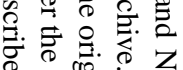

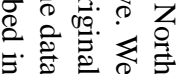


The second criterion relates to the ability of a quantitative determination of the EC.

For marine cores, we rely on the original and subsequent authors' evaluation of contamination, e.g., the possibility of non-eolian inputs, such as from sediment focusing, volcanic, fluvial, hemipelagic, and ice-rafted materials. Marine records that are definitely or very likely to be affected by unaccounted for non-eolian inputs are rated as having critical uncertainty. These include sites in regions that have been identified as being affected by non-eolian inputs, such as the volcanic materials and ice-rafted detritus in the North Pacific (Serno et al., 2014), volcanic inputs in the eastern equatorial Pacific (Olivarez et al., 1991), possible non-eolian detritus in the western Pacific Ontong Java Plateau (Kawahata, 1999), or sediment focusing and ice-rafted debris (IRD) in the Southern Ocean (Kohfeld and Harrison, 2001). When the possible presence of non-eolian components is more speculative, we attribute a substantial level of uncertainty. In addition, estimates of EC made using quartz concentrations or elemental (e.g., $\mathrm{Al}$ ) proxies were rated as having substantial uncertainty. Records based on ${ }^{232} \mathrm{Th}$, the experimental isolation of eolian components, or a differencing method $(\mathrm{EC}=1$ $-\mathrm{CaCO}_{3}-$ opal $-\mathrm{C}_{\text {organic }}$ ) to determine $\mathrm{EC}$ were preferred.

For ice cores, primary non-eolian inputs to the insoluble particle material are volcanic in origin and can usually be singled out and selectively removed from the records (Narcisi et al., 2010). In some cases though, they may be a widespread presence in a record (Gabrielli et al., 2014), which we consider cause for the attribution of substantial uncertainty. We consider particle counters the more robust methods for the determination of EC. Uncalibrated (for the size) laser counters give unreliable results, as both the size distributions and the EC may be significantly affected, which we consider a critical uncertainty. Among the 124 records initially selected, a few ice core records rely on calcium as a proxy for dust. Subtleties include the fact that total calcium is a worse proxy than non-sea-salt (nss) calcium and that calcium in general is a better proxy in Greenland than in Antarctica because of the proportions of crustal versus nss-Ca in the two cases, with sea salt deposition 1 order of magnitude higher than dust in Antarctica but much lower in Greenland (Ruth et al., 2002, 2008). We simply assume a substantial uncertainty for all records based on calcium.

For terrestrial records, we attribute substantial uncertainty to the presence of non-eolian inputs, as identified by authors. We attribute substantial uncertainty when an elemental proxy was used for the determination of EC rather than relying on the sedimentation rate of the eolian sediment or the residual fraction after the elimination of non-eolian inputs. A critical uncertainty is attributed to the use of quartz as a quantitative proxy for EC.

The third criterion focuses on the quantitative and sizeresolved separation of local versus remote dust.

This criterion in fact does not apply to loess-paleosol sequences, where instead we applied constraints on the ne- cessity of size information. For the other types of natural archives, all the other records that we found to be most likely affected by unaccounted for local dust inputs are rated as having critical uncertainty. When the possible presence of local dust inputs is likely, but more speculative, we attribute a substantial level of uncertainty.

Records that meet all criteria are labeled with "high confidence", whereas failing to meet one criterion results in a record receiving the attribution of "medium confidence" level. A record is given a low level of confidence when either (a) two or more aspects are considered to be affected by substantial uncertainty or (b) even just one aspect is considered to be a critical uncertainty. We only included those records in the compilation (45 out of 124) that have high and medium confidence levels (Table 1; Supplement).

\subsection{Ages and chronologies}

All the ages reported in this compilation are expressed in thousands of years before 1950 AD (ka BP). We do not rederive the age models for the records in this compilation but use the original chronologies reported in the relevant publications. This is the case for all records included in this compilation. The only exceptions are the case of the Antarctic ice cores, which have been reported according to the AICC2012 chronology (Veres et al., 2013), and a specific approach for loess-paleosol sequences described below.

In Sect. 3.1, we explained how loess-paleosol sequences with a medium confidence level satisfy the condition of being representative of large-scale patterns. This is based on the possibility of grouping them within subregional settings where sequences exhibit a common stratigraphy. These groups should also account for spatial variability in the timing of the onset of climatic conditions that are linked to specific loess-paleosol subunits, e.g., on the CLP. When possible (i.e., for the records in the western CLP: Duowa and Jiuzhoutai), we constructed SBMAR records for those sites, based on selecting (or interpolating in the case of Duowa; see Supplement) only the dates at the interface between two consecutive subunits, in fact reflecting the alternation of soil and loess subunits (S0.S1-S0.L1-S0.S2-S0.L2-S0.S3). We consider this as a slightly conservative approach, which has the advantage of (a) limiting potential abrupt fluctuations in DMARs, which may just be reflecting dating errors (e.g., related to bioturbation), and (b) pairing the records to some extent, consistently with the criteria mentioned earlier. Note that a similar approach was used for the two loesspaleosol sequences from Nebraska included in this compilation (Wauneta, Logan Roadcut). For Jingyuan and the central CLP (Beiguoyuan, Xifeng, Luochuan, Weinan), no such distinction of subunits within the Holocene paleosol (S0) is visible; thus, the time series are based on all the available dates. The same holds for the one single site in Alaska (Chitina).

In the previous section we discussed how either a linear or a more sophisticated age model is used to determine a pro- 
file's chronology. Each numeric age or tie point is characterized by some uncertainty. The nature and magnitude of the error depend on the specific technique and include the analytical error, and the calibration or wiggle-matching error when applicable. We try to estimate this type of uncertainty quantitatively. Unquantifiable uncertainties include the effects of bioturbation, sample contamination, etc.

Age uncertainties that can be estimated arise from three different processes: (1) experimental error in a measurement (e.g., ${ }^{14} \mathrm{C}, \mathrm{OSL}$ ); (2) calibration errors (e.g., ${ }^{14} \mathrm{C}$ calibration software, OSL measurement in water content); (3) other age-model uncertainties. For instance, radiocarbon dating requires corrections to account for the carbon reservoir effect (Brauer et al., 2014). Calibration software has been developed to perform this task (e.g., Bronk Ramsey, 1995; Reimer et al., 2009). All radiocarbon ages reported in this paper are calibrated, according to the original references.

In the case of age models more complicated than the simple linear relation used to derive an LSR, errors associated with ages are usually reported in the publications. An example of this are the new ice core chronologies, such as AICC2012, which report the associated age uncertainties (Veres et al., 2013).

For a linear sedimentation model, the age of a given depth horizon is calculated by linear interpolation between two dated horizons. In this case the age error of the samples is bound to the uncertainties associated with the bracketing ages. The age-model error of the sample can then be derived through the error propagation formula:

$\varepsilon_{\text {sample }}=\sqrt{\varepsilon_{a}^{2}+\varepsilon_{b}^{2}}$,

where $\varepsilon_{a}$ and $\varepsilon_{b}$ are the age errors of the two adjacent dated points between which the linearly interpolated sample age was calculated.

The other usual possibility is that the age model of a site was determined without the help of any absolute age marker, but just by using stratigraphic correlation. A typical example of such an age model is one based on stratigraphic correlation of a marine sediment core site's $\delta^{18} \mathrm{O}$ profile with the SPECMAP stack (Imbrie et al., 1984). In this case and in all other circumstances where the age error is not reported, we arbitrarily assume an uncertainty of $6.8 \%$ ( $1 \sigma$, corresponding to an overall $10 \%$ ).

\subsection{Eolian dust MARs}

Dust MARs constitute the key element of this compilation. We previously discussed (Fig. 2) the nonparallel depth resolution of the age samples and the EC samples. Unless stated otherwise, we always use a chronology targeted at the final DMAR resolution, which is determined ultimately by the EC resolution (see also Fig. 1). The typical exceptions are loesspaleosol sequences, where SR alone (hence the resolution of the age samples) determines the dust MAR.
We report both the SBMAR (or SR and DBD) and EC for each point in the records, with relative uncertainties. The uncertainties are taken from the original sources when available and assigned otherwise. The dust MAR uncertainty is determined from the relative uncertainties in the factors SBMAR and EC, combined through the error propagation formula:

$\varepsilon_{\mathrm{MAR}}=\sqrt{\left(\frac{\varepsilon_{\mathrm{SBMAR}}}{\mu_{\mathrm{SBMAR}}}\right)^{2}+\left(\frac{\varepsilon_{\mathrm{EC}}}{\mu_{\mathrm{EC}}}\right)^{2}}$,

with $\varepsilon_{\mathrm{SBMAR} / \mathrm{EC}}$ and $\mu_{\mathrm{SBMAR} / \mathrm{EC}}$ representing the absolute errors and the absolute values, respectively.

In this compilation, there are two cases when SBMAR is provided directly instead of being the combination of SR - DBD: ice cores and marine sediment records derived using the thorium profiling method. In the case of ice cores SBMAR corresponds to the ice accumulation rate, expressed in meters (water equivalent) per year, which incorporates information about ice density and thinning with depth (Alley, 2000; Veres et al., 2013). When it is not reported, we assume that the relative uncertainty is the same as that of the age uncertainty. This is a reasonable approximation for the Holocene records from the ice cores presented here, but significantly larger uncertainties related to ice thinning models should be considered for deeper sections of ice cores and for glacial stages (Kindler et al., 2014). For marine cores, we consider the relative uncertainty in the thorium excess (xs$\mathrm{Th}$ ) parameter. When it is not reported, we assumed a relative uncertainty of $5 \%$, assigned based on an expert informed guess.

In all other cases, for SR we consider that the relative uncertainty is the same as the age uncertainty, which again is combined, through the error propagation formula with the other uncertainties. DBD is sometimes measured but often just assumed, based on the literature from the broader region. When no information was reported in the original works, we assumed a dry bulk density of $1.48 \mathrm{~g} \mathrm{~cm}^{-3}$ for the CLP (Kohfeld and Harrison, 2003) and $1.45 \mathrm{~g} \mathrm{~cm}^{-3}$ for North America (Bettis III et al., 2003). When not measured, we assumed a $15 \%$ relative uncertainty for DBD (Kohfeld and Harrison, 2003).

With the exception of loess, for which we assume $\mathrm{EC}=1$ unless otherwise stated, EC is either expressed in terms of the fraction or concentration of dust or a proxy in the bulk sediment. For the Antarctic ice cores considered in this compilation, the EC is determined according to the volume dust concentrations determined by a Coulter counter; the mass concentration is calculated by multiplying the volume with the assumed dust density of $2.5 \mathrm{~g} \mathrm{~cm}^{-3}$ (Delmonte et al., 2004). The uncertainty in this case is taken from the standard deviation of the $\sim$ three replicate measurements. When a dust proxy is used instead to determine the EC, its concentration is divided by the element's typical abundance in dust (or crustal abundance). In this case the analytical uncertainty (if not reported, we assume $5 \%$ ) is combined with the uncertainty of 
the dust proxy, i.e., the variability in its amount in dust. We keep the proxy-dust relation from the original studies when available.

Several records in this compilation use ${ }^{232} \mathrm{Th}$ as a dust proxy, for which we assume $10.7 \mathrm{ppm}$ in dust (McGee et al., 2007) if not specified otherwise in the original papers. We always assumed $9.3 \%$ uncertainty for ${ }^{232} \mathrm{Th}$ as a dust proxy (McGee et al., 2007) or a combined uncertainty of $15 \%$ when the analytical uncertainty was not available. In one case (GISP2), we used calcium as a dust proxy (Mayewski et al., 1997), assuming a variable calcium-dust relation in Greenland with respect to changing climate conditions, resulting in $26 \%$ calcium in dust (Ruth et al., 2002; Steffensen, 1997), with an arbitrarily assigned uncertainty of $20 \%$.

When the isolation of the detrital component from the sediment matrix is done by the removal of carbonates, opal, and organic matter, then the EC can be estimated from the bulk terrigenous component. We assume $5 \%$ uncertainty in this procedure.

We stress once again that the quantitative uncertainties estimated here do not fully represent the overall uncertainty of a record, which should be considered in combination with the confidence level (Table 1).

\subsection{Dust grain size distributions}

Here, we focus on the importance of the grain size information and its close link to the DMAR. When possible, we retrieved the size distributions associated with the records in this compilation. Depending on the technique used, the size data was collected in the form of size distributions (e.g., by particle counters and laser particle analyzer) or size classes (using the sieve and pipette method), e.g., the percentages of sand, silt, and clay (Muhs et al., 2013; Lu et al., 1999).

Despite the differences and uncertainties associated with specific methods (Mahowald et al., 2014; Reid, 2003), we include the available information according to the original sources. In the case of size classes, we report the information as provided in the original papers. In addition, we take an innovative approach to organizing the size distribution data. First of all, we carry the original size distributions to a new, common binning in order to enhance the accessibility of the data and to facilitate the intercomparison among records. Second, we associate the size distributions with the DMAR time series sample-to-sample where possible so that DMAR time series for different size ranges can be easily determined.

The re-binning procedure to adapt the original size distributions from observations is organized in a series of steps: (1) definition of a new binning model; (2) building the cumulative distribution from the normalized observations; (3) fitting a spline curve to the observation cumulative distribution; (4) integration of the fitted spline curve into the new bins; (5) evaluation and summary of the fit of the new binned data to the original observations. The fitting spline in (3) is bounded to have values between 0 and 1 and to be monotonically nondecreasing.

One challenge in finding a new binning model is to avoid significant distortion to the original size distribution, given that observations have both a different resolution and a different size range. A compromise is necessary to preserve both the actual dust flux (i.e., a size range wide enough to include most observations) and the shape of the distributions. The preservation of the size distribution properties, i.e., the mass partitioning across the size spectrum, requires an adequate number of bins and adequate spacing. We adopted a new bin model with $n=76$ bins, spanning the interval of particle diameters between 0.28 and $208.34 \mu \mathrm{m}$. The bin spacing is defined by a monotonically increasing function: $y=0.089 \cdot x+0.002$, where $x$ is the $n$th bin center, $y$ is the $(n+1)$ th bin center, and $x 0=0.35 \mu \mathrm{m}$ (first bin center). Bin edges are calculated by linear interpolation, halfway between two consecutive bin centres. This binning model is very similar to the instrumental size binning of, e.g., Mulitza et al. (2010) or McGee et al. (2013), in the same size range. For all samples subject to re-binning, visual inspection of the original and new distributions as well as the production of objective metrics (Supplement) were performed,.

All references to size in this work refer to the particle's diameter. We always refer to volume or mass size distributions, both in the main text and the Supplement.

\subsection{Modelling the global dust cycle}

Paleodust records not only represent excellent climate proxies, but they also offer the possibility to quantitatively constrain the mass balance (or magnitude) of the global dust cycle. Here, we use a dust model to extrapolate the available data to allow global coverage for the deposition, as well as estimates of sources, concentrations, and aerosol optical depth using the Community Earth System Model (Albani et al., 2014; Mahowald et al., 2006, 2011). To represent the impact of climate variability during the Holocene on the dust cycle, we chose two reference periods for our simulations with the CESM: the MH (6 ka BP) and the preindustrial (1850 AD), which we assume to be representative for the early and mid-Holocene (5-11 ka BP) and the late Holocene (1-5 ka BP) respectively, based on the first-order differences in orbital forcing and climate in the two periods (e.g., Wanner et al., 2008). The initial conditions for the MH simulations are taken from a fully coupled climate equilibrium simulation for $6 \mathrm{kaBP}$ (http://www.cesm.ucar.edu/experiments/cesm1. 0/\#paleo), which follows the PMIP3 prescriptions for greenhouse gas concentrations and orbital forcing, with preindustrial prescribed vegetation (Otto-Bliesner et al., 2009), and which was part of the PMIP3-CMIP5 (Coupled Model Intercomparison Project Phase 5) model experiments for the IPCC Fifth Assessment Report (AR5) (Masson-Delmotte et al., 2013; Flato et al., 2013). For the preindustrial simulation 
we take the initial conditions from an equilibrium reference simulation described in Brady et al. (2013).

The dust model integrated into the CESM used for this study uses the Community Atmosphere Model version 4 with a Bulk Aerosol Model (CAM4-BAM) and is described in detail in Albani et al. (2014). The dust model simulates dust emission, transport, dry and wet deposition, and direct interactions with radiation in the long- and shortwave spectrum. The dust mass is partitioned into four size classes spanning the $0.1-10 \mu \mathrm{m}$ diameter range. Modeled dust emissions are primarily a function of surface wind speed, vegetation (and snow) cover, and soil erodibility, which is a spatially varying parameter summarizing the differences in susceptibility to erosion related to, e.g., soil textures and geomorphology (Zender et al., 2003).

Although the physical model does not include changes in vegetation, following the PMIP protocols (Otto-Bliesner et al., 2009), we accounted for different vegetation cover in the MH by removing the online dependence of dust mobilization on preindustrial vegetation. For the $6 \mathrm{ka}$ BP equilibrium climate, we instead simulated new vegetation cover with the coupled biogeography and biogeochemistry equilibrium model (BIOME4) (Kaplan et al., 2003), following the methodology of Mahowald et al. (2006). The effects of vegetation were incorporated into the soil erodibility map by applying a scale factor to each grid cell, proportional to the fraction of the grid cell available for dust emission in arid areas (same as for the LGM in Albani et al., 2014). We also accounted for glaciogenic sources in Alaska, which are not explicitly simulated by the model, by prescribing them according to Albani et al. (2014) and Mahowald et al. (2006).

In addition, we relaxed the dampening effect of vegetation cover on dust mobilization in the model in one specific region, i.e., the Nebraska Sand Dunes, to account for a known dust source relevant for the Holocene (Miao et al., 2007). In that region, too much vegetation cover from the prescribed input data sets would otherwise inhibit dust mobilization both for the preindustrial and $\mathrm{MH}$ simulations.

We provided observational constraints on the model dust deposition flux by considering the dust MAR from the data compilation, limited to the model's size range, i.e., $<10 \mu \mathrm{m}$ : we considered only the relevant fine fraction from the new binning. For each record we calculated MAR time series during 2 ka long time intervals centered on 2, 4, 6, 8, and $10 \mathrm{kaBP}$ by averaging the original data across each of the macro-regions (Fig. 4). Linear interpolation was then used to fill in the gaps.

The model's fit to the observations was improved through a spatial optimization of the soil erodibility by applying a set of scale factors specific to macro-areas, which is reflected in dust mobilization from those macro-areas (Albani et al., 2012b, 2014; Mahowald et al., 2006, 2010, 2011). We applied this procedure to preindustrial and $\mathrm{MH}$ simulations constrained by the data in the $4 \mathrm{ka} \mathrm{BP}$ and $6 \mathrm{ka} \mathrm{BP}$ time slices, respectively. In order to account for dust variability in the
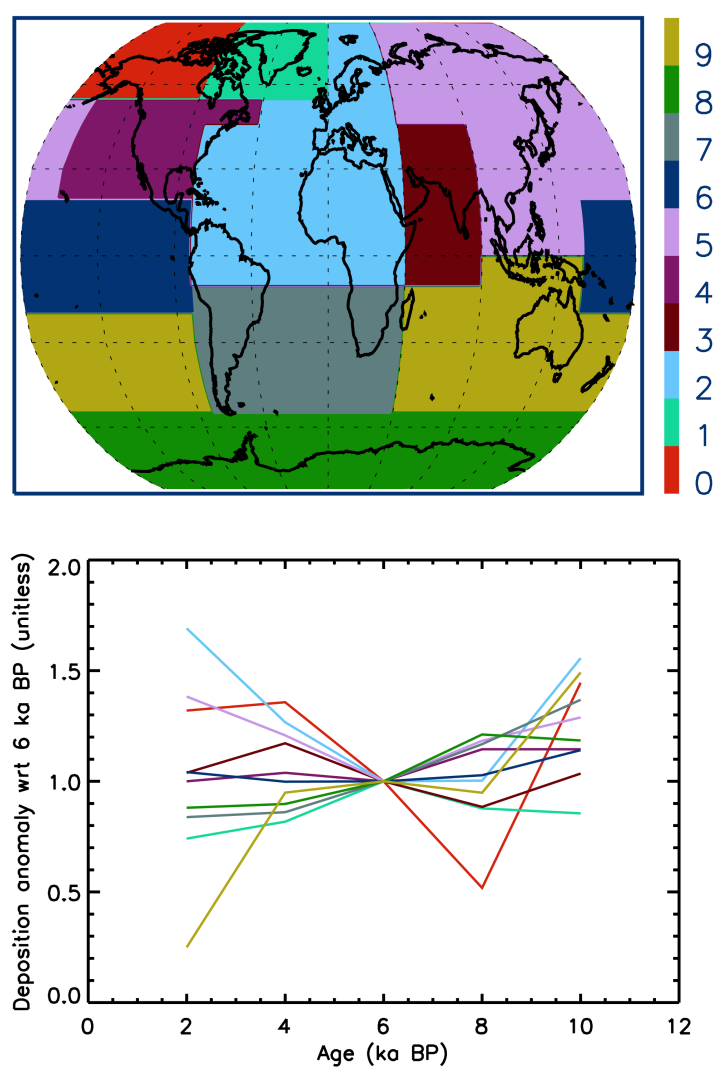

Figure 4. Upper panel: subdivision of the globe into different areas, based on the spatial distribution of data in this compilation ( 0 : Alaska; 1: Greenland; 2: northern Africa and North Atlantic; 3: Arabian Sea; 4: North America; 5: eastern Asia and North Pacific; 6: equatorial Pacific; 7: South Atlantic; 8: Antarctica; 9: Australia). Bottom panel: time series (at a $2 \mathrm{kyr}$ interval) of the dust deposition anomaly with respect to (wrt) $6 \mathrm{ka} \mathrm{BP}$ for the different areas, as estimated from the observations. Color-coding of the different areas is consistent between upper and lower panel.

other time periods $(2,8$, and $10 \mathrm{kaBP})$, we linked them to the respective reference case for the late $(4 \mathrm{kaBP})$ and midto late Holocene ( $6 \mathrm{ka} \mathrm{BP}$ ) by prescribing an additional set of scale factors for dust emissions in the same model macroareas. Those scale factors are expressed as anomalies in relation to the reference period and are determined based on the observations: each time series in the compilation at the $2 \mathrm{kyr}$ interval was reduced to an anomaly with respect to its value at $6 \mathrm{kaBP}$ (and $4 \mathrm{kaBP}$ in parallel); then, a regional average anomaly was calculated within specific regions determined based on the geographical distributions of the observations (Fig. 4). We assume that emissions in each of the model macro-areas are related to observations from specific geographic regions, which act as sinks for dust originating from each dust source macro-area (Mahowald et al., 2010). The anomaly in dust emissions was then calculated as the average of the anomalies from the group of forcing regions 
Table 2. Dust source areas in the CESM model and scale factors expressed as anomalies with respect to a reference period, derived from the observations. The first column lists the model dust source areas. The second column gives the geographical regions where observations are clustered; these are used to scale the dust from the corresponding model macro-areas. The reference periods are 4 for $2 \mathrm{ka} \mathrm{BP}$, and $6 \mathrm{ka}$ BP for 8 and $10 \mathrm{kaBP}$.

\begin{tabular}{lcccccc}
\hline Source area & Anomaly forcing regions & $2 \mathrm{ka} \mathrm{BP}$ & $4 \mathrm{ka} \mathrm{BP}$ & $6 \mathrm{ka} \mathrm{BP}$ & $8 \mathrm{ka} \mathrm{BP}$ & $10 \mathrm{ka} \mathrm{BP}$ \\
\hline Alaska & 0 & 0.6224 & 1 & 1 & 1.0800 & 1.3381 \\
North America (southwest) & 4,6 & 0.8961 & 1 & 1 & 0.8810 & 0.9452 \\
North America (Midwest) & 4 & 1.0081 & 1 & 1 & 0.9929 & 0.9481 \\
Northern Africa & 2 & 1.3350 & 1 & 1 & 1.0030 & 1.5563 \\
Central Asia & 3,1 & 0.9628 & 1 & 1 & 1.1448 & 1.1448 \\
Eastern Asia & 5,1 & 1.0257 & 1 & 1 & 1.0304 & 1.0720 \\
South America (northern regions) & $7,8,6$ & 0.7396 & 1 & 1 & 1.1093 & 1.3482 \\
South America (Patagonia) & 7,8 & 0.9995 & 1 & 1 & 1.1358 & 1.2313 \\
South Africa & $7,8,9$ & 0.9777 & 1 & 1 & 1.1898 & 1.2764 \\
Australia & 9,8 & 0.9723 & 1 & 1 & 0.5183 & 1.4452 \\
\hline
\end{tabular}
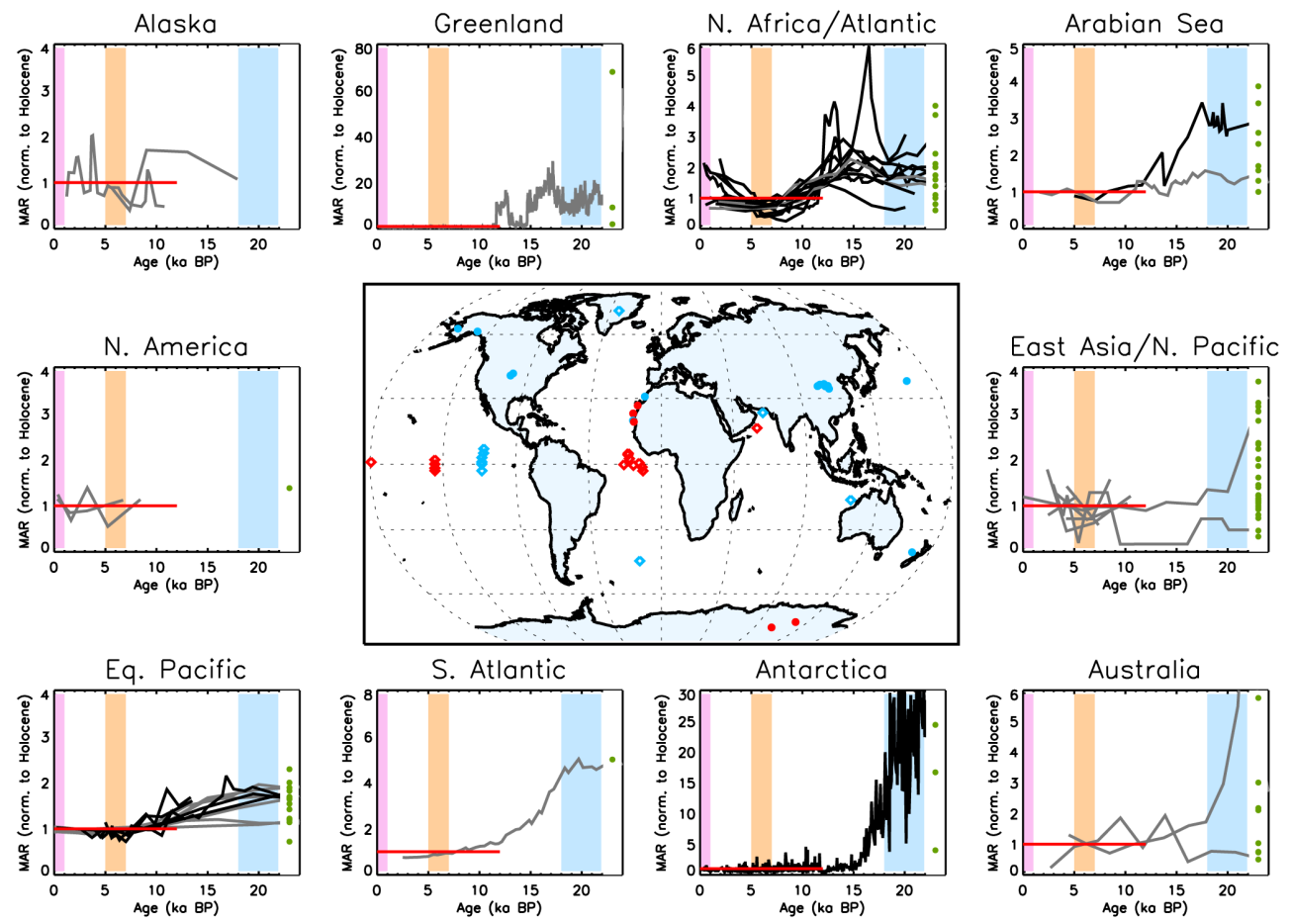

Figure 5. Overview of the data compilation. Central plot: global overview of the location of the paleodust records. Color indicates the confidence level (red: high confidence; blue: medium confidence). Marker's shape indicates whether size distributions or classes are available (filled circles: yes; empty diamonds: no). Framing plots: time series of bulk dust MAR in the different areas, normalized to their Holocene (0$12 \mathrm{ka} \mathrm{BP}$ ) average (red solid line for reference, which represents the time span over which DMARs were averaged in the original DIRTMAP; Kohfeld and Harrison, 2001). Black solid lines represent high-confidence records; gray lines identify medium-confidence records. Records are plotted in the 0-22 ka BP interval to allow a comparison with DIRTMAP3 (Maher et al., 2010) data (as reported in Albani et al., 2014), represented by their glacial-interglacial ratio (green solid circles). Vertical color shading bands highlight the last millennium (pink), the MH (5-7 ka BP, salmon), and the Last Glacial Maximum (18-22 ka BP, light blue).

(Table 2). We acknowledge that this simple procedure implies possible discontinuity at the 4 to $6 \mathrm{ka} \mathrm{BP}$ transition.

\section{Holocene dust variability}

\subsection{Global overview}

A total of 45 high- and medium-confidence paleodust records (out of 124) from ice and terrestrial and marine archives dis- 
tributed worldwide comprise the data compilation (Fig. 5). It is noteworthy that, while in a few regions there is a relative abundance of observations (North Atlantic, equatorial Pacific), there are few data from other parts of the world (North Pacific, Southern Hemisphere) after the application of filtering criteria.

The amplitude of bulk dust variability recorded from natural archives during the last $22 \mathrm{kyr}$ relative to their Holocene average allows a comparison with the DIRTMAP3 (Maher et al., 2010) data with regard to the glacial-interglacial variability within several regions around the globe (Fig. 5).

Different regions show different patterns of variability during the Holocene (e.g., the apparent low degree of variability in the equatorial Pacific versus the mid-Holocene minimum in the North African Margin), and even within certain regions there may be significantly diverse trends, which will be discussed in more detail in the following sections.

\subsection{Northern Africa and North Atlantic}

The most striking display of variability during the Holocene is shown by the cores from the northwestern African Margin (5 records), with an amplitude comparable to glacialinterglacial variability (Fig. 5) (Adkins et al., 2006; McGee et al., 2013). As first suggested by deMenocal et al. (2000), this would be a clear mark of the significant changes in the climatic conditions in northern Africa between the wetter early to mid-Holocene compared to the drier late glacial and late Holocene. During the so called "African Humid Period" in the early to mid-Holocene, greening of the Sahara occurred, i.e., changes in vegetation in response to increased humidity and precipitation, as seen in pollen records and lake level changes (e.g., Hoelzmann et al., 1998; Jolly et al., 1998; Street-Perrott and Perrott, 1993). The cause of these changes has been identified as an enhanced summer monsoon, driven by changes in orbital forcing, sea surface temperature, and vegetation (e.g., Braconnot et al., 2007; Claussen et al., 1999; Kutzbach and Liu, 1997).

Figure 6 shows the large range of values (spanning 2 orders of magnitude) encompassed by the DMAR estimates from marine sediment cores to the west of the African coast. Records from the equatorial Atlantic (lower temporal resolution) tend to show decreasing trends from the early to midHolocene, with little or no variability afterwards (Bradtmiller et al., 2007; François et al., 1990), compared to the sites on the northwestern African Margin (higher temporal resolution) that show a minimum in DMAR in the $\sim 5-9 \mathrm{kaBP}$ period (McGee et al., 2013).

The absolute values of bulk DMARs (dotted lines) are higher for the sites close to the coast of northwestern Africa (bluish colors) compared to the sites in the equatorial Atlantic (reddish and greenish tones). When considering only the fine fraction $(<10 \mu \mathrm{m}$ : solid lines), three (out of five) records from the northwestern African Margin are comparable in magnitude to those in the equatorial Atlantic, at least
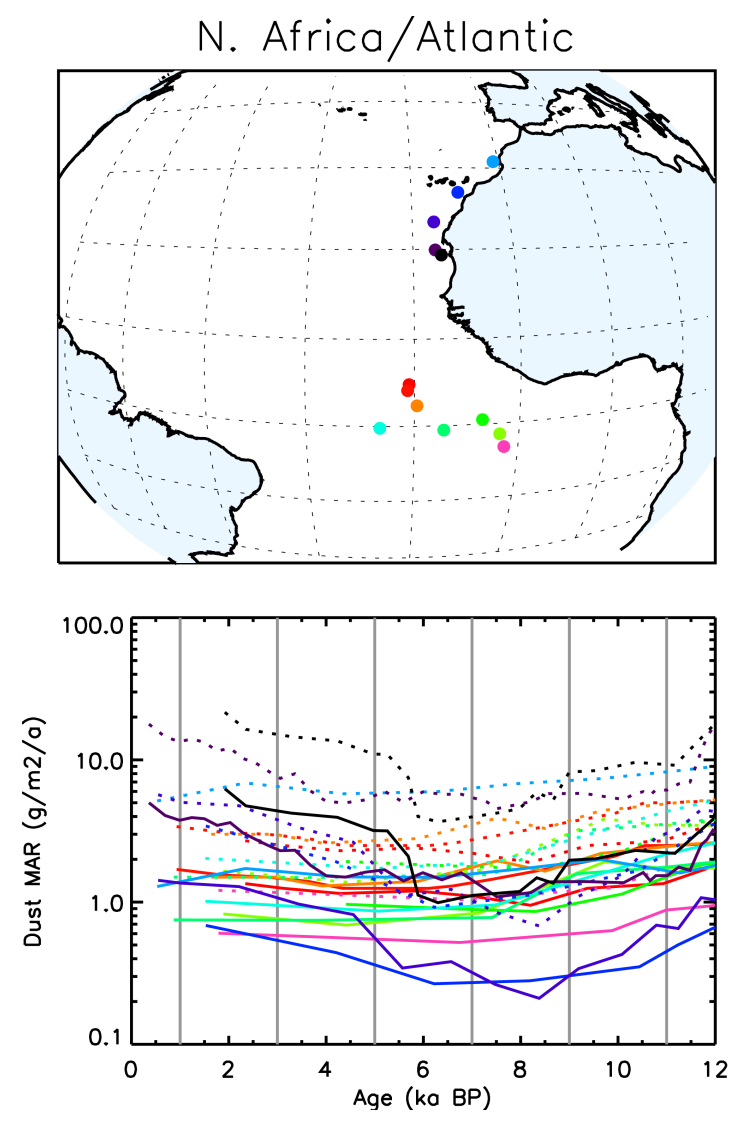

Figure 6. Detailed view of the dust records in the northern AfricaNorth Atlantic region. Upper panel: geographical location of the paleodust records. Bottom panel: time series of the bulk (dotted lines) and "fine", i.e., < $10 \mu \mathrm{m}$ (solid lines), dust MARs. Color-coding is consistent between upper and lower panel. Vertical grey solid lines mark the subperiods within the Holocene as described in Sect. 3.4 at an interval of $2 \mathrm{kyr}$. Please refer to the descriptive sheets in the Supplement for a graphical display of the uncertainties for each record.

for the early to mid-Holocene, although they tend to be larger in the late Holocene. On the other hand, two of the records display very low values of DMARs, lower than the records from the equatorial Atlantic, and are comparable to the equatorial Pacific.

Core top bulk dust MARs from northwestern African Margin cores match very well with modern sediment trap data (Ratmeyer et al., 1999). On the other hand there is substantial uncertainty in the attribution of the fine fractions, with records in the equatorial Atlantic loosely constrained by present-day sediment trap data from the Cape Verde area (Ratmeyer et al., 1999) and size data for the northwestern African Margin based on actual measurements from sediment samples but relying on end-member modeling for the separation between riverine and eolian inputs (McGee et al., 2013).

This compilation and comparison suggests that there is still a substantial knowledge gap in the area and ample space 
to debate the causes of the differences in magnitude and trends between the records from the northwestern African Margin and the equatorial Atlantic. For instance, there could be differences related to shifts in the position of the ITCZ in relation to the dust plume or related to differences in the interpretation of the data, in particular with reference to the grain size distributions and potential non-eolian components; this would have implications for the spatial representativeness of the records.

\subsection{Arabian Sea}

Marine sediments from the Arabian Sea are of great value, as they provide a rare opportunity to gather information about past dust variability from the Middle East and central Asia, about which little is known despite this arid belt being one of the major dust sources worldwide (Prospero et al., 2002). The most relevant climatic feature in the region is the seasonality related to the onset of the southwestern Indian monsoon. The largest dust activity in the region is from summer dust emissions from Mesopotamia and the Arabian Peninsula, which are thought to constitute the major dust sources at present for the Arabian Sea, although contributions from Somalia and Iran and Pakistan may be important (Prospero et al., 2002).

We report data from the cores RC-27-42 and 93KL, recovered from the central Arabian Sea (Pourmand et al., 2007) and the Little Murray Ridge in the northeast (Pourmand et al., 2004), respectively. There are no clear common trends between the two records, which indeed show very different DMARs, 1 order of magnitude apart (Fig. 7). There is little information to explain the difference in magnitude, which is perhaps related to different sources, although possible fluvial inputs to $93 \mathrm{KL}$ cannot be conclusively ruled out. There is clear evidence that dust grains larger than $10 \mu \mathrm{m}$ are present in the Arabian Sea sediments (Clemens and Prell, 1990; Clemens, 1998; Sirocko et al., 1991). The fine-fraction ratio for the two records is a rough approximation common to both records (Table 1).

\subsection{North America}

Evidence of dust deposition and accumulation during the Holocene in North America is widespread and mainly linked to loess deposits in the mid-continent (Bignell loess), particularly in Nebraska (Mason et al., 2003; Miao et al., 2007), Kansas (Feng et al., 1994), North Dakota (Mason et al., 2008), and eastern Colorado (Muhs et al., 1999; Pigati et al., 2013). Most areas are characterized by relatively low thickness, so that low temporal resolution does not allow assessing Holocene variability, with the exception of a few sites in Nebraska (Miao et al., 2007).

Unlike the other areas where loess origin is related to local river systems, loess deposits in Nebraska have their immediate sources in the extensive dune fields to the northwest. Changes in the climatic conditions affecting vegetation cover
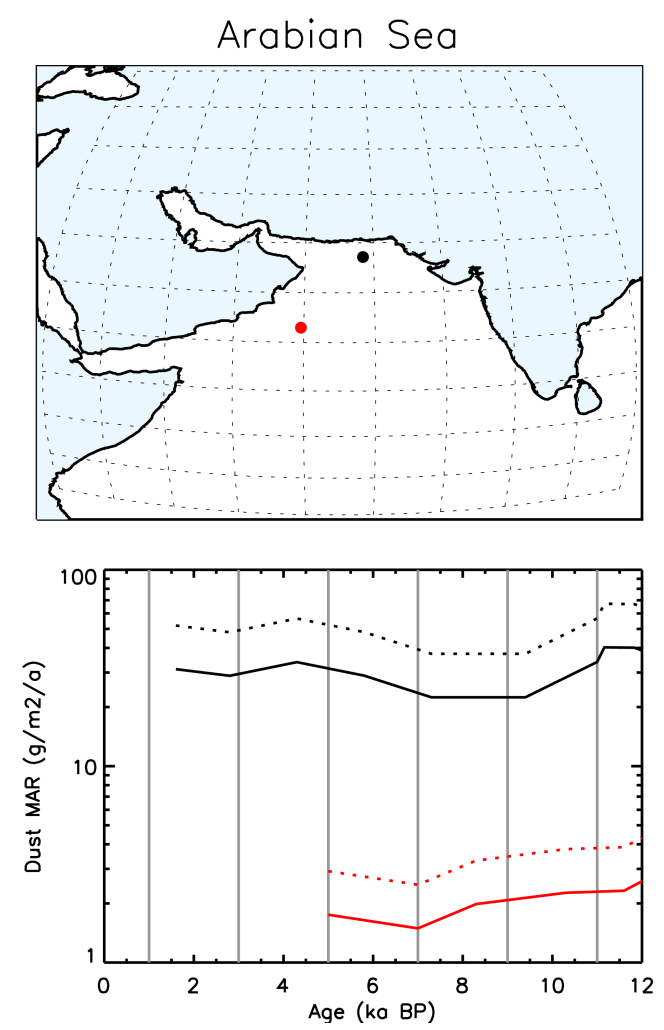

Figure 7. Same as Fig. 6 but for the Arabian Sea region.

have the potential to loosen or stabilize the dunes, altering their potential as dust sources (Miao et al., 2007).

Well-studied sites at Wauneta have very high temporal resolution due to the high DMARs and allowed the identification of different phases of dust accumulation and pedogenesis during the Holocene. The high accumulation rates are related to the location, on the edge of tableland escarpments facing the immediate source areas of the dust. The accumulation rate drops off drastically in the downwind direction from these sites; for example, the $\sim 6 \mathrm{~m}$ of Holocene loess in the Old Wauneta Section thins to a little over $1 \mathrm{~m}$ within a few hundred meters downwind, where a rather uniform loess mantle covers the upland sites (Jacobs and Mason, 2007; Mason et al., 2003). Another site to the northeast (Logan Roadcut) shows lower bulk DMAR but similar phasing, associated with the sequence of pedostratigraphic horizons (Miao et al., 2007). When accounting for the size information, i.e., when focusing on the fine-fraction DMARs, both the absolute values of DMAR drastically decrease and become comparable in magnitude (Fig. 8). This suggests that the fine-fraction DMARs (rather than bulk DMAR) can be considered more representative of accumulation rates over large areas.

\subsection{Alaska}

Dust activity in Alaska has been reported for both the present day (Crusius et al., 2011) and the past, in glacial and in- 

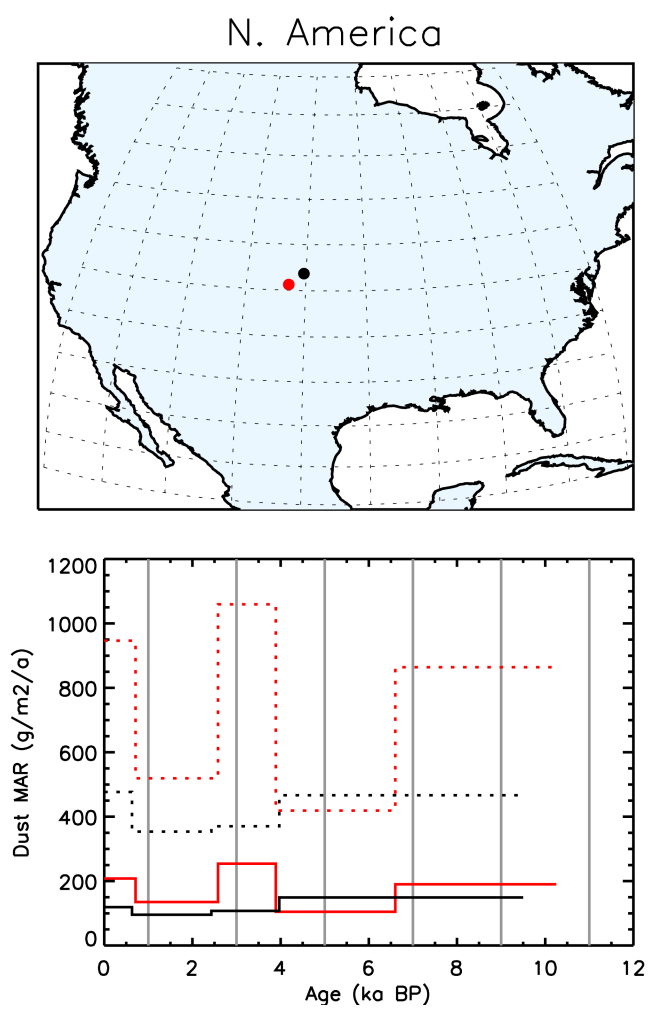

Figure 8. Same as Fig. 6 but for the North American region.

terglacial times (Muhs et al., 2003a). Dust in Alaska is of glaciogenic origin, i.e., results from the formation of loose sediments characterized by fine particles, produced by the abrasion of the surface sediments or bedrock by ice and released onto river or stream outwash plains during the melting season (Bullard, 2013).

Loess deposits of Holocene origin have been identified in central (Begét, 1990) and southern Alaska (Muhs et al., 2004, 2013b; Pigati et al., 2013). The only site with high temporal resolution and numerical dating is the Chitina Section in the Wrangell-St. Elias National Park (Muhs et al., 2013b; Pigati et al., 2013). The high bulk DMAR (Fig. 9) suggests that the dust sources (attributed to the Copper River Basin) lay very close. This notion is supported by the coarseness of grain size data, comparable to analogous data from sites in the Matanuska Valley, which are located within $10 \mathrm{~km}$ of the putative source (Muhs et al., 2004).

Another record with Holocene temporal resolution is from a maar lake (Zagoskin Lake, on St. Michael Island) in western Alaska, which is thought to be representative of proximal but not strictly local sources (Yukon River Valley), as also shown by the grain size (Muhs et al., 2003b). When the fine fraction of DMAR is considered, the Chitina Section and Zagoskin Lake show a comparable magnitude (Fig. 9), which, we observe, is rather large from a global perspective. While this indicates that dust deposition into the Alaskan Gulf and other surrounding seas is probably rel- atively large (Crusius et al., 2011), it is difficult to assess whether the spatial extent of Alaskan dust sources is such that the region is a quantitatively relevant source for dust in the high latitudes (Bullard, 2013; Muhs et al., 2013b). Geochemical tracer studies in the North Pacific may provide some clues (Serno et al., 2014).

\subsection{East Asia and North Pacific}

The deserts in western and northern China are major global dust sources with relevance for the mid- and high latitudes of the Northern Hemisphere (e.g., An et al., 1991; Lu and Sun, 2000; Bory et al., 2003; Prospero et al., 2002). The most stunning evidence of eastern Asian dust history in the Quaternary and beyond in response to orbital forcing lies in the thick deposits of the Chinese Loess Plateau (CLP), which covers extremely vast areas of the upper and middle reaches of the Yellow River to the southeast of the Badain Juran, Tengger, and Ordos deserts (e.g., Ding et al., 2005; Kohfeld and Harrison, 2003; Kukla and An, 1989; Porter, 2001). In relation to the vastness of the CLP, different climatic forcing mechanisms may have interacted in a varying fashion in different regions in response to changes related to the monsoon system (Cosford et al., 2008; Dong et al., 2010), including in the extent or activity of the source areas (e.g., Lu et al., 2013, 2010); in transport, i.e., wind strength and/or seasonality (e.g., An et al., 1991; Ding et al., 2005); and in climatic conditions controlling the balance of pedogenesis and loess accumulation (e.g., Jiang et al., 2014).

Despite several studies conducted on the CLP, few absolutely dated records exist that have a Holocene temporal resolution (Kohfeld and Harrison, 2003; Roberts et al., 2001), with some additions in more recent years (Stevens et al., 2006, 2008; Stevens and Lu, 2009; Lu et al., 2006, 2013). In many areas agricultural practices carried out for at least the last $\sim 2.5 \mathrm{kyr}$ complicate the interpretations of the upper parts of several loess-paleosol sequences (e.g., Roberts et al., 2001). We selected two sites with loess-paleosol sequences from the western CLP: Duowa (Maher et al., 2003; Roberts et al., 2001) and Jiuzhoutai (Kohfeld and Harrison, 2003; Sun et al., 2000). The two sites show the same sequence of pedostratigraphic succession of loess and paleosol subunits (Kohfeld and Harrison, 2003; Roberts et al., 2001; Sun et al., 2000), and the bulk DMARs corresponding to the alternation of those subunits show similar trends (Fig. 10). When the fine component alone is considered, the DMARs from the two sites are very similar. For those reasons, the two sites seem to be representative of large-scale patterns in the western CLP. We also report DMAR from another site in the western CLP (Jingyan: Sun et al., 2012) and from four sites located in the central CLP: Xifeng and Beiguoyuan (Stevens and Lu, 2009), Luochuan (Lu et al., 2000, 2013), and Weinan (Kang et al., 2013). Those sequences have a similar soil unit stratigraphy for the Holocene (Sect. 3.2), but the DMARs relative trends are not consistent (Fig. 10), possibly indicat- 

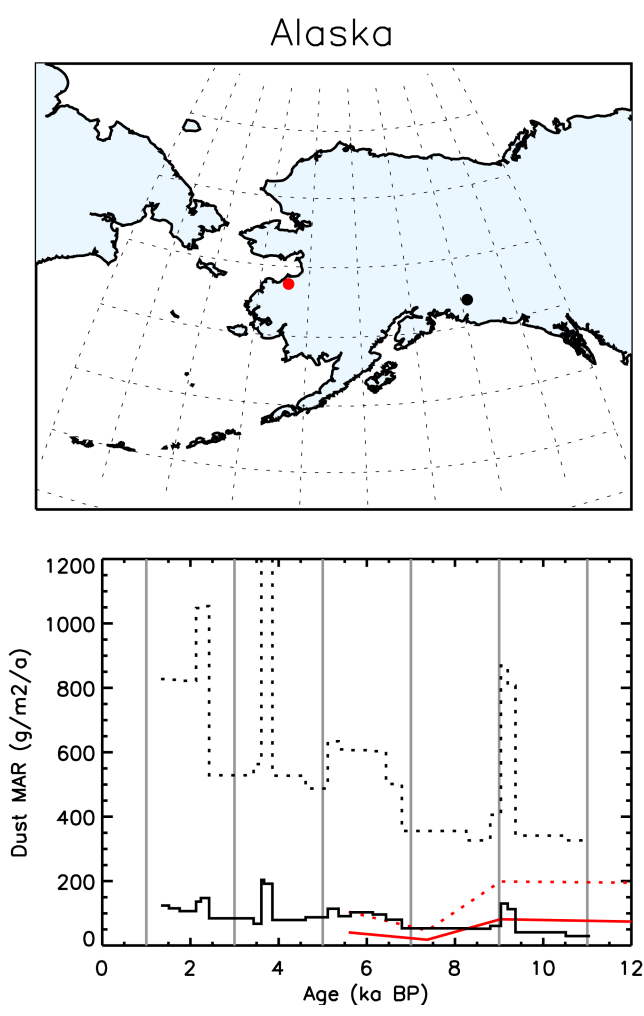

Figure 9. Same as Fig. 6 but for Alaska.

ing that local effects may have a more diffuse influence on DMARs at the central CLP sites. The central sites show a more uniform stratigraphy during the Holocene (prevalence of pedogenesis) with respect to the sites in the western CLP, possibly indicating a stronger influence of the summer monsoon.

Dust plumes emanating from Asian deserts provide dust inputs to the North Pacific Ocean (Rea, 1994), but because of low sedimentation rates and the lack of carbonate-rich sediments, the information from records with temporally resolved Holocene data is very limited. We show one record from core V21-146 (Hovan et al., 1991) which exhibits relatively little variability during the Holocene.

\subsection{Greenland}

Ice core records from Greenland are among the best temporally resolved paleoclimate proxies. They show the sharpest and largest-amplitude oscillations observed in paleodust records worldwide, following the trends exhibited by the other proxies such as, e.g., $\delta^{18} \mathrm{O}$, in the alternation of stadial and interstadial phases during the last glacial period and the deglaciation (Fuhrer et al., 1999; Mayewski et al., 1997; Ruth et al., 2003; Steffensen et al., 2008).

Among the ice cores drilled in Greenland, only one has a full Holocene dust record: GISP2 (Mayewski et al., 1997; Zdanowicz et al., 2000; Zielinski and Mershon, 1997); for
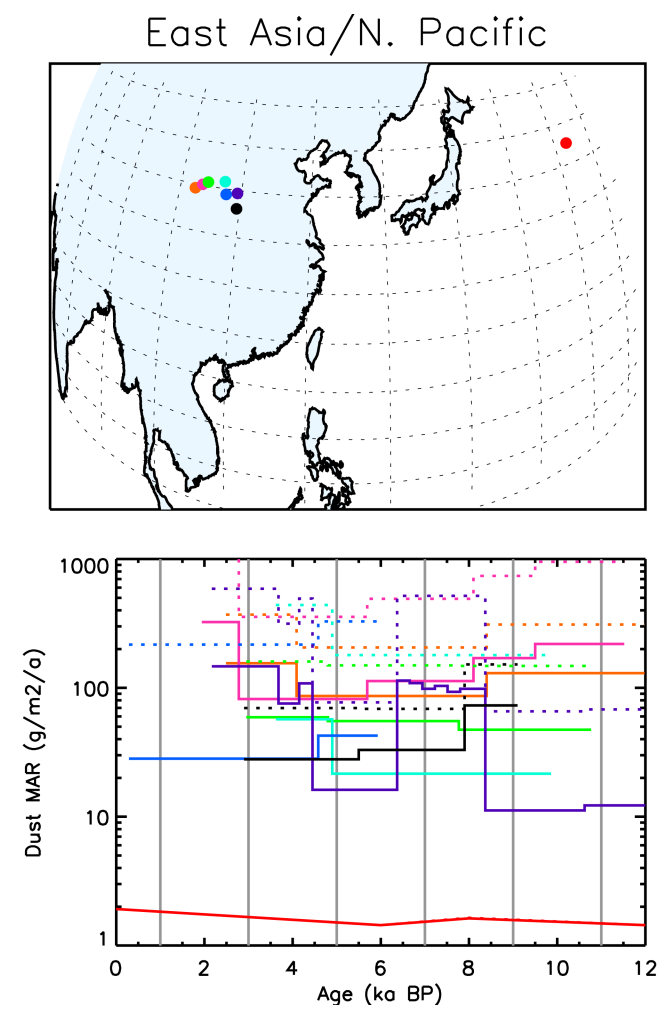

Figure 10. Same as Fig. 6 but for eastern Asia and the North Pacific Ocean.

this core we considered the calcium record as a proxy for dust (Mayewski et al., 1997). Compared to the large variability in the glacial period, the Holocene dust MAR is rather flat, but a closer inspection shows an increasing trend from the early to the mid-Holocene, followed by a declining trend in the late Holocene and a rise during the last millennium (Fig. 11).

It is not clear whether dust variability during the Holocene at GISP2 is related to (1) changes in the dust sources, which are thought to be in central and eastern Asia (e.g., Bory et al., 2003), (2) the atmospheric circulation, which did indeed play a major role during the sharp glacial climate transitions (Mayewski et al., 2014; Meeker and Mayewski, 2002; Steffensen et al., 2008), or (3) changes in deposition mechanisms, which were suggested to be important on glacialinterglacial timescales but may be of minor relevance during the Holocene when accumulation rates are thought to be rather stable (Unnerstad and Hansson, 2001). New studies spanning the Holocene perhaps using dust MARs from particle counters at other sites may help understand whether this is a consistent feature of dust deposition in Greenland.

\subsection{Equatorial Pacific}

The equatorial Pacific Ocean is one of the most remote regions in the world. It is characterized by low dust deposition, correlated with global ice volume and dust in Antarc- 

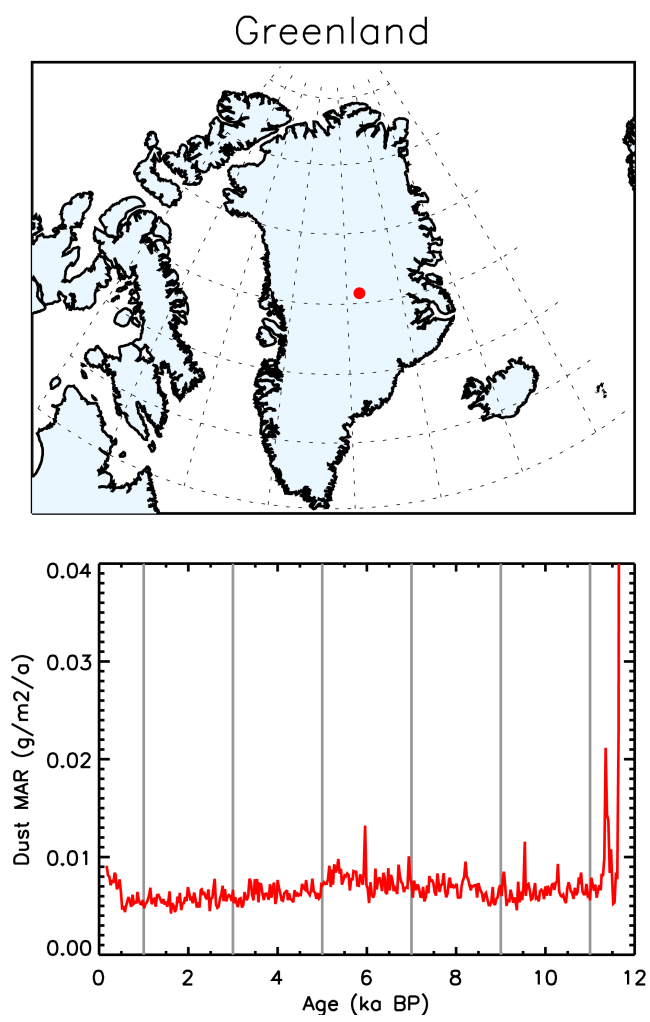

Figure 11. Same as Fig. 6 but for Greenland.

tic ice cores over glacial-interglacial cycles (Winckler et al., 2008). The spatial coverage in the region is relatively good in that there are north-south and east-west transects of cores with temporally resolved Holocene to Last Glacial Maximum dust records (Anderson et al., 2006; Bradtmiller et al., 2006; McGee et al., 2007).

The sites consistently show larger DMARs during the early Holocene compared to the $\mathrm{MH}$ and late Holocene (Fig. 12), with the two northernmost records from $110 \mathrm{~W}$ (green tones) showing the highest DMARs in then region. Due to the low sedimentation rates of equatorial Pacific sediments (typically $1-2 \mathrm{~cm} \mathrm{kyr}^{-1}$ ), it is uncertain whether these Holocene trends are real or simply reflect the bioturbative mixing of glacial sediments characterized by high dust MARs with lowermost Holocene sediments. The records generally show a decreasing DMAR from north to south and from east to west. Geochemical fingerprinting of dust in the equatorial Pacific sediments indicates a complex situation, with a mixture of potential dust sources including Asia, North and Central or South America, the Sahara, and Australia (Xie and Marcantonio, 2012; Ziegler et al., 2007).

\subsection{Australia}

Australia's drylands are among the largest dust sources in the Southern Hemisphere in the present day (Prospero et al., 2002), and dust deposits on land and in the surrounding seas
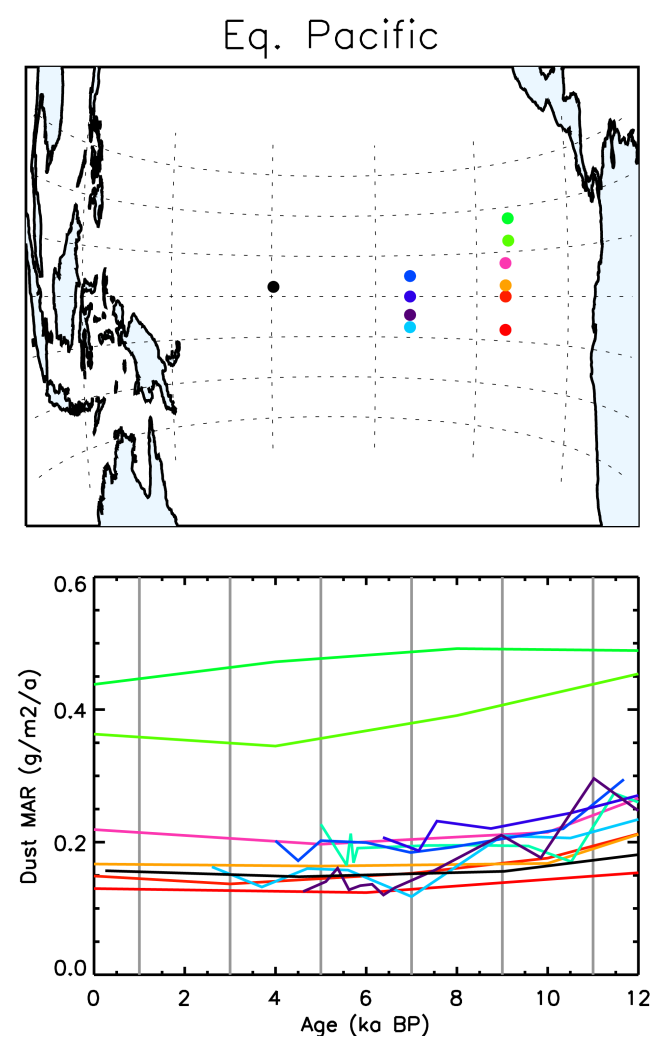

Figure 12. Same as Fig. 6 but for the equatorial Pacific.

archive evidence of the continent's dust history during glacial and interglacial cycles (De Deckker et al., 2012; Hesse and McTainsh, 2003; Lamy et al., 2014). The paucity of data for the Holocene in the Australian region was stated at the time of the DIRTMAP compilation (Kohfeld and Harrison, 2001), and since then more research has been carried out (Fitzsimmons et al., 2013; Marx et al., 2009; McGowan et al., 2010).

We report (Fig. 13) two marine sediment records sampling the two main dust corridors emanating from Australia: the Tasman Sea (Fitzsimmons et al., 2013; Hesse, 1994), and the eastern Indian Ocean (Fitzsimmons et al., 2013; Hesse and McTainsh, 2003). The northwestern core from the monsooninfluenced zone shows relatively high dust MARs during the early Holocene and a declining trend toward the mid- and late Holocene (Fitzsimmons et al., 2013). On the other hand, the core from the Tasman Sea shows a minimum dust MAR during the early Holocene compared to the $\mathrm{MH}$, in line with trends reported from a peat bog in New Zealand (Fitzsimmons et al., 2013; Marx et al., 2009).

\subsection{South Atlantic Ocean}

There is some information about lithogenic DMAR in the southern oceans in the literature, but a quantitative estimation of eolian DMAR directly related to the atmospheric DF can be problematic because of low dust DF coupled with strong 
sediment redistribution by currents and the input of noneolian material carried by floating icebergs, i.e., ice-rafted debris (e.g., Kohfeld et al., 2013; Bradtmiller et al., 2009). Nonetheless, a few studies exploiting the thorium profiling method attempted to correct SBMAR for sediment redistribution, providing new data (Anderson et al., 2014; Lamy et al., 2014).

In particular the dust record from core PS2498-1 recovered from the Mid-Atlantic Ridge in the sub-Antarctic South Atlantic Ocean (Anderson et al., 2014) is characterized by a high temporal resolution during the Holocene (Fig. 14). The dust, whose source is hypothesized to be from South America, shows a marked declining trend during the Holocene, with late Holocene values a factor of $\sim 2$ lower than those found in the early Holocene.

\subsection{Antarctica}

Ice core records from the East Antarctic Plateau (Delmonte et al., 2004; Lambert et al., 2008) represent high-quality dust records in terms of temporal resolution, reliability of the age model (Veres et al., 2013), isolation of the eolian component and measure of its size distribution (Delmonte et al., 2004, 2013), identification of remote sources (Albani et al., 2012b; Delmonte et al., 2010b), and broadscale spatial representativeness (Mahowald et al., 2011). Similar to Greenland, the Holocene dust MAR in the East Antarctic Plateau shows little variability compared to the large glacial-interglacial and stadial-interstadial variations.

Both records considered in this study, EPICA (European Project for Ice Coring in Antarctica) Dome C (EDC) and Vostok-BH7 (Delmonte et al., 2004; Lambert et al., 2008), show a slightly declining trend in dust MAR throughout the Holocene, superimposed on large variability (Lambert et al., 2012) (Fig. 15). Some deglaciated areas and nunataks at the edges of the ice sheets are prone to act as dust sources (Bory et al., 2010; Bullard, 2013; Chewings et al., 2014; Delmonte et al., 2010b, 2013). In such a remote environment, even small amounts of local dust can give a relevant contribution to the dust budget of ice cores, e.g., TALDICE (Albani et al., 2012a; Delmonte et al., 2010b). Because dust from Antarctic sources does not travel in significant amounts to the interior of the East Antarctic Plateau (Delmonte et al., 2013), it is unlikely that the declining Holocene DMARs at Vostok and Dome $\mathrm{C}$ are related to the large variations seen in the TALDICE record (Albani et al., 2012a).

Possible explanations may be related to the interplay of the contributions from different dust source from South America and Australia (Albani et al., 2012b; Delmonte et al., 2010b) and atmospheric circulation changes.
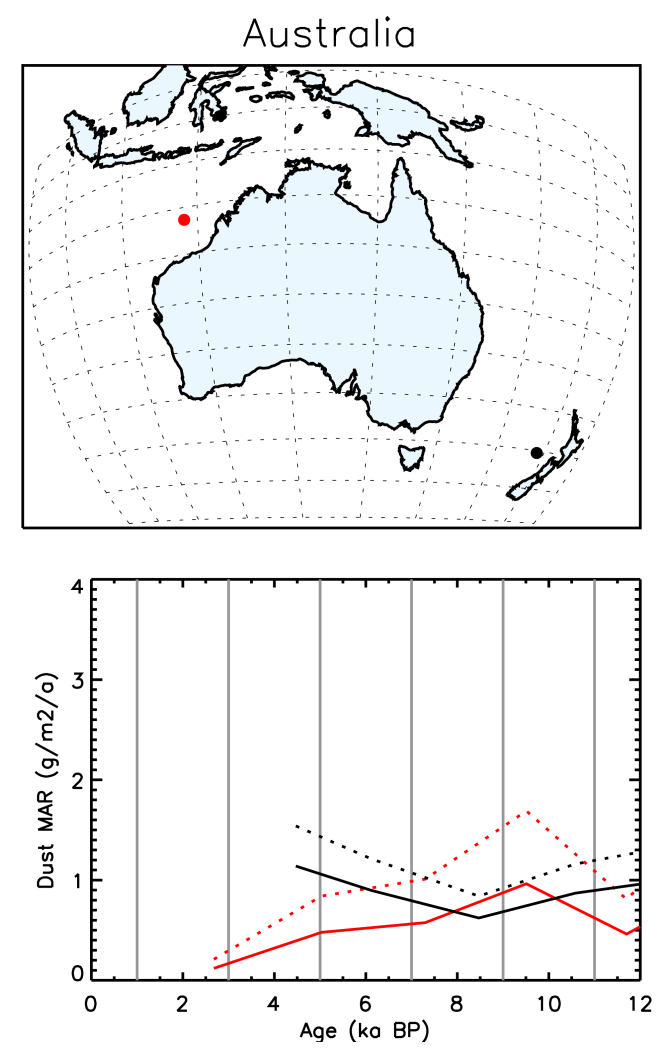

Figure 13. Same as Fig. 6, the Australian region.

\subsection{Mass balance of the global dust cycle throughout the Holocene}

A detailed comparison of modeled and observed dust deposition $(<10 \mu \mathrm{m})$ for $6 \mathrm{kaBP}(5-7 \mathrm{ka} \mathrm{BP}$ interval $)$ is shown in Fig. 16 (see the Supplement for the other time periods and the dominant sources). The modeled deposition is generally consistent with the observations of dust MAR spanning 6 orders of magnitude, within a factor of 10 , similar to previous studies (Albani et al., 2014; Mahowald et al., 2006). Nonetheless, there are a few notable outliers.

While modeled deposition in the equatorial Atlantic is very well reproduced, observations of DMAR in the northwestern African Margin appear to suggest overestimation by the model for some sites in that region. There are several possible (perhaps concurrent) explanations worth considering. First of all, the model may not be able to represent adequately the spatial distribution of dust sources within northern Africa, resulting in a different localization of the dust plume and hence a different north-south gradient in the dust deposition. On the other hand, it is possible that some inconsistencies exist among observations, due to different methodological approaches, as discussed in Sect. 4.2. From a global perspective, there is an interesting aspect emerging from the data in Fig. 16, which may support this argument. The observational DMARs in some of the North African Margin cores 

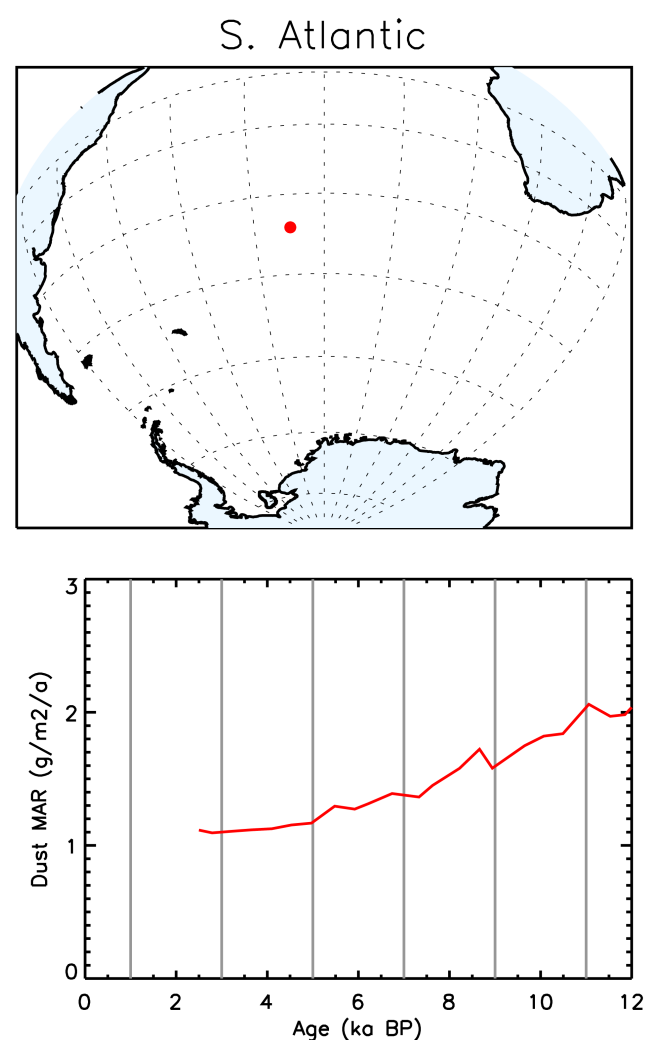

Figure 14. Same as Fig. 6 but for the South Atlantic Ocean.
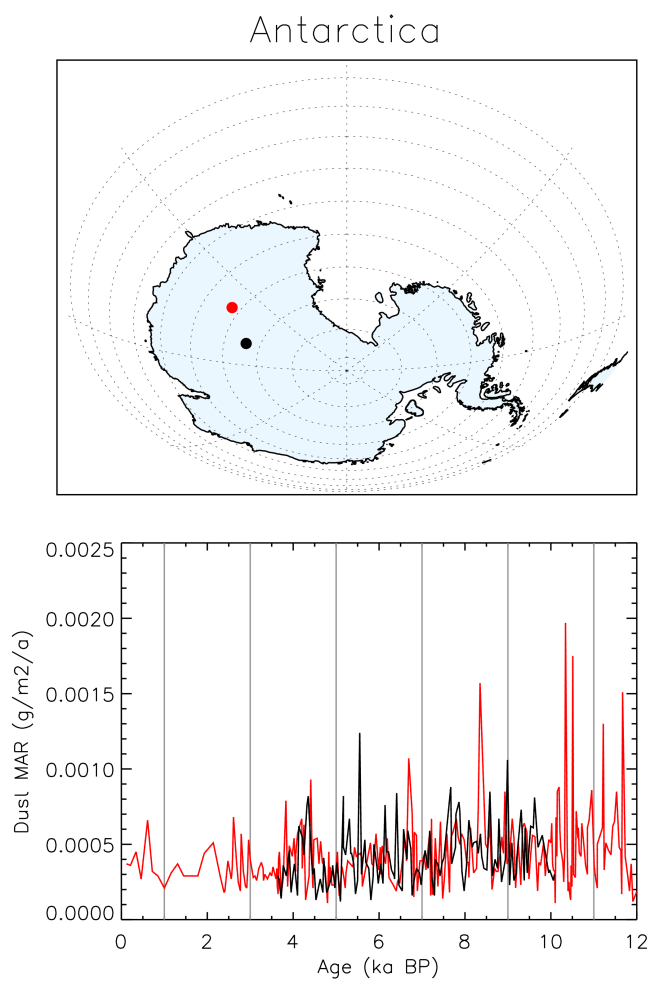

Figure 15. Same as Fig. 6 but for Antarctica. are comparable to or smaller in magnitude than some of the cores in the equatorial Pacific, which was unexpected; this became evident once the size information was taken into account and coupled to the dust MARs.

In addition to the possible methodological inconsistencies outlined above, two other potential explanations for comparable fine $(<10 \mu \mathrm{m})$ DMARs on the northwestern African Margin and the equatorial Pacific could be (a) a lack of wet deposition on the northwestern African Margin, possibly leading to low deposition of fine dust particles there, despite high atmospheric dust loads; (b) a possible substantial overestimation of dust deposition in the Holocene in the equatorial Pacific, due to bioturbative mixing of glacial and Holocene sediments in this region with very low sedimentation rates $\left(1-2 \mathrm{~cm} \mathrm{ka}^{-1}\right)$.

We also note how South Atlantic DMARs are almost as large as the largest deposition rates observed downwind of northern Africa for the fine fraction, in a region where satellite images show little dust loading today (Prospero et al., 2002), possibly indicating that either sediment redistribution or non-eolian inputs may not be fully constrained in that region (Anderson et al., 2014).

A significant underestimation of dust deposition by the model in Alaska is also suggested by the observations. Note that dust sources in Alaska are glaciogenic, and in the model for the $\mathrm{MH}$, we prescribed them; we allowed particular grid cells to emit dust with no constraints provided by vegetation cover or geomorphic soil erodibility. The prescribed sources are the Matanuska Valley, the Copper River Valley, and the belt in central Alaska from Fairbanks to the west coast, including the Yukon Valley. The total amount of dust that we allowed to be emitted from Alaska as a whole is constrained by the fact that larger emissions would result in a prevalence of Alaskan dust in Greenland in the model, which would not be consistent with observations (e.g., Bory et al., 2003). Satellite imagery clearly shows that even in large dust source areas, at a small spatial scale dust emanates from a constellation of localized hotspots and then gets mixed downwind (e.g., Knippertz and Todd, 2012). Global-scale ESMs such as the CESM have a spatial resolution good enough to capture a process of a large spatial extent but may be more sensitive to the exact localization of small dust hotspots when they are scattered over disparate valley settings, as in the case of Alaska. An insight from a slightly different angle could be that it is still unclear to what extent the very large DMARs from localized sources in low hotspot density regions such as Alaska are representative of large-scale dust emissions, as discussed in Sect. 4.5.

The temporal evolution of the global dust cycle (Fig. 17) shows a decreasing trend in dustiness from the early to midHolocene, with a minimum between 6 and $8 \mathrm{kaBP}$, and an increasing tendency in the late Holocene, with the global dust load varying between 17.2 and $20.8 \mathrm{Tg}$, which corresponds to a difference of $\sim 17 \%$. For reference, dust load estimates with the same model are $23.8 \mathrm{Tg}$ for the current 
a. Observed Deposition $\left(\mathrm{g} \mathrm{m}^{-2} \mathrm{a}^{-1}\right) 6 \mathrm{ka}$ BP

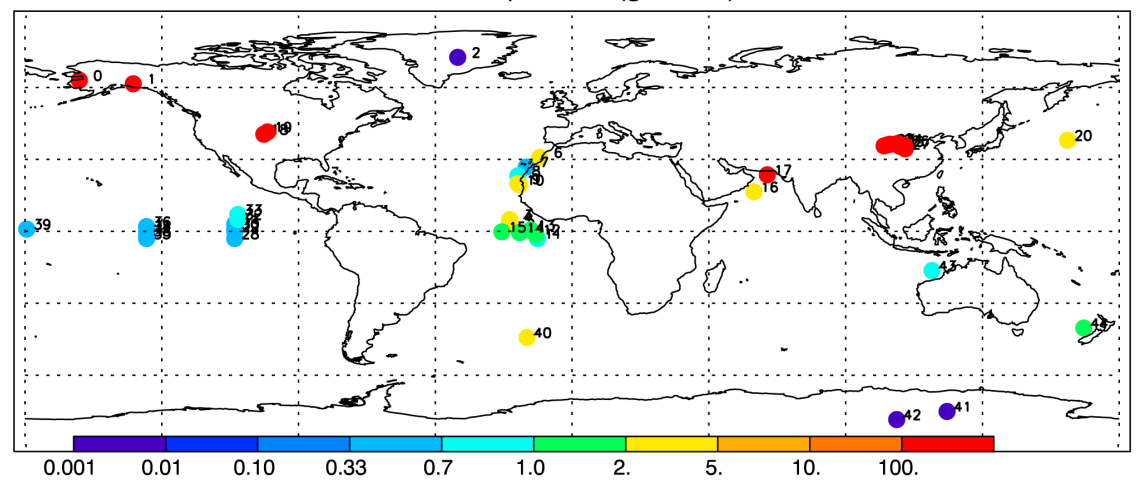

b. Model Deposition $\left(\mathrm{g} \mathrm{m}^{-2} \mathrm{a}^{-1}\right) 6 \mathrm{ka} \mathrm{BP}$

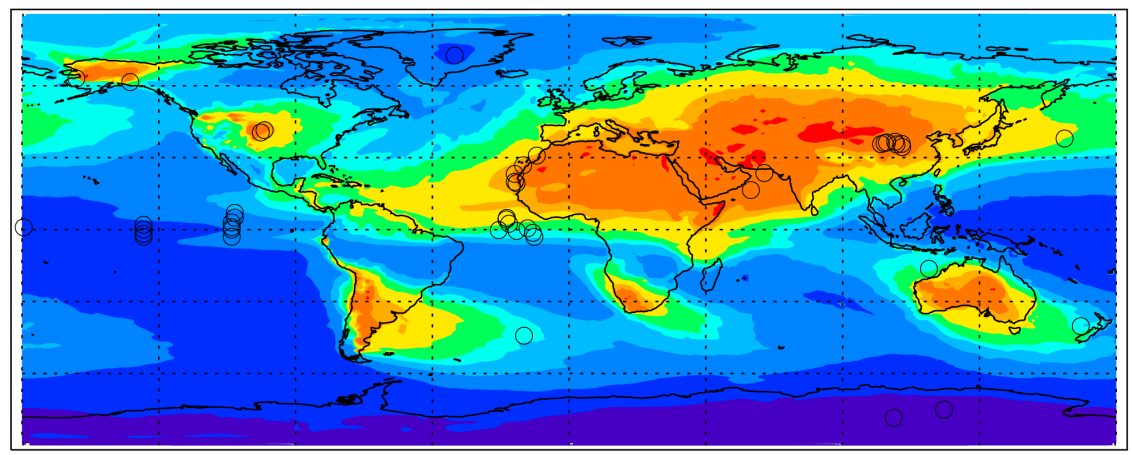

c. Scatter diagram

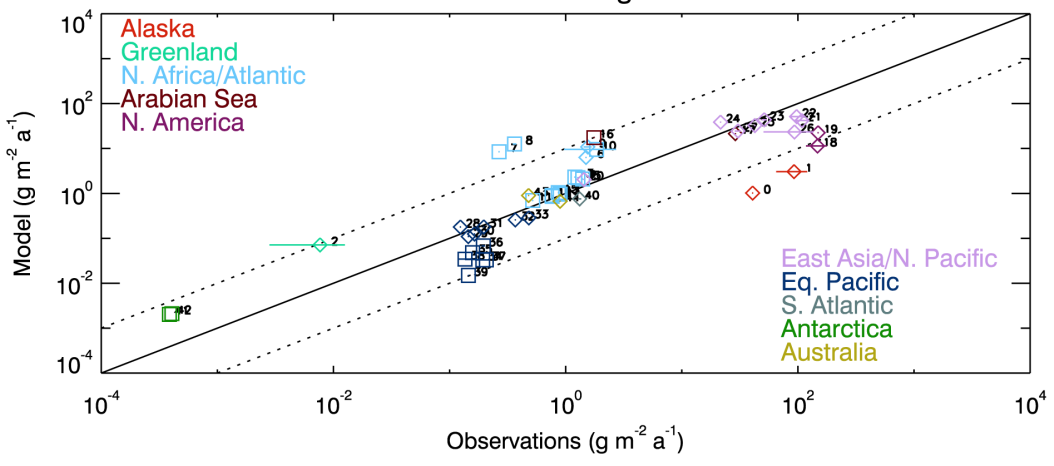

Figure 16. Comparison of simulated dust deposition $\left(\mathrm{g} \mathrm{m}^{-2} \mathrm{a}^{-1}\right)$ for the $6 \mathrm{kaBP}$ case compared to observational estimates of the fine $(<10 \mu \mathrm{m})$ eolian mass accumulation rate for the period 5-7 ka BP: observations (top); model (middle); model (bottom) versus observations scatterplot. Horizontal bars represent the variability in observational data averaged within the 5-7 ka BP time lapse $(1 \sigma)$. Locations of observational sites are clustered in the scatterplots based on their geographical location, as indicated by the color-coding. In the bottom scatterplot, squares indicate high confidence level, and diamonds represent medium confidence level.

climate and 37.4 Tg for the LGM (Albani et al., 2014). Similarly, global dust deposition estimates during the Holocene vary by $\sim 16 \%$, between $\sim 2900 \mathrm{Tga}^{-1}(10 \mathrm{kaBP})$ and $\sim 2400 \mathrm{Tg} \mathrm{a}^{-1}$ (8 ka BP) (Fig. 17).

Two distinct features characterize the spatial distribution of dust during the Holocene. First, the early to mid-Holocene is characterized by enhanced dustiness in the Southern Hemisphere compared to the late Holocene. Second, there are shifts between the relative importance of Asian versus northern African sources. Even in the late Holocene though, there seems to be an imbalance towards Asian sources, compared to the present day. This may be related to the difficulties of constraining the model to the observations in general and for the northern African regions in particular, although the relative role of northern Africa as a dust source may have actually increased significantly since the preindustrial period due to much increased dustiness (Mulitza et al., 2010). 


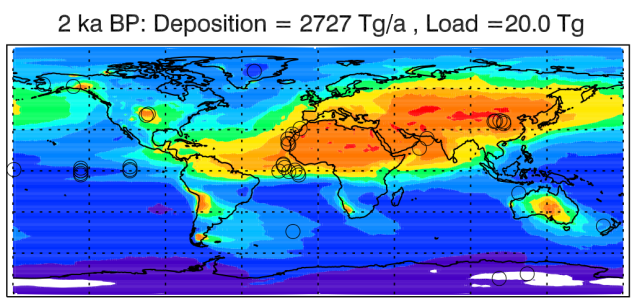

6 ka BP: Deposition $=2532 \mathrm{Tg} / \mathrm{a}, \mathrm{Load}=18.0 \mathrm{Tg}$

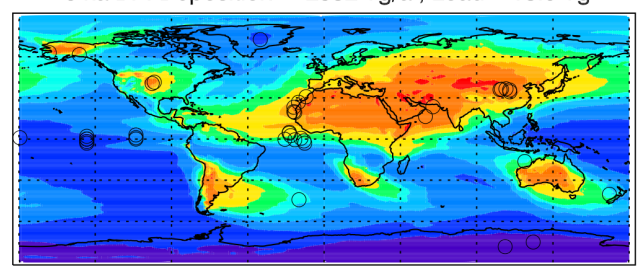

0 ka BP: Deposition $=2899 \mathrm{Tg} / \mathrm{a}$, Load $=20.8 \mathrm{Tg}$

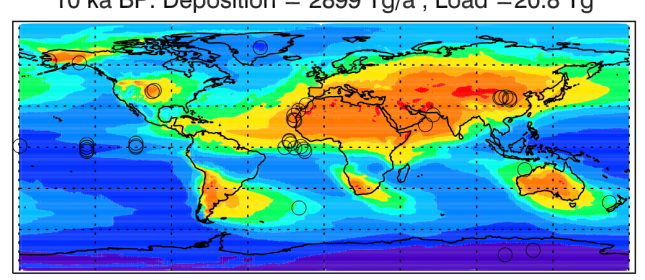

4 ka BP: Deposition $=2626 \mathrm{Tg} / \mathrm{a}, \mathrm{Load}=18.8 \mathrm{Tg}$

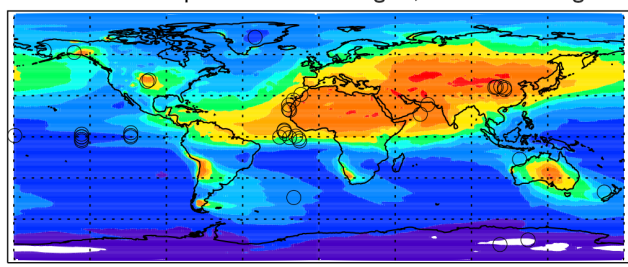

8 ka BP: Deposition $=2427 \mathrm{Tg} / \mathrm{a}, \mathrm{Load}=17.2 \mathrm{Tg}$

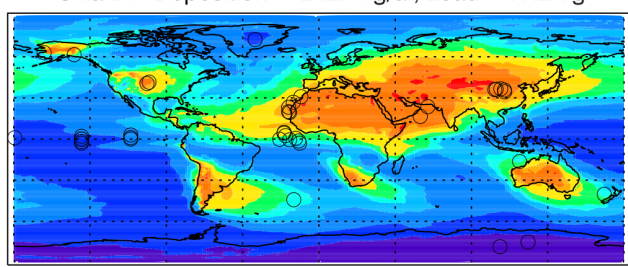

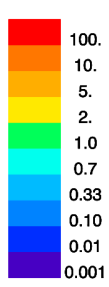

Figure 17. Dust deposition flux $\left(\mathrm{g} \mathrm{m}^{-2} \mathrm{a}^{-1}\right.$ ) from the CESM during the Holocene snapshots at 2, 4, 6, 8, and $10 \mathrm{ka}$ BP, based on spatially variable emissions constrained by the observational mass accumulation rates. Black circles mark the locations of the observational records in this compilation.

\subsection{Particle size distributions}

The organization of the available size distribution data into a common binning scheme not only provides the tool to relate DMARs within a common size range but also allows comparing modeled and observed size distributions (e.g., Albani et al., 2014; Mahowald et al., 2014). In Fig. 18 we make this kind of comparison for the $6 \mathrm{kaBP}$ time slice, which highlights how the observed size distribution (blue solid lines) is coarser close to the source areas and becomes finer for more remote dust deposits such as marine sediments or ice core archives. While significant uncertainties and biases may affect the different observations of size distributions (e.g., Mahowald et al., 2014; Reid et al., 2003), this relation between dust particle size and long-range transport is widely recognized (e.g., Lawrence and Neff, 2009; Pye, 1995).

Modeled size distributions (red dashed lines) in general capture this trend, with coarser size distributions simulated for terrestrial deposits compared to dust deposition further away from the dust sources. Notable exceptions are the Antarctic ice core sites, which exhibit coarse distributions in the model. This feature was already observed in previous studies and attributed mainly to biases in transport in the CAM4-BAM, which is used for this study as well (Albani et al., 2014; Mahowald et al., 2014).

Focussing on terrestrial deposits, we can also see the gradual tendency for the observed and modeled size distributions to shift towards finer distributions for larger distances from the sources. For instance Weinan lies farther away from the major dust sources in the Ordos, Badain Juran, and Tengger (Fig. 18k) and shows the smallest relative contribution of dust in the model's bin $4(5-10 \mu \mathrm{m})$ compared to the other sites in the CLP. Similarly, Zagoskin Lake in Alaska lies farther away from the putative sources in the Yukon Valley than OWR does from the Sand Dunes in Nebraska (Fig. 181), and Zagoskin Lake exhibits finer particle size distributions.

The temporal variability in dust size distributions during the Holocene is very limited both in the observations and the model (not shown).

\section{Conclusions}

Here, we present the first study using an innovative approach to organize a paleodust compilation for the Holocene from different sedimentary archives by collecting and evaluating dust records that allow the reconstruction of time series of eolian mass accumulation rates with size information, with relevance for medium- to long-range transport.

The resulting database has the following characteristics:

- It is concise and accessible. The main information for each site included in the compilation is a time series including age (with uncertainty), dust MAR (with uncertainty), and size distribution (where available), stan- 

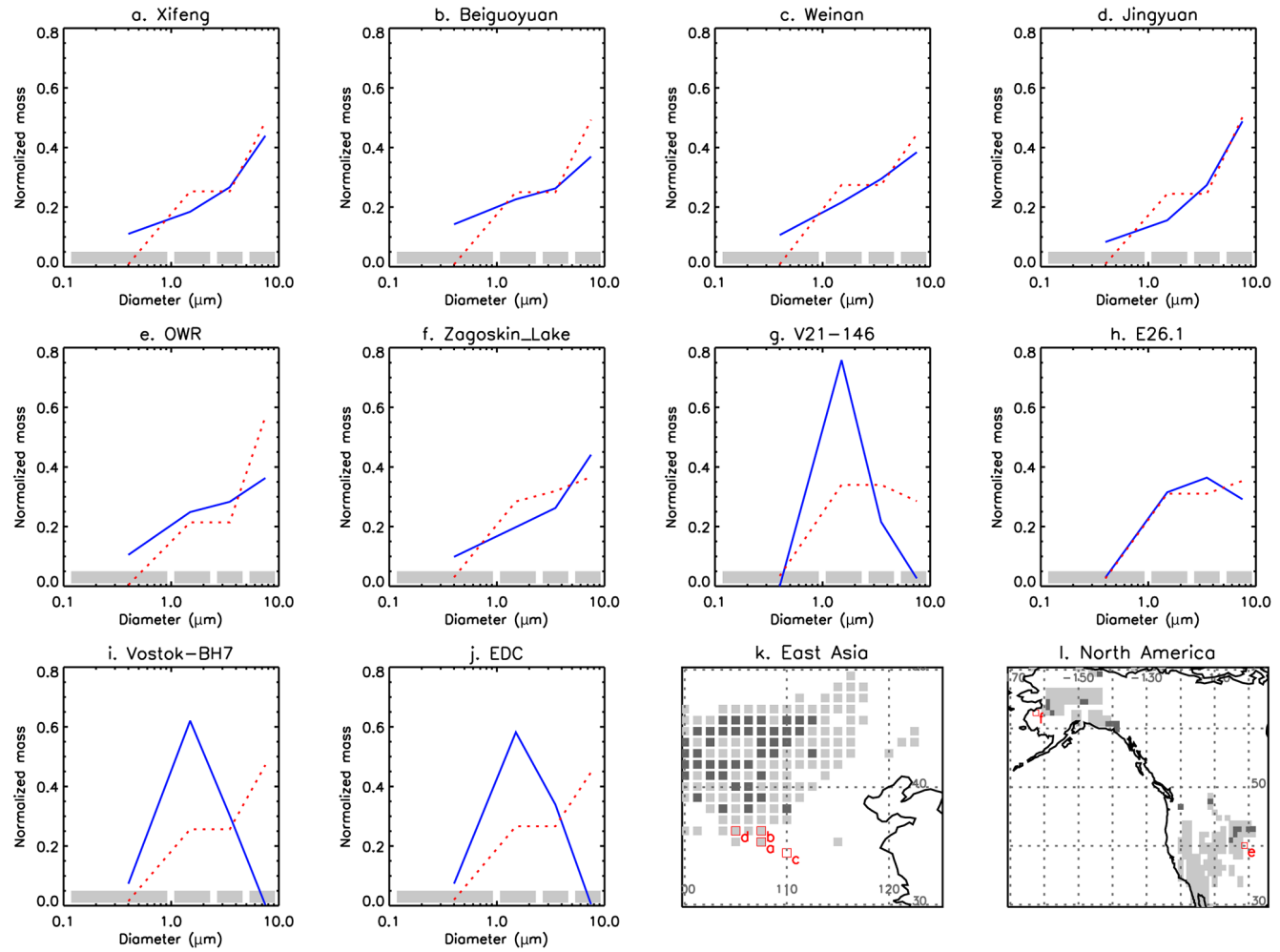

Figure 18. Comparison of modeled and observed particle size distributions for the $6 \mathrm{ka} \mathrm{BP}$ time slice. Panels (a)-(j) show the modeled size distribution (red dashed line) and the observed particle size distribution (blue solid line). The normalized observational size data from the re-binned distributions were first averaged over the 5-7 ka BP interval; then the size distribution data were aggregated in order to match the model dimensional bins (highlighted by the horizontal grey bars). Both the modeled and observed size distributions are normalized over the model size range, i.e., over the four size bins. Panels (k) and (l) show the relative geographical position of terrestrial records (red empty squares) and the model dust sources (filled grey squares) for eastern Asia and North America, respectively. Light grey squares indicate modeled dust mobilization flux $>0$, and dark grey squares denote the major dust sources, i.e., mobilization flux $>200 \mathrm{~g} \mathrm{~m}^{-2} \mathrm{a}^{-1}$.

dardized by the use of a common binning scheme. The data are organized in text tables with a coherent formatting, easily accessible by scripting or for importing into spreadsheets. The data will be publicly accessible on the web and released with this paper. We also provide a graphical overview that synthesizes "at a glance" the intrinsic characteristics and uncertainties for all the different records included in the compilation. Complementary to the data is a categorical attribution of the confidence level of each record in terms of providing a reliable quantitative DMAR time series of eolian dust relevant to medium- to long-range transport. Finally, we report detailed information of the dust size distributions when available. In particular, when full size distributions were available (rather than mineralogical size classes), we standardized them to a common binning scheme to facilitate comparability.

- It is detailed and flexible. Ongoing research often provides the opportunity of refining age models for sedimentary records, so we left the compilation open for easy future updates. In addition to the basic information mentioned above, we report the ancillary information necessary to re-derive the dust MARs time series: the detailed depths and the relevant dust variables, i.e., dust concentration or dust proxy concentration or dust fraction and bulk density if applicable.

- Its compilation was highly participatory. It results from an extensive collaboration among scientists from the observational and modeling communities, which allowed more in-depth analysis beyond the original studies.

One merit of the database is also to document and archive the data, and the full size distribution data in particular, which would otherwise risk being lost. In most cases only one metric, typically the median, is reported in papers, and in fact some of the size distributions that were once available were not retrievable for this paper.

We focused on dust variability during the Holocene, with an emphasis on the MH as a key PMIP scenario and also in relation to the large amount of variability that affected the present world's largest dust source, northern Africa, with the 
termination of the African Humid Period (deMenocal et al., 2000; McGee et al., 2013).

An integrated approach of merging data and modeling with the CESM allowed a spatially consistent reconstruction of the global dust cycle and its variability throughout the Holocene. Our simulations indicate that the global dust load showed significant variability ranging between 17.2 and $20.8 \mathrm{Tg}$, with a minimum during the early to mid-Holocene. The model-data compilation is likely to be useful to both dust and ocean biogeochemical modelers, who may use iron and mineral dust as a ballast input to their model (e.g., Moore et al., 2006), or for observational studies for putting to put their cores into the context of existing estimates of depositional fluxes (e.g., Winckler et al., 2008).

In addition we report on two relevant aspects that emerged from this work.

First, we showed how the size distribution of dust is intrinsically related to the DMAR: ignoring this tight coupling would cause a misleading interpretation of the dust cycle, not only for modeling studies but also in a broader sense.

Second, comparing DMARs within a consistent size range allows for a consistent analysis of the spatial features of the global dust cycle, which are not deducible by the simple analysis of relative timing and amplitude of the variations among different paleodust reconstructions.

Our analysis shows that a knowledge gap in understanding the relevant features of the global dust cycle still exists, in particular for key regions such as northern African and Asian dust sources, where quantitative information on the dust cycle is limited or not fully consistent.

In our representation of the loess-paleosol data, we depict them as DMAR time series, which is a rather innovative approach introduced in previous compilation efforts (Kohfeld and Harrison, 2003) as well as in a few observational studies (e.g., Muhs et al., 2013a; Roberts et al., 2003; Stevens and $\mathrm{Lu}, 2009)$ but which is not widespread in the loess community at large. We tentatively used an approach that privileges pairing of the time series with the soil subunit stratigraphy. Future work will be needed to better asses this approach as well as alternative approaches.
The possibility of comparing not only the size range but also the size distributions of dust particles offers additional tools to understand the spatial evolution of the dust cycle (as well as its temporal variability in principle). At a given climate state, for instance, it allows relating the records from different sites to the major dust sources.

The work presented in this paper provides the tools for relating DMARs and climate; future work will need to place the dust records in the context of the climate conditions of the different regions by comparing dust records to other paleoclimate proxies.

We present a framework for future work on dust compilations, and although we focused on the Holocene here, future updates using this framework are intended to improve the compilation. In addition, the framework provided for this compilation can be extended to wider time periods in the future, for example, the full span of the last glacial cycle and the deglaciation and the late Holocene to the present day; this would allow linking the past and the present dust cycle.

In conclusion, our work provides the framework for organizing a new-generation dust database, with time- and size-resolved records of dust mass accumulation rates. In its present form the compilation includes data spanning the Holocene period. The use of a common, quantitative metric allows comparing paleodust records in a consistent way. Our analysis, based on the emerging properties of the data collection, emphasizes the intimate link between particle size distributions and DMARs and highlights apparent inconsistencies among the records - hidden when the size information is ignored; this indicates knowledge gaps in key regions. Simulations with the CESM constrained by the data from the compilation provide, for the first time, a reconstruction of the variability in the global dust cycle during the Holocene, which can be used as the basis for future studies of dust, climate, and biogeochemistry interactions. 


\section{Appendix A: Description of the template database tables and site sheets}

All records in this compilation include a basic piece of information: a time series of eolian DMAR, with $1 \sigma$ uncertainty on both ages and DMARs (Supplement), and a categorical attribution of the confidence level (Table 1).

Because each record is characterized by a different number of age points, a separate table is associated with each record. In addition, a descriptive sheet is provided for each record, with a graphical overview of the sampling of the profile and the time-dependent dust MAR with uncertainties as well as metadata. For sites where size information is available, an additional integrative table is provided, as well as a document with details about the re-binning procedure.

Each table in the database is a tab key-separated text document, named after the site, as reported in Table 1. The first four columns contain the basic information: age (ka BP), dust MAR $\left(\mathrm{g} \mathrm{m}^{-2} \mathrm{a}^{-1}\right)$, age error (ka), and Dust MAR error $\left(\mathrm{g} \mathrm{m}^{-2} \mathrm{a}^{-1}\right)$. A second set of columns includes data relative to the depth of the samples and their age: depth top $(\mathrm{cm})$, depth bottom $(\mathrm{cm})$, depth center $(\mathrm{cm})$, age top (ka BP), age bottom (ka BP), and age center (ka BP). Finally, a third set of columns contains information relevant for the dust MAR calculation: sediment bulk MAR $\left(\mathrm{g} \mathrm{m}^{-2} \mathrm{a}^{-1}\right)$, SBMAR relative error, sediment dry bulk density (SDBD) $\left(\mathrm{g} \mathrm{cm}^{-3}\right)$, SDBD relative error, $\mathrm{SR}\left(\mathrm{cm} \mathrm{kyr}^{-1}\right)$, SR relative error, eolian contribution (fraction), EC (ppm), and EC relative error. All entries are filled either with data or "NA".

The tables with size information are also TAB-separated text documents. There are two types of them: one with size classes and one with the re-binned size distributions. The first four columns again contain the basic information: age (ka BP), dust MAR $\left(\mathrm{g} \mathrm{m}^{-2} \mathrm{a}^{-1}\right)$, age error (ka), and dust MAR error $\left(\mathrm{g} \mathrm{m}^{-2} \mathrm{a}^{-1}\right)$. The other columns contain either the size classes as reported in the original work or the binned data, with upper and lower limits indicated in the first two rows of the table. The numbers represent the percentage contribution of each bin to the total dust mass. "NA" indicates no data for bins outside the original measurements size range.
The descriptive sheet is composed of three panels. The upper one shows the dust MAR as a function of depth and highlights (grey shading) the sampling stratigraphy. The central panel shows the dust MAR time series, with relative uncertainties. The bottom panel contains a concise summary of the sampling and of the methods used to determine the ages, age model, SBMAR and EC (with relative uncertainties), and size.

For the records with size distributions associated, an additional PDF document is provided, showing the fitting procedure for each site: original (black) and new (red) cumulative distributions, fitting spline (green), and original (black) and new (red) mass-size distribution (scaled). In addition, several percentiles across the size spectrum are compared for the original and re-binned distributions. For the overall record from one site, two summary metrics are produced, which synthesize the overall fit to the original data: the Pearson's correlation coefficient of the 5th, 25th, 50th, 90th, and 95th percentiles and the mean normalized bias (MNB):

$\mathrm{MNB}=\frac{1}{n_{\mathrm{obs}} \cdot n_{i}} \sum_{\mathrm{obs}} \sum_{i} \frac{\left(x_{\mathrm{obs}, i}\right)-\left(y_{\mathrm{obs}, i}\right)}{x_{\mathrm{obs}, i}} m$,

where $n_{\text {obs }}$ is the number of samples for a site, $n_{i}$ is the number of percentiles included in the calculation (here, five), $x_{\mathrm{obs}, i}$ is the original $i$ th percentile for a given sample, and $y_{\mathrm{obs}, i}$ is the corresponding new binning percentile. In this context, the MNB is a metric of the average over- or underestimation of the "coarseness" of the re-binned size distributions compared to the original observations. 


\section{The Supplement related to this article is available online at doi:10.5194/cp-11-869-2015-supplement.}

Acknowledgements. We acknowledge assistance from NSF grants 0932946, 1003509, and DOE-SC00006735. S. Albani acknowledges funding from "Dote ricercatori": FSE, Regione Lombardia. G. Winckler acknowledges funding from NSF grant AGS-1003505. Computing resources were provided by the Climate Simulation Laboratory at NCAR's Computational and Information Systems Laboratory (CISL), sponsored by the National Science Foundation and other agencies. We gratefully acknowledge Dan Muhs for sharing his data and for thorough discussions on the interpretation of terrestrial sediment records. We would like to thank Youbin Sun for sharing his data from the Jingyuan section and for his valuable comments on the manuscript. We also acknowledge the constructive comments by F. Lambert and one anonymous referee. We also would like to thank the following colleagues for constructive discussions: L. Thompson, P. Gabrielli, C. Zdanowicz, S. Marx, M. Kylander, G. Le Roux, F. De Vleeschouwer, P. DeDeckker, and D. Rea. The model dust fields discussed in the paper are available upon request to the corresponding author.

Edited by: D.-D. Rousseau

\section{References}

Adkins, J., deMenocal, P., and Eshel, G.: The "African humid period" and the record of marine upwelling from excess ${ }^{230} \mathrm{Th}$ in Ocean Drilling Program Hole 658C, Paleoceanography, 21, PA4203, doi:10.1029/2005PA001200, 2006.

Albani, S., Delmonte, B., Maggi, V., Baroni, C., Petit, J.-R., Stenni, B., Mazzola, C., and Frezzotti, M.: Interpreting last glacial to Holocene dust changes at Talos Dome (East Antarctica): implications for atmospheric variations from regional to hemispheric scales, Clim. Past, 8, 741-750, doi:10.5194/cp-8-7412012, 2012a.

Albani, S., Mahowald, N. M., Delmonte, B., Maggi, V., and Winckler, G.: Comparing modeled and observed changes in mineral dust transport and deposition to Antarctica between the Last Glacial Maximum and current climates, Clim. Dynamam., 38, 1731-1755, doi:10.1007/s00382-011-1139-5, 2012b.

Albani, S., Mahowald, N. M., Perry, A. T., Scanza, R. A., Zender, C. S., Heavens, N. G., Maggi, V., Kok, J. F., and OttoBliesner, B. L.: Improved dust representation in the Community Atmosphere Model, J. Adv. Model. Earth Syst., 6, 541-570, doi:10.1002/2013MS000279, 2014.

Alley, R. B.: The Younger Dryas cold interval as viewed from central Greenland, Quat. Sci. Rev., 19, 213-226, doi:10.1016/S0277-3791(99)00062-1, 2000.

An, Z., Kukla, G., Porter, S. C., and Xiao, J.: Late quaternary dust flow on the chinese Loess Plateau, Catena, 18, 125-132, doi:10.1016/0341-8162(91)90012-M, 1991.

Anderson, R. F., Fleisher, M. Q., and Lao, Y.: Glacial-interglacial variability in the delivery of dust to the central equatorial Pacific Ocean, Earth Planet. Sci. Lett., 242, 406-414, doi:10.1016/j.epsl.2005.11.061, 2006.
Anderson, R. F., Fleisher, M. Q., Lao, Y., and Winckler, G.: Modern $\mathrm{CaCO}_{3}$ preservation in equatorial Pacific sediments in the context of late-Pleistocene glacial cycles, Mar. Chem., 111, 30-46, doi:10.1016/j.marchem.2007.11.011, 2008.

Anderson, R. F., Barker, S., Fleisher, M., Gersonde, R., Goldstein, S. L., Kuhn, G., Mortyn, P. G., Pahnke, K., and Sachs, J. P.: Biological response to millennial variability of dust and nutrient supply in the Subantarctic South Atlantic Ocean, Philos. Trans. A. Math. Phys. Eng. Sci., 372, 20130054, doi:10.1098/rsta.2013.0054, 2014.

Bacon, M. P.: Glacial to interglacial changes in carbonate and clay sedimentation in the Atlantic Ocean estimated from ${ }^{230} \mathrm{Th}$ measurements, Isotope Geosci., 2, 97-111, 1984.

Bacon, M. P. and Anderson, R. F.: Distribution of thorium isotopes between dissolved and particulate forms in the deep sea, J. Geophys. Res., 87, 2045, doi:10.1029/JC087iC03p02045, 1982.

Bard, E., Arnold, M., Duprat, J., Moyes, J., and Duplessy, J.C.: Reconstruction of the last deglaciation: deconvolved records of $\delta^{18} \mathrm{O}$ profiles, micropaleontological variations and accelerator mass spectrometric ${ }^{14} \mathrm{C}$ dating, Clim. Dynam., 1, 101-112, doi:10.1007/BF01054479, 1987.

Bauer, E. and Ganopolski, A.: Sensitivity simulations with direct shortwave radiative forcing by aeolian dust during glacial cycles, Clim. Past, 10, 1333-1348, doi:10.5194/cp-10-1333-2014, 2014.

Begét, J.: Middle Wisconsinan Climate Fluctuations Recorded in Central Alaskan Loess, Géographie Phys. Quat., 44, 3-13, doi:10.7202/032793ar, 1990.

Bettis III, E. A., Muhs, D. R., Roberts, H. M., and Wintle, A. G.: Last Glacial loess in the conterminous USA, Quat. Sci. Rev., 22, 1907-1946, doi:10.1016/S0277-3791(03)00169-0, 2003.

Bory, A., Wolff, E., Mulvaney, R., Jagoutz, E., Wegner, A., Ruth, U., and Elderfield, H.: Multiple sources supply eolian mineral dust to the Atlantic sector of coastal Antarctica: Evidence from recent snow layers at the top of Berkner Island ice sheet, Earth Planet. Sci. Lett., 291, 138-148, doi:10.1016/j.eps1.2010.01.006, 2010.

Bory, A. J.-M. and Newton, P. P.: Transport of airborne lithogenic material down through the water column in two contrasting regions of the eastern subtropical North Atlantic Ocean, Global Biogeochem. Cy., 14, 297-315, doi:10.1029/1999GB900098, 2000.

Bory, A. J.-M., Biscaye, P., and Grousset, F. E.: Two distinct seasonal Asian source regions for mineral dust deposited in Greenland (NorthGRIP), Geophys. Res. Lett., 30, 1167, doi:10.1029/2002GL016446, 2003.

Boucher, O., Randall, D., Artaxo, P., Bretherton, C., Feingold, G., Forster, P., Kerminen, V.-M., Kondo, Y., Liao, H., Lohmann, U., Rasch, P., Satheesh, S. K., Sherwood, S., Stevens, B., and Zhang, X. Y.: Clouds and Aerosols, in: Climate Change 2013: The Physical Science Basis. Contribution of Working Group I to the Fifth Assessment Report of the Intergovernmental Panel on Climate Change edited by: Stocker, T. F., Qin, D., Plattner, G.-K., Tignor, M., Allen, S. K., Boschung, J., Nauels, A., Xia, Y., Bex, V., and Midgley, P. M., Cambridge University Press, Cambridge, UK and New York, NY, USA, 2013.

Bowen, A. J. and Lindley, D.: A wind-tunnel investigation of the wind speed and turbulence characteristics close to the ground over various escarpment shapes, Bound.-Layer Meteorol., 12, 259-271, doi:10.1007/BF00121466, 1977. 
Box, M. R., Krom, M. D., Cliff, R. A., Bar-Matthews, M., Almogi-Labin, A., Ayalon, A., and Paterne, M.: Response of the Nile and its catchment to millennial-scale climatic change since the LGM from $\mathrm{Sr}$ isotopes and major elements of East Mediterranean sediments, Quat. Sci. Rev., 30, 431-442, doi:10.1016/j.quascirev.2010.12.005, 2011.

Braconnot, P., Otto-Bliesner, B., Harrison, S., Joussaume, S., Peterchmitt, J.-Y., Abe-Ouchi, A., Crucifix, M., Driesschaert, E., Fichefet, T., Hewitt, C. D., Kageyama, M., Kitoh, A., Laîné, A., Loutre, M.-F., Marti, O., Merkel, U., Ramstein, G., Valdes, P., Weber, S. L., Yu, Y., and Zhao, Y.: Results of PMIP2 coupled simulations of the Mid-Holocene and Last Glacial Maximum Part 1: experiments and large-scale features, Clim. Past, 3, 261277, doi:10.5194/cp-3-261-2007, 2007.

Bradley, R. S.: Paleoclimatology: Reconstructing Climates of the Quaternary, 2nd ed., Academic, San Diego, CA, 610 pp., 1999.

Bradtmiller, L. I., Anderson, R. F., Fleisher, M. Q., and Burckle, L. H.: Diatom productivity in the equatorial Pacific Ocean from the last glacial period to the present: A test of the silicic acid leakage hypothesis, Paleoceanography, 21, PA4201, doi:10.1029/2006PA001282, 2006.

Bradtmiller, L. I., Anderson, R. F., Fleisher, M. Q., and Burckle, L. H.: Opal burial in the equatorial Atlantic Ocean over the last $30 \mathrm{ka}$ : Implications for glacial-interglacial changes in the ocean silicon cycle, Paleoceanography, 22, PA4216, doi:10.1029/2007PA001443, 2007.

Bradtmiller, L. I., Anderson, R. F., Fleisher, M. Q., and Burckle, L. H.: Comparing glacial and Holocene opal fluxes in the Pacific sector of the Southern Ocean, Paleoceanography, 24, PA2214, doi:10.1029/2008PA001693, 2009.

Brady, E. C., Otto-Bliesner, B. L., Kay, J. E., and Rosenbloom, N.: Sensitivity to glacial forcing in the CCSM4, J. Clim., 26, 19011925, doi:10.1175/JCLI-D-11-00416.1, 2013.

Brauer, A., Hajdas, I., Blockley, S. P. E., Bronk Ramsey, Christopher Christl, M., Ivy-Ochs, S., Moseley, G. E., Nowaczyk, N. N., Rasmussen, S. O., Roberts, H. M., Spötl, C., Staff, R. A., and Svensson, A.: The importance of independent chronology in integrating records of past climate change for the 608 ka INTIMATE time interval, Quat. Sci. Rev., 106, 47-66, doi:10.1016/j.quascirev.2014.07.006, 2014.

Bronk Ramsey, C.: Radiocarbon calibration and analysis of stratigraphy : The OxCal Program, Radiocarbon, 37, 425-430, available at: http://ci.nii.ac.jp/naid/80008936407/en/ (last access: 25 July 2014), 1995.

Bullard, J. E.: Contemporary glacigenic inputs to the dust cycle, Earth Surf. Process. Landf., 38, 71-89, doi:10.1002/esp.3315, 2013.

Buylaert, J.-P., Murray, A., Vandenberghe, D., Vriend, M., De Corte, F., and Van den haute, P.: Optical dating of Chinese loess using sand-sized quartz: Establishing a time frame for Late Pleistocene climate changes in the western part of the Chinese Loess Plateau, Quat. Geochron., 3, 99-113, doi:10.1016/j.quageo.2007.05.003, 2008.

Chewings, J. M., Atkins, C. B., Dunbar, G. B., and Golledge, N. R.: Aeolian sediment transport and deposition in a modern highlatitude glacial marine environment, edited by: N. Lancaster, Sedimentology, 61, 1535-1557, doi:10.1111/sed.12108, 2014.

Claussen, M., Kubatzki, C., Brovkin, V., Ganopolski, A., Hoelzmann, P., and Pachur, H.-J.: Simulation of an abrupt change in
Saharan vegetation in the Mid-Holocene, Geophys. Res. Lett., 26, 2037-2040, doi:10.1029/1999GL900494, 1999.

Clemens, S. C.: Dust response to seasonal atmospheric forcing: Proxy evaluation and calibration, Paleoceanography, 13, 471490, doi:10.1029/98PA02131, 1998.

Clemens, S. C. and Prell, W. L.: Late Pleistocene variability of Arabian Sea summer monsoon winds and continental aridity: Eolian records from the lithogenic component of deep-sea sediments, Paleoceanography, 5, 109-145, doi:10.1029/PA005i002p00109, 1990.

Cook, B. I., Seager, R., Miller, R. L., and Mason, J. A.: Intensification of North American Megadroughts through Surface and Dust Aerosol Forcing, J. Clim., 26, 4414-4430, doi:10.1175/JCLI-D12-00022.1, 2013.

Cosford, J., Qing, H. R., Eglington, B., Mattey, D., Yuan, D. X., Zhang, M. L., and Cheng, H.: East Asian monsoon variability since the Mid-Holocene recorded in a high-resolution, absolutedated aragonite speleothem from eastern China, Earth Planet. Sci. Lett., 275, 296-307, 2008.

Crusius, J., Schroth, A. W., Gassó, S., Moy, C. M., Levy, R. C., and Gatica, M.: Glacial flour dust storms in the Gulf of Alaska: Hydrologic and meteorological controls and their importance as a source of bioavailable iron, Geophys. Res. Lett., 38, L06602, doi:10.1029/2010GL046573, 2011.

De Deckker, P., Moros, M., Perner, K., and Jansen, E.: Influence of the tropics and southern westerlies on glacial interhemispheric asymmetry, Nat. Geosci., 5, 266-269, doi:10.1038/ngeo1431, 2012.

De La Rocha, C. L., Nowald, N., and Passow, U.: Interactions between diatom aggregates, minerals, particulate organic carbon, and dissolved organic matter: Further implications for the ballast hypothesis, Global Biogeochem. Cy., 22, GB4005, doi:10.1029/2007GB003156, 2008.

Delmonte, B., Petit, J. R., Andersen, K. K., Basile-Doelsch, I., Maggi, V., and Ya Lipenkov, V.: Dust size evidence for opposite regional atmospheric circulation changes over east Antarctica during the last climatic transition, Clim. Dynam., 23, doi:10.1007/s00382-004-0450-9, 2004.

Delmonte, B., Andersson, P., Schöberg, H., Hansson, M., Petit, J. R., Delmas, R., Gaiero, D. M., Maggi, V., and Frezzotti, M.: Geographic provenance of aeolian dust in East Antarctica during Pleistocene glaciations: preliminary results from Talos Dome and comparison with East Antarctic and new Andean ice core data, Quat. Sci. Rev., 29, 256-264, doi:10.1016/j.quascirev.2009.05.010, 2010a.

Delmonte, B., Baroni, C., Andersson, P. S., Schoberg, H., Hansson, M., Aciego, S., Petit, J.-R., Albani, S., Mazzola, C., Maggi, V., and Frezzotti, M.: Aeolian dust in the Talos Dome ice core (East Antarctica, Pacific/Ross Sea sector): Victoria Land versus remote sources over the last two climate cycles, J. Quat. Sci., 25, 13271337, doi:10.1002/jqs.1418, 2010b.

Delmonte, B., Baroni, C., Andersson, P. S., Narcisi, B., Salvatore, M. C., Petit, J. R., Scarchilli, C., Frezzotti, M., Albani, S., and Maggi, V.: Modern and Holocene aeolian dust variability from Talos Dome (Northern Victoria Land) to the interior of the Antarctic ice sheet, Quat. Sci. Rev., 64, 76-89, doi:10.1016/j.quascirev.2012.11.033, 2013.

deMenocal, P., Ortiz, J., Guilderson, T., Adkins, J., Sarnthein, M., Baker, L., and Yarusinsky, M.: Abrupt onset and termination 
of the African Humid Period, Quat. Sci. Rev., 19, 347-361, doi:10.1016/S0277-3791(99)00081-5, 2000.

Derbyshire, E.: Loess, and the Dust Indicators and Records of Terrestrial and Marine Palaeoenvironments (DIRTMAP) database, Quat. Sci. Rev., 22, 1813-1819, doi:10.1016/S02773791(03)00209-9, 2003.

Derbyshire, E., Kemp, R., and Meng, X.: Variations in loess and palaeosol properties as indicators of palaeoclimatic gradients across the Loess Plateau of North China, Quat. Sci. Rev., 14, 681-697, doi:10.1016/0277-3791(95)00077-1, 1995.

De Vleeschouwer, F., Pazdur, A., Luthers, C., Streel, M., Mauquoy, D., Wastiaux, C., Le Roux, G., Moschen, R., Blaauw, M., Pawlyta, J., Sikorski, J., and Piotrowska, N.: A millennial record of environmental change in peat deposits from the Misten bog (East Belgium), Quat. Int., 268, 44-57, doi:10.1016/j.quaint.2011.12.010, 2012.

Ding, Z. L., Derbyshire, E., Yang, S. L., Sun, J. M., and Liu, T. S.: Stepwise expansion of desert environment across northern China in the past $3.5 \mathrm{Ma}$ and implications for monsoon evolution, Earth Planet. Sci. Lett., 237, 45-55, doi:10.1016/j.eps1.2005.06.036, 2005.

Dong, J., Wang, Y., Cheng, H., Hardt, B., Edwards, R. L., Xinggong, K., Jiangying, W., Shitao, C., Dianbing, L., Xiuyang, J., and Kan, Z.: A high-resolution stalagmite record of the Holocene East Asian monsoon from Mt Shennongjia, central China, The Holocene, 20, 257-264, 2010.

Feng, Z.-D., Johnson, W. C., Sprowl, D. R., and Lu, Y.: Loess accumulation and soil formation in central Kansas, United States, during the past 400000 years, Earth Surf. Process. Landf., 19, 55-67, doi:10.1002/esp.3290190105, 1994.

Ferrat, M., Weiss, D. J., Strekopytov, S., Dong, S., Chen, H., Najorka, J., Sun, Y., Gupta, S., Tada, R., and Sinha, R.: Improved provenance tracing of Asian dust sources using rare earth elements and selected trace elements for palaeomonsoon studies on the eastern Tibetan Plateau, Geochim. Cosmochim. Ac., 75, 6374-6399, doi:10.1016/j.gca.2011.08.025, 2011.

Fischer, H., Fundel, F., Ruth, U., Twarloh, B., Wegner, A., Udisti, R., Becagli, S., Castellano, E., Morganti, A., Severi, M., Wolff, E., Littot, G., Röthlisberger, R., Mulvaney, R., Hutterli, M. A., Kaufmann, P., Federer, U., Lambert, F., Bigler, M., Hansson, M., Jonsell, U., de Angelis, M., Boutron, C., SiggaardAndersen, M.-L., Steffensen, J. P., Barbante, C., Gaspari, V., Gabrielli, P., and Wagenbach, D.: Reconstruction of millennial changes in dust emission, transport and regional sea ice coverage using the deep EPICA ice cores from the Atlantic and Indian Ocean sector of Antarctica, Earth Planet. Sci. Lett., 260, 340354, doi:10.1016/j.eps1.2007.06.014, 2007.

Fitzsimmons, K. E., Cohen, T. J., Hesse, P. P., Jansen, J., Nanson, G. C., May, J.-H., Barrows, T. T., Haberlah, D., Hilgers, A., Kelly, T., Larsen, J., Lomax, J., and Treble, P.: Late Quaternary palaeoenvironmental change in the Australian drylands, Quat. Sci. Rev., 74, 78-96, doi:10.1016/j.quascirev.2012.09.007, 2013.

Flato, G., Marotzke, J., Abiodun, B., Braconnot, P., Chou, S. C., Collins, W., Cox, P., Driouech, F., Emori, S., Eyring, V., Forest, C., Gleckler, P., Guilyardi, E., Jakob, C., Kattsov, V., Reason, C., and Rummukainen, M.: Evaluation of Climate Models. In: Climate Change 2013: The Physical Science Basis. Contribution of Working Group I to the Fifth Assessment Report of the Intergov- ernmental Panel on Climate Change, edited by: Stocker, T. F., Qin, D., Plattner, G.-K., Tignor, M., Allen, S. K., Boschung, J., Nauels, A., Xia, Y., Bex, V., and Midgley, P. M., Cambridge University Press, Cambridge, United Kingdom and New York, NY, USA, 2013.

Formenti, P., Schütz, L., Balkanski, Y., Desboeufs, K., Ebert, M., Kandler, K., Petzold, A., Scheuvens, D., Weinbruch, S., and Zhang, D.: Recent progress in understanding physical and chemical properties of African and Asian mineral dust, Atmos. Chem. Phys., 11, 8231-8256, doi:10.5194/acp-11-8231-2011, 2011.

François, R., Bacon, M. P., and Suman, D. O.: Thorium 230 profiling in deep-sea sediments: High-resolution records of flux and dissolution of carbonate in the equatorial Atlantic during the last 24,000 years, Paleoceanography, 5, 761-787, doi:10.1029/PA005i005p00761, 1990.

François, R., Frank, M., Rutgers van der Loeff, M. M., and Bacon, M. P.: 230 Th normalization: An essential tool for interpreting sedimentary fluxes during the late Quaternary, Paleoceanography, 19, PA1018, doi:10.1029/2003PA000939, 2004.

Frezzotti, M., Urbini, S., Proposito, M., Scarchilli, C., and Gandolfi, S.: Spatial and temporal variability of surface mass balance near Talos Dome, East Antarctica, J. Geophys. Res., 112, F02032, doi:10.1029/2006JF000638, 2007.

Fuhrer, K., Wolff, E. W., and Johnsen, S. J.: Timescales for dust variability in the Greenland Ice Core Project (GRIP) ice core in the last 100,000 years, J. Geophys. Res., 104, 31043, doi:10.1029/1999JD900929, 1999.

Gabrielli, P., Hardy, D., Kehrwald, N., Cozzi, G., Turetta, C., Barbante, C., and Thompson, L.: Deglaciated areas of Kilimanjaro as a source of volcanic trace elements deposited on the ice cap during the late Holocene, Quatern. Sci. Rev., 93, 1-10, 2014.

Han, Q., Moore, J. K., Zender, C., Measures, C., and Hydes, D.: Constraining oceanic dust depostion using surface ocean dissolved Al, Global Biogeochem. Cy., 22, doi:10.1029/2007GB002975, 2008.

Hansson, M. E.: The Renland ice core. A Northern Hemisphere record of aerosol composition over 120,000 years, Tellus B, 46, 390-418, doi:10.1034/j.1600-0889.1994.t01-4-00005.x, 1994.

Henderson, G. M., Heinze, C., Anderson, R. F., and Winguth, A. M. E.: Global distribution of the ${ }^{230}$ Th flux to ocean sediments constrained by GCM modeling, Deep Sea Res. Part I, 46, 18611893, 1999.

Hesse, P. P.: The record of continental dust from Australia in Tasman Sea Sediments, Quat. Sci. Rev., 13, 257-272, doi:10.1016/0277-3791(94)90029-9, 1994.

Hesse, P. P. and McTainsh, G. H.: Australian dust deposits: modern processes and the Quaternary record, Quat. Sci. Rev., 22, 20072035, doi:10.1016/S0277-3791(03)00164-1, 2003.

Hoelzmann, P., Jolly, D., Harrison, S. P., Laarif, F., Bonnefille, R., and Pachur, H.-J.: Mid-Holocene land-surface conditions in northern Africa and the Arabian Peninsula: A data set for the analysis of biogeophysical feedbacks in the climate system, Global Biogeochem. Cy., 12, 35-51, doi:10.1029/97GB02733, 1998.

Hovan, S. A., Rea, D. K., and Pisias, N. G.: Late Pleistocene Continental Climate and Oceanic Variability Recorded in Northwest Pacific Sediments, Paleoceanography, 6, 349-370, doi:10.1029/91PA00559, 1991. 
Iizuka, Y., Delmonte, B., Oyabu, I., Karlin, T., Maggi, V., Albani, S., Fukui, M., Hondoh, T., and Hansson, M.: Sulphate and chloride aerosols during Holocene and last glacial periods preserved in the Talos Dome Ice Core, a peripheral region of Antarctica, Tellus B, 65, doi:10.3402/tellusb.v65i0.20197, 2013.

Imbrie, J., Hays, J. D., Martinson, D. G., McIntyre, A., Mix, A. C., Morley, J. J., Pisias, N. G., Prell, W. L., and Shackleton, N. J.: The orbital theory of Pleistocene climate: support from a revised chronology of the marine $\delta^{18} \mathrm{O}$ record, Milankovitch Clim. Underst. Response to Astron. Forcing, 1, 269, available at: http://adsabs.harvard.edu/abs/1984mcur.conf..269I, (last access: 9 May 2014), 1984.

Jacobs, P. M. and Mason, J. A.: Late Quaternary climate change, loess sedimentation, and soil profile development in the central Great Plains: A pedosedimentary model, Geol. Soc. Am. Bull., 119, 462-475, doi:10.1130/B25868.1, 2007.

Jiang, W., Yang, X., and Cheng, Y.: Spatial patterns of vegetation and climate on the Chinese Loess Plateau since the Last Glacial Maximum, Quat. Int., 334-335, 52-60, doi:10.1016/j.quaint.2013.10.039, 2014.

Jolly, D., Harrison, S., Damnati, B., and Bonnefille, R.: Simulated climate and biomes of Africa during the late quaternary, Quat. Sci. Rev., 17, 629-657, doi:10.1016/S0277-3791(98)00015-8, 1998.

Joussaume, S. and Taylor, K. E.: The Paleoclimate Modeling Intercomparison Project. In: PMIP, Paleoclimate Modeling Intercomparison Project (PMIP): proceedings of the third PMIP workshop, Canada, 4-8 october 1999, in WCRP-111, WMO/TD1007, edited by: Braconnot, P., 271, 2000.

Kang, S. G., Wang, X. L., and Lu, Y. C.: Quartz OSL chronology and dust accumulation rate changes since the Last Glacial at Weinan on the southeastern Chinese Loess Plateau, Boreas, 42, 815-829, 2013.

Kaplan, J. O., Bigelow, N. H., Prentice, I. C., Harrison, S. P., Bartlein, P. J., Christensen, T. R., Cramer, W., Matveyeva, N. V., McGuire, A. D., Murray, D. F., Razzhivin, V. Y., Smith, B., Walker, D. A., Anderson, P. M., Andreev, A. A., Brubaker, L. B., Edwards, M. E., and Lozhkin, A. V.: Climate change and Arctic ecosystems: 2. Modeling, paleodata-model comparisons, and future projections, J. Geophys. Res., 108, 8171, doi:10.1029/2002JD002559, 2003.

Kawahata, H.: Fluctuations in the ocean environment within the Western Pacific Warm Pool during Late Pleistocene, Paleoceanography, 14, 639-652, doi:10.1029/1999PA900023, 1999.

Kemp, R. A.: Pedogenic modification of loess: significance for palaeoclimatic reconstructions, Earth-Sci. Rev., 54, 145-156, doi:10.1016/S0012-8252(01)00045-9, 2001.

Kindler, P., Guillevic, M., Baumgartner, M., Schwander, J., Landais, A., and Leuenberger, M.: Temperature reconstruction from 10 to 120 kyr b2k from the NGRIP ice core, Clim. Past, 10, 887-902, doi:10.5194/cp-10-887-2014, 2014.

Knippertz, P. and Todd, M. C.: Mineral dust aerosols over the Sahara: Meteorological controls on emission and transport and implications for modeling, Rev. Geophys., 50, RG1007, doi:10.1029/2011RG000362, 2012.

Kohfeld, K. E. and Harrison, S. P.: DIRTMAP: the geological record of dust, Earth-Sci. Rev., 54, 81-114, doi:10.1016/S00128252(01)00042-3, 2001.
Kohfeld, K. and Harrison, S. P.: Glacial-interglacial changes in dust deposition on the Chinese Loess Plateau, Quat. Sci. Rev., 22, 1859-1878, doi:10.1016/S0277-3791(03)00166-5, 2003.

Kohfeld, K. and Tegen, I.: Record of mineral aerosols and their role in the Earth system, Treatise Geochem., 4, 1-26, 2007.

Kohfeld, K. E., Graham, R. M., de Boer, A. M., Sime, L. C., Wolff, E. W., Le Quéré, C., and Bopp, L.: Southern Hemisphere westerly wind changes during the Last Glacial Maximum: paleo-data synthesis, Quat. Sci. Rev., 68, 76-95, doi:10.1016/j.quascirev.2013.01.017, 2013.

Kukla, G. and An, Z. S.: Loess stratigraphy in central China, Palaeogeogr. Palaeoclim. Palaeoecol., 72, 203-225, 1989.

Kutzbach, J. E. and Liu, Z.: Response of the African Monsoon to Orbital Forcing and Ocean Feedbacks in the Middle Holocene, Science, 278, 40-443, doi:10.1126/science.278.5337.440, 1997.

Kylander, M. E., Bindler, R., Cortizas, A. M., Gallagher, K., Mörth, C.-M., and Rauch, S.: A novel geochemical approach to paleorecords of dust deposition and effective humidity: 8500 years of peat accumulation at Store Mosse (the "Great Bog"), Sweden, Quat. Sci. Rev., 69, 69-82, doi:10.1016/j.quascirev.2013.02.010, 2013.

Lambert, F., Bigler, M., Steffensen, J. P., Hutterli, M., and Fischer, H.: Centennial mineral dust variability in high-resolution ice core data from Dome C, Antarctica, Clim. Past, 8, 609-623, doi:10.5194/cp-8-609-2012, 2012.

Lambert, F., Delmonte, B., Petit, J. R., Bigler, M., Kaufmann, P. R., Hutterli, M. A., Stocker, T. F., Ruth, U., Steffensen, J. P., and Maggi, V.: Dust-climate couplings over the past 800,000 years from the EPICA Dome C ice core, Nature, 452, 616-619, doi:10.1038/nature06763, 2008.

Lamy, F., Gersonde, R., Winckler, G., Esper, O., Jaeschke, A., Kuhn, G., Ullermann, J., Martinez-Garcia, A., Lambert, F., and Kilian, R.: Increased dust deposition in the Pacific Southern Ocean during glacial periods, Science, 343, 403-407, doi:10.1126/science.1245424, 2014.

Lawrence, C. R. and Neff, J. C.: The contemporary physical and chemical flux of aeolian dust: A synthesis of direct measurements of dust deposition, Chem. Geol., 267, 46-63, doi:10.1016/j.chemgeo.2009.02.005, 2009.

Lisiecki, L. E. and Raymo, M. E.: A Pliocene-Pleistocene stack of 57 globally distributed benthic $\delta^{18} \mathrm{O}$ records, Paleoceanography, 20, PA1003, doi:10.1029/2004PA001071, 2005.

Liu, T. S.: Loess and Environment, China Ocean Press, Beijing, 3167, 1985.

Liu, T. S. and Ding, Z. L.: Chinese loess and the palaeomonsoon, Ann. Rev. Earth Planet. Sci., 26, 111-145, 1998.

Liu, Z., Otto-Bliesner, B. L., He, F., Brady, E. C., Tomas, R., Clark, P. U., Carlson, A. E., Lynch-Stieglitz, J., Curry, W., Brook, E., Erickson, D., Jacob, R., Kutzbach, J., and Cheng, J.: Transient simulation of last deglaciation with a new mechanism for Bolling-Allerod warming, Science, 325, 310-314, doi:10.1126/science.1171041, 2009.

Loulergue, L., Schilt, A., Spahni, R., Masson-Delmotte, V., Blunier, T., Lemieux, B., Barnola, J.-M., Raynaud, D., Stocker, T. F., and Chappellaz, J.: Orbital and millennial-scale features of atmospheric $\mathrm{CH}_{4}$ over the past 800,000 years, Nature, 453, $383-$ 386, doi:10.1038/nature06950, 2008. 
Lu, H. and Sun, D.: Pathways of dust input to the Chinese Loess Plateau during the Last Glacial and Interglacial periods, Catena, 40, 251-261, 2000.

Lu, H., Van Huissteden, J., An, Z. S., Nugteren, G., and Vandenberghe, J.: East Asia winter monsoon changes on millennial time scale before the Last Glacial-interglacial cycle, J. Quat. Sci., 14, 101-111, 1999.

Lu, H., Stevens, T., Yi, S., and Sun, X.: An erosional hiatus in Chinese loess sequences revealed by closely spaced optical dating, Chinese Sci. Bull., 51, 2253-2259, doi:10.1007/s11434006-2097-x, 2006.

Lu, H., Wang, X. Y., Li, L. P.: Aeolian sediment evidence that global cooling has driven late Cenozoic stepwise aridification in central Asia, edited by: Clift, P. D., Tada, R., and Zheng, H., in: Monsoon Evolution and Tectonics-Climate Linkage in Asia, Geological Society, London, Special Publications, 342, 29-44, 2010.

Lu, H., Yi, S., Liu, Z., Mason, J. A., Jiang, D., Cheng, J., Stevens, T., Xu, Z., Zhang, E., Jin, L., Zhang, Z., Guo, Z., Wang, Y., and Otto-Bliesner, B.: Variation of East Asian monsoon precipitation during the past 21 k.y., and potential CO2 forcing, Geology, 41, 1023-1026, doi:10.1130/G34488.1, 2013.

Maher, B. A., Meng Yu, H., Roberts, H. M., and Wintle, A. G.: Holocene loess accumulation and soil development at the western edge of the Chinese Loess Plateau: implications for magnetic proxies of palaeorainfall, Quat. Sci. Rev., 22, 445-451, doi:10.1016/S0277-3791(02)00188-9, 2003.

Maher, B. A., Prospero, J. M., Mackie, D., Gaiero, D., Hesse, P. P., and Balkanski, Y.: Global connections between aeolian dust, climate and ocean biogeochemistry at the present day and at the last glacial maximum, Earth-Science Rev., 99, 61-97, doi:10.1016/j.earscirev.2009.12.001, 2010.

Mahowald, N., Kohfeld, K., Hansson, M., Balkanski, Y., Harrison, S. P., Prentice, I. C., Schulz, M., and Rodhe, H.: Dust sources and deposition during the last glacial maximum and current climate: A comparison of model results with paleodata from ice cores and marine sediments, J. Geophys. Res., 104, 15895, doi:10.1029/1999JD900084, 1999.

Mahowald, N., Albani, S., Engelstaedter, S., Winckler, G., and Goman, M.: Model insight into glacial-interglacial paleodust records, Quat. Sci. Rev., 30, 832-854, 2011.

Mahowald, N., Albani, S., Kok, J. F., Engelstaeder, S., Scanza, R., Ward, D. S., and Flanner, M. G.: The size distribution of desert dust aerosols and its impact on the Earth system, Aeolian Res., 15, 53-71, doi:10.1016/j.aeolia.2013.09.002, 2014.

Mahowald, N. M., Muhs, D. R., Levis, S., Rasch, P. J., Yoshioka, M., Zender, C. S., and Luo, C.: Change in atmospheric mineral aerosols in response to climate: Last glacial period, preindustrial, modern, and doubled carbon dioxide climates, J. Geophys. Res., 111, D10202, doi:10.1029/2005JD006653, 2006.

Mahowald, N. M., Kloster, S., Engelstaedter, S., Moore, J. K., Mukhopadhyay, S., McConnell, J. R., Albani, S., Doney, S. C., Bhattacharya, A., Curran, M. A. J., Flanner, M. G., Hoffman, F. M., Lawrence, D. M., Lindsay, K., Mayewski, P. A., Neff, J., Rothenberg, D., Thomas, E., Thornton, P. E., and Zender, C. S.: Observed 20th century desert dust variability: impact on climate and biogeochemistry, Atmos. Chem. Phys., 10, 10875-10893, doi:10.5194/acp-10-10875-2010, 2010.

Marković, S. B., Hambach, U., Stevens, T., Kukla, G. J., Heller, F., McCoy, W. D., Oches, E. A., Buggle, B., and Zöller, L.:
The last million years recorded at the Stari Slankamen (Northern Serbia) loess-palaeosol sequence: revised chronostratigraphy and long-term environmental trends, Quat. Sci. Rev., 30, 1142 1154, doi:10.1016/j.quatscirev.2011.02.003, 2011.

Martin, J. H.: Glacial-interglacial CO 2 change: The Iron Hypothesis, Paleoceanography, 5, 1-13, doi:10.1029/PA005i001p00001, 1990.

Martinson, D. G., Pisias, N. G., Hays, J. D., Imbrie, J., Moore, T. C., and Shackleton, N. J.: Age dating and the orbital theory of the ice ages: Development of a high-resolution 0 to 300,000year chronostratigraphy, Quat. Res., 27, 1-29, doi:10.1016/00335894(87)90046-9, 1987.

Marx, S. K., McGowan, H. A., and Kamber, B. S.: Long-range dust transport from eastern Australia: A proxy for Holocene aridity and ENSO-type climate variability, Earth Planet. Sci. Lett., 282, 167-177, doi:10.1016/j.epsl.2009.03.013, 2009.

Mason, J. A., Jacobs, P. M., Hanson, P. R., Miao, X., and Goble, R. J.: Sources and paleoclimatic significance of Holocene Bignell Loess, central Great Plains, USA, Quat. Res., 60, 330-339, doi:10.1016/j.yqres.2003.07.005, 2003.

Mason, J. A., Miao, X., Hanson, P. R., Johnson, W. C., Jacobs, P. M., and Goble, R. J.: Loess record of the Pleistocene-Holocene transition on the northern and central Great Plains, USA, Quat. Sci. Rev., 27, 1772-1783, doi:10.1016/j.quascirev.2008.07.004, 2008.

Masson-Delmotte, V., Schulz, M., Abe-Ouchi, A., Beer, J., Ganopolski, A., González Rouco, J. F., Jansen, E., Lambeck, K., Luterbacher, J., Naish, T., Osborn, T., Otto-Bliesner, B., Quinn, T., Ramesh, R., Rojas, M., Shao, X., and Timmermann, A.: Information from Paleoclimate Archives, in: Climate Change 2013: The Physical Science Basis. Contribution of Working Group I to the Fifth Assessment Report of the Intergovernmental Panel on Climate Change edited by: Stocker, T. F., Qin, D., Plattner, G.-K., Tignor, M., Allen, S. K., Boschung, J., Nauels, A., Xia, Y., Bex, V., and Midgley, P. M., Cambridge University Press, Cambridge, UK and New York, NY, USA, 2013.

Mayewski, P. A., Meeker, L. D., Twickler, M. S., Whitlow, S., Yang, Q., Lyons, W. B., and Prentice, M.: Major features and forcing of high-latitude northern hemisphere atmospheric circulation using a 110,000-year-long glaciochemical series, J. Geophys. Res., 102, 26345, doi:10.1029/96JC03365, 1997.

Mayewski, P. A., Sneed, S. B., Birkel, S. D., Kurbatov, A. V., and Maasch, K. A.: Holocene warming marked by abrupt onset of longer summers and reduced storm frequency around Greenland, J. Quat. Sci., 29, 99-104, doi:10.1002/jqs.2684, 2014.

McConnell, J. R., Aristarain, A. J., Banta, J. R., Edwards, P. R., and Simões, J. C.: 20th-Century doubling in dust archived in an Antarctic Peninsula ice core parallels climate change and desertification in South America, P. Natl. Acad. Sci. USA, 104, 57435748, doi:10.1073/pnas.0607657104, 2007.

McGee, D., Marcantonio, F., and Lynch-Stieglitz, J.: Deglacial changes in dust flux in the eastern equatorial Pacific, Earth Planet. Sci. Lett., 257, 215-230, doi:10.1016/j.epsl.2007.02.033, 2007.

McGee, D., Broecker, W. S., and Winckler, G.: Gustiness: The driver of glacial dustiness?, Quat. Sci. Rev., 29, 2340-2350, doi:10.1016/j.quascirev.2010.06.009, 2010.

McGee, D., deMenocal, P. B., Winckler, G., Stuut, J. B. W., and Bradtmiller, L. I.: The magnitude, timing and abrupt- 
ness of changes in North African dust deposition over the last 20,000yr, Earth Planet. Sci. Lett., 371-372, 163-176, doi:10.1016/j.eps1.2013.03.054, 2013.

McGowan, H. A., Marx, S. K., Soderholm, J., and Denholm, J.: Evidence of solar and tropical-ocean forcing of hydroclimate cycles in southeastern Australia for the past 6500 years, Geophys. Res. Lett., 37, RG1007, doi:10.1029/2010GL042918, 2010.

Meeker, L. D. and Mayewski, P. A.: A 1400-year high-resolution record of atmospheric circulation over the North Atlantic and Asia, Holocene, 12, 257-266, 2002.

Miao, X., Mason, J. A., Johnson, W. C., and Wang, H.: High-resolution proxy record of Holocene climate from a loess Section in Southwestern Nebraska, USA, Palaeogeogr. Palaeoclimatol. Palaeoecol., 245, 368-381, doi:10.1016/j.palaeo.2006.09.004, 2007.

Moore, J. K., Doney, S., Lindsay, K., Mahowald, N., and Michaels, A.: Nitrogen fixation amplifies the ocean biogeochemical response to decadal timesclae variations in mineral dust deposition, Tellus, 58B, 560-572, 2006.

Muhs, D. R., Agera, T., Bettis III, E. A., McGeehinc, J., Beena, J. M., Begétd, J. E., Pavichc, M. J., Stafford, T. W., and Stevens, D. A. S. P.: Stratigraphy and palaeoclimatic significance of Late Quaternary loess-palaeosol sequences of the Last InterglacialGlacial cycle in central Alaska, Quat. Sci. Rev., 22, 1947-1986, doi:10.1016/S0277-3791(03)00167-7, 2003a.

Muhs, D. R., Ager, T. A., Been, J., Bradbury, J. P., and Dean, W. E.: A late quaternary record of eolian silt deposition in a maar lake, St. Michael Island, western Alaska, Quat. Res., 60, 110122, doi:10.1016/S0033-5894(03)00062-0, 2003b.

Muhs, D. R., McGeehin, J. P., Beann, J., and Fisher, E.: Holocene loess deposition and soil formation as competing processes, Matanuska Valley, southern Alaska, Quat. Res., 61, 265-276, doi:10.1016/j.yqres.2004.02.003, 2004.

Muhs, D. R., Bettis III, E. A., Aleinikoff, J. N., McGeehin, J. P., Beann, J., Skipp, G., Marshall, B. D., Roberts, H. M., Johnson, W. C., and Benton, R.: Origin and paleoclimatic significance of late Quaternary loess in Nebraska: Evidence from stratigraphy, chronology, sedimentology, and geochemistry, Geol. Soc. Am. Bull., 120, 1378-1407, doi:10.1130/B26221.1, 2008.

Muhs, D. R., Aleinikoff, J. N., Stafford, T. W. . J., Kihl, R., Been, J., Mahan, S. A., and Cowherd, S.: Late Quaternary loess in northeastern Colorado: Part I - Age and paleoclimatic significance, Geol. Soc. Am. Bull., 111, 1861-1875, doi:10.1130/00167606(1999)111, 1999.

Muhs, D. R., Bettis, E. A., Roberts, H. M., Harlan, S. S., Paces, J. B., and Reynolds, R. L.: Chronology and provenance of lastglacial (Peoria) loess in western Iowa and paleoclimatic implications, Quat. Res., 80, 468-481, doi:10.1016/j.yqres.2013.06.006, 2013a.

Muhs, D. R., Budahn, J. R., McGeehin, J. P., Bettis, E. A., Skipp, G., Paces, J. B., and Wheeler, E. A.: Loess origin, transport, and deposition over the past 10,000 years, WrangellSt. Elias National Park, Alaska, Aeolian Res., 11, 85-99, doi:10.1016/j.aeolia.2013.06.001, 2013b.

Mulitza, S., Heslop, D., Pittauerova, D., Fischer, H. W., Meyer, I., Stuut, J.-B., Zabel, M., Mollenhauer, G., Collins, J. A., Kuhnert, H., and Schulz, M.: Increase in African dust flux at the onset of commercial agriculture in the Sahel region, Nature, 466, 226228, doi:10.1038/nature09213, 2010.
Nagashima, K., Tada, R., Matsui, H., Irino, T., Tani, A., and Toyoda, S.: Orbital- and millennial-scale variations in Asian dust transport path to the Japan Sea, Palaeogeogr. Palaeoclimatol. Palaeoecol., 247, 144-161, doi:10.1016/j.palaeo.2006.11.027, 2007.

Narcisi, B., Petit, J.-R., and Chappellaz, J.: A 70 ka record of explosive eruptions from the TALDICE ice core (Talos Dome, East Antarctic plateau), J. Quaternary Sci., 25, 844-849, 2010.

Olivarez, A. M., Owen, R. M., and Rea, D. K.: Geochemistry of eolian dust in Pacific pelagic sediments: Implications for paleoclimatic interpretations, Geochim. Cosmochim. Acta, 55, 21472158, doi:10.1016/0016-7037(91)90093-K, 1991.

Otto-Bliesner, B. L., Joussaume, S., Braconnot, P., Harrison, S. P., and Abe-Ouchi, A.: Modeling and Data Syntheses of Past Climates: Paleoclimate Modelling Intercomparison Project Phase II Workshop; Estes Park, Colorado, 15-19 September 2008, Eos, Trans. Am. Geophys. Union, 90, 93, doi:10.1029/2009EO110013, 2009.

Petit, J. R., Jouzel, J., Raynaud, D., Barkov, N. I., Barnola, J. M., Basile, I., Bender, M., Chappellaz, J., Davis, M., Delaygue, G., Delmotte, M., Kotlyakov, V. M., Legrand, M., Lipenkov, V. Y., Lorius, C., Pepin, L., Ritz, C., Saltzman, E., and Stievenard, M.: Climate and atmospheric history of the past 420,000 years from the Vostok ice core, Antarctica, Nature, 399, 429-436, doi:10.1038/20859, 1999.

Pigati, J. S., McGeehin, J. P., Muhs, D. R., and Bettis, E. A.: Radiocarbon dating late Quaternary loess deposits using small terrestrial gastropod shells, Quat. Sci. Rev., 76, 114-128, doi:10.1016/j.quascirev.2013.05.013, 2013.

Porter, S. C.: Chinese loess record of monsoon climate during the last glacial-interglacial cycle, Earth-Science Rev., 54(1-3), 115128, doi:10.1016/S0012-8252(01)00043-5, 2001.

Pourmand, A., Marcantonio, F., and Schulz, H.: Variations in productivity and eolian fluxes in the northeastern Arabian Sea during the past $110 \mathrm{ka}$, Earth Planet. Sci. Lett., 221, 39-54, doi:10.1016/S0012-821X(04)00109-8, 2004.

Pourmand, A., Marcantonio, F., Bianchi, T. S., Canuel, E. A., and Waterson, E. J.: A 28-ka history of sea surface temperature, primary productivity and planktonic community variability in the western Arabian Sea, Paleoceanography, 22, PA4208, doi:10.1029/2007PA001502, 2007.

Prins, M. A., Vriend, M., Nugteren, G., Vandenberghe, J., Lu, H., Zheng, H., and Jan Weltje, G.: Late Quaternary aeolian dust input variability on the Chinese Loess Plateau: inferences from unmixing of loess grain-size records, Quat. Sci. Rev., 26, 230-242, doi:10.1016/j.quascirev.2006.07.002, 2007.

Prospero, J. M., Ginoux, P., Torres, O., Nicholson, S. E., and Gill, T. E.: Environmental characterization of global sources of atmospheric soil dust identified with the NIMBUS 7 Total Ozone Mapping Spectrometer (TOMS) absorbing aerosol product, Rev. Geophys., 40, 1002, doi:10.1029/2000RG000095, 2002.

Pye, K.: The nature, origin and accumulation of loess, Quat. Sci. Rev., 14, 653-667, doi:10.1016/0277-3791(95)00047-X, 1995.

Ratmeyer, V., Fischer, G., and Wefer, G.: Lithogenic particle fluxes and grain size distributions in the deep ocean off NW Africa: implications for seasonal changes of aeolian dust input and downward transport, Deep-Sea Res. I, 46, 1289-1337, 1999. 
Rea, D. K.: The paleoclimatic record provided by eolian deposition in the deep sea: The geologic history of wind, Rev. Geophys., 32, 159, doi:10.1029/93RG03257, 1994.

Rea, D. K. and Hovan, S. A.: Grain size distribution and depositional processes of the mineral component of abyssal sediments: Lessons from the North Pacific, Paleoceanography, 10, 251-258, doi:10.1029/94PA03355, 1995.

Rea, D. K. and Janecek, T. R.: Late cretaceous history of eolian deposition in the mid-pacific mountains, central North Pacific Ocean, Palaeogeogr. Palaeoclimatol. Palaeoecol., 36, 5567, doi:10.1016/0031-0182(81)90048-1, 1981.

Reid, J. S., Jonsson, H. H., Maring, H. B., Smirnov, A., Savoie, D. L., Cliff, S. S., Reid, E. A., Livingston, J. M., Meier, M. M., Dubovik, O., and Tsay, S. C.: Comparison of size and morphological measurements of coarse mode dust particles from Africa, J. Geophys. Res., 108, 8593, doi:10.1029/2002JD002485, 2003.

Reimer, P. J., Baillie, M. G. L., Bard, E., Bayliss, A., Beck, J. W., Blackwell, P. G., Ramsey, C. B., Buck, C. E., Burr, G. S., Edwards, R. L., Friedrich, M., Grootes, P. M., Guilderson, T. P., Hajdas, I., Heaton, T. J., Hogg, A. G., Hughen, K. A., Kaiser, K. F., Kromer, B., McCormac, F. G., Manning, S. W., Reimer, R. W., Richards, D. A., Southon, J. R., Talamo, S., Turney, C. S. M., van der Plicht, J., and Weyhenmeyer, C. E.: IntCal09 and Marine09 radiocarbon age calibration curves, $0-50,000$ yeats cal BP, [online] available at: http://researchcommons.waikato.ac.nz/ handle/10289/3622 (last access: 25 July 2014), 2009.

Roberts, H. M.: The development and application of luminescence dating to loess deposits: a perspective on the past, present and future, Boreas, 37, 483-507, doi:10.1111/j.15023885.2008.00057.x, 2008.

Roberts, H. M., Muhs, D. R., Wintle, A. G., Duller, G. A. T., and Bettis, E. A.: Unprecedented last-glacial mass accumulation rates determined by luminescence dating of loess from western Nebraska, Quat. Res., 59, 411-419, doi:10.1016/S00335894(03)00040-1, 2003.

Roberts, H. M., Wintle, A. G., Maher, B. A., and Hu, M.: Holocene sediment-accumulation rates in the western Loess Plateau, China, and a 2500-year record of agricultural activity, revealed by OSL dating, The Holocene, 11, 477-483, doi:10.1191/095968301678302913, 2001.

Röthlisberger, R., Mulvaney, R., Wolff, E. W., Hutterli, M. A., Bigler, M., Sommer, S., and Jouzel, J.: Dust and sea-salt variability in central East Antarctica (Dome C) over the last 45 kyrs and its implications for southern high-latitude climate, Geophys. Res. Lett., 29, 1963, doi:10.1029/2002GL015186, 2002.

Rousseau, D.-D., Antoine, P., Gerasimenko, N., Sima, A., Fuchs, M., Hatté, C., Moine, O., and Zoeller, L.: North Atlantic abrupt climatic events of the last glacial period recorded in Ukrainian loess deposits, Clim. Past, 7, 221-234, doi:10.5194/cp-7-2212011, 2011.

Le Roux, G., Fagel, N., De Vleeschouwer, F., Krachler, M., Debaille, V., Stille, P., Mattielli, N., van der Knaap, W. O., van Leeuwen, J. F. N., and Shotyk, W.: Volcano- and climatedriven changes in atmospheric dust sources and fluxes since the Late Glacial in Central Europe, Geology, 40, 335-338, doi:10.1130/G32586.1, 2012.

Ruth, U., Wagenbach, D., Bigler, M., Steffensen, J. P., Röthlisberger, R., and Miller, H.: High-resolution microparticle profiles at NorthGRIP, Greenland: case studies of the calcium-dust relationship, Ann. Glaciol., 35, 237-242, doi:10.3189/172756402781817347, 2002.

Ruth, U., Wagenbach, D., Steffensen, J. P., and Bigler, M.: Continuous record of microparticle concentration and size distribution in the central Greenland NGRIP ice core during the last glacial period, J. Geophys. Res., 108, 4098, doi:10.1029/2002JD002376, 2003.

Ruth, U., Barbante, C., Bigler, M., Delmonte, B., Fischer, H., Gabrielli, P., Gaspari, V., Kaufmann, P., Lambert, F., Maggi, V., Marino, F., Petit, J.-R., Udisti, R., Wagenbach, D., Wegner, A., and Wolff, E. W.: Proxies and Measurement Techniques for Mineral Dust in Antarctic Ice Cores, Environ. Sci. Technol., 42, 5675-5681, doi:10.1021/es703078z, 2008.

Sapkota, A., Cheburkin, A. K., Bonani, G., and Shotyk, W.: Six millennia of atmospheric dust deposition in southern South America (Isla Navarino, Chile), The Holocene, 17, 561-572, doi:10.1177/0959683607078981, 2007.

Schulz, M., Balkanski, Y. J., Guelle, W., and Dulac, F.: Role of aerosol size distribution and source location in a threedimensional simulation of a Saharan dust episode tested against satellite-derived optical thickness, J. Geophys. Res., 103, 10579, doi:10.1029/97JD02779, 1998.

Schüpbach, S., Federer, U., Kaufmann, P. R., Albani, S., Barbante, C., Stocker, T. F., and Fischer, H.: High-resolution mineral dust and sea ice proxy records from the Talos Dome ice core, Clim. Past, 9, 2789-2807, doi:10.5194/cp-9-2789-2013, 2013.

Serno, S., Winckler, G., Anderson, R. F., Hayes, C. T., McGee, D., Machalett, B., Ren, H., Straub, S. M., Gersonde, R., and Haug, G. H.: Eolian dust input to the Subarctic North Pacific, Earth Planet. Sci. Lett., 387, 252-263, doi:10.1016/j.eps1.2013.11.008, 2014.

Siegel, D. A. and Armstrong, R. A.: Corrigendum to "Trajectories of sinking particles in the Sargasso Sea: modeling of statistical funnels above deep-ocean sediment traps" [Deep-Sea Res. 44, 1519-1541], Deep-Sea Res., 49, 1115-1116, 2002.

Siegel, D. A. and Deuser, W. G.: Trajectories of sinking particles in the Sargasso Sea: modeling of statistical funnels above deepocean sediment traps, Deep-Sea Res., 44, 1519-1541, 1997.

Sirocko, F., Sarnthein, M., Lange, H., and Erlenkeuser, H.: Atmospheric summer circulation and coastal upwelling in the Arabian Sea during the Holocene and the last glaciation, Quat. Res., 36, 72-93, doi:10.1016/0033-5894(91)90018-Z, 1991.

Sun, J. M., Kohfeld, K. E., and Harrison, S. P.: Records of aeolian dust deposition on the Chinese Loess Plateau during the Late Quaternary, Technical Reports - Max-Planck-Institute für Biogeochemie 1, pp 318, 2000.

Steffensen, J. P.: The size distribution of microparticles from selected segments of the Greenland Ice Core Project ice core representing different climatic periods, J. Geophys. Res., 102, 26755, doi:10.1029/97JC01490, 1997.

Steffensen, J. P., Andersen, K. K., Bigler, M., Clausen, H. B., DahlJensen, D., Fischer, H., Goto-Azuma, K., Hansson, M., Johnsen, S. J., Jouzel, J., Masson-Delmotte, V., Popp, T., Rasmussen, S. O., Röthlisberger, R., Ruth, U., Stauffer, B., Siggaard-Andersen, M.-L., Sveinbjörnsdóttir, A. E., Svensson, A., and White, J. W. C.: High-resolution Greenland ice core data show abrupt climate change happens in few years., Science, 321, 680-684, doi:10.1126/science.1157707, 2008.

Stevens, T. and Lu, H.: Optically stimulated luminescence dating as a tool for calculating sedimentation rates in Chinese loess: 
comparisons with grain-size records, Sedimentology, 56, 911934, doi:10.1111/j.1365-3091.2008.01004.x, 2009.

Stevens, T., Armitage, S. J., Lu, H. Y., and Thomas, D. S. G.: Sedimentation and diagenesis of Chinese loess: Implications for the preservation of continuous high-resolution climate records, Geology, 34, 849-852, doi:10.1130/G22472.1, 2006.

Stevens, T., Thomas, D. S. G., Armitage, S. J., Lunn, H. R., and Lu, H. Y.: Reinterpreting climate proxy records from late Quaternary Chinese loess: A detailed OSL investigation, Earth-Sci. Rev., 80, 111-136, 2007.

Stevens, T., Lu, H., Thomas, D. S. G., and Armitage, S. J.: Optical dating of abrupt shifts in the late Pleistocene East Asian Monsoon, Geology, 36, 415-418, doi:10.1130/G24524A.1, 2008.

Street-Perrott, F. A. and Perrott, R. A.: Holocene vegetation, lake levels and climate of Africa. In: Global climates since the last glacial maximum, 318-356, University of Minnesota Press, Minnesota, 1993.

Sun, J. M., Kohfeld, K. E., and Harrison, S. P.: Records of aeolian dust deposition on the Chinese Loess Plateau during the Late Quaternary, Technical Reports - Max-Planck-Institute für Biogeochemie, 1, 318 pp., 2000.

Sun, D., Chen, F., Bloemendal, J., and Su, R.: Seasonal variability of modern dust over the Loess Plateau of China, J. Geophys. Res., 108, 4665, doi:10.1029/2003JD003382, 2003.

Sun, Y., Clemens, S. C., Morrill, C., Lin, X., Wang, X., and An, Z:: Influence of Atlantic meridional overturning circulation on the East Asian winter monsoon, Nat. Geosci., 5, 46-49, doi:10.1038/NGEO1326, 2012.

Tegen, I., Harrison, S. P., Kohfeld, K. E., Prentice, I. C., Coe, M., and Heimann, M.: The impact of vegetation and preferential source areas on the dust aerosol cycle, J. Geophys. Res., 107, 4576, doi:10.1029/2001JD000963, 2002.

Thompson, L. G., Mosley-Thompson, E., Davis, M. E., Lin, P. N., Henderson, K. A., Cole-Dai, J., Bolzan, J. F., and Liu, K. B.: Late Glacial Stage and Holocene tropical ice core records from Huascaran, Peru, Science, 80, 269, 46-50, doi:10.1126/science.269.5220.46, 1995.

Thompson, L. G., Yao, T., Davis, M. E., Henderson, K. A., MosleyThompson, E., Lin, P.-N., Beer, J., Synal, H.-A., Cole-Dai, J., and Bolzan, J. F.: Tropical Climate Instability: The Last Glacial Cycle from a Qinghai-Tibetan Ice Core, Science, 80, 276, 18211825, doi:10.1126/science.276.5320.1821, 1997.

Tiedemann, R., Sarnthein, M., and Shackleton, N. J.: Astronomic timescale for the Pliocene Atlantic $\delta 180$ and dust flux records of Ocean Drilling Program Site 659, Paleoceanography, 9, 619638, doi:10.1029/94PA00208, 1994.

Unnerstad, L. and Hansson, M.: Simulated airborne particle size distributions over Greenland during Last Glacial Maximum, Geophys. Res. Lett., 28, 287-290, 2001.

Veres, D., Bazin, L., Landais, A., Toyé Mahamadou Kele, H., Lemieux-Dudon, B., Parrenin, F., Martinerie, P., Blayo, E., Blunier, T., Capron, E., Chappellaz, J., Rasmussen, S. O., Severi, M., Svensson, A., Vinther, B., and Wolff, E. W.: The Antarctic ice core chronology (AICC2012): an optimized multi-parameter and multi-site dating approach for the last 120 thousand years, Clim. Past, 9, 1733-1748, doi:10.5194/cp-9-1733-2013, 2013.
Vinther, B. M., Clausen, H. B., Johnsen, S. J., Rasmussen, S. O., Andersen, K. K., Buchardt, S. L., Dahl-Jensen, D., Seierstad, I. K., Siggaard-Andersen, M.-L., Steffensen, J. P., Svensson, A., Olsen, J., and Heinemeier, J.: A synchronized dating of three Greenland ice cores throughout the Holocene, J. Geophys. Res., 111, D13102, doi:10.1029/2005JD006921, 2006.

Wanner, H., Beer, J., Bütikofer, J., Crowley, T. J., Cubasch, U., Flückiger, J., Goosse, H., Grosjean, M., Joos, F., Kaplan, J. O., Küttel, M., Müller, S. A., Prentice, I. C., Solomina, O., Stocker, T. F., Tarasov, P., Wagner, M., and Widmann, M.: Mid- to Late Holocene climate change: An overview, Quat. Sci. Rev., 27, 1791-1828, doi:10.1016/j.quascirev.2008.06.013, 2008.

Weltje, G. J.: End-member modeling of compositional data: numerical statistical algorithms for solving the explicit mixing problem, Math. Geol., 29, 503-549, 1997.

Winckler, G., Anderson, R. F., Fleisher, M. Q., McGee, D., and Mahowald, N.: Covariant glacial-interglacial dust fluxes in the equatorial Pacific and Antarctica, Science, 320, 93-96, doi:10.1126/science.1150595, 2008.

Wintle, A. G. and Murray, A. S.: A review of quartz optically stimulated luminescence characteristics and their relevance in singlealiquot regeneration dating protocols, Radiat. Meas., 41, 369391, doi:10.1016/j.radmeas.2005.11.001, 2006.

Winton, V. H. L., Dunbar, G. B., Bertler, N. A. N., Millet, M.-A., Delmonte, B., Atkins, C. B., Chewings, J. M., and Andersson, P.: The contribution of aeolian sand and dust to iron fertilization of phytoplankton blooms in southwestern Ross Sea, Antarctica, Global Biogeochem. Cy., 28, 423-436, doi:10.1002/2013GB004574, 2014.

Xie, R. C. and Marcantonio, F.: Deglacial dust provenance changes in the Eastern Equatorial Pacific and implications for ITCZ movement, Earth Planet. Sci. Lett., 317-318, 386-395, doi:10.1016/j.eps1.2011.11.014, 2012.

Zdanowicz, C. M., Zielinski, G. A., Wake, C. P., Fisher, D. A., and Koerner, R. M.: A Holocene Record of Atmospheric Dust Deposition on the Penny Ice Cap, Baffin Island, Canada, Quat. Res., 53, 62-69, doi:10.1006/qres.1999.2091, 2000.

Zender, C. S., Newman, D., and Torres, O.: Spatial heterogeneity in aeolian erodibility: Uniform, topographic, geomorphic, and hydrologic hypotheses, J. Geophys. Res., 108, 4543, doi:10.1029/2002JD003039, 2003.

Ziegler, C. L., Murray, R. W., Hovan, S. A., and Rea, D. K.: Resolving eolian, volcanogenic, and authigenic components in pelagic sediment from the Pacific Ocean, Earth Planet. Sci. Lett., 254, 416-432, 2007.

Zielinski, G. A. and Mershon, G. R.: Paleoenvironmental implications of the insoluble microparticle record in the GISP2 (Greenland) ice core during the rapidly changing climate of the Pleistocene-Holocene transition, Geol. Soc. Am. Bull., 109, 547559, doi:10.1130/0016-7606(1997)109, 1997. 